\title{
Nitrogen efficiency in semi-dwarf and normal hybrids of oilseed rape
}

\author{
Sebastian Miersch
}

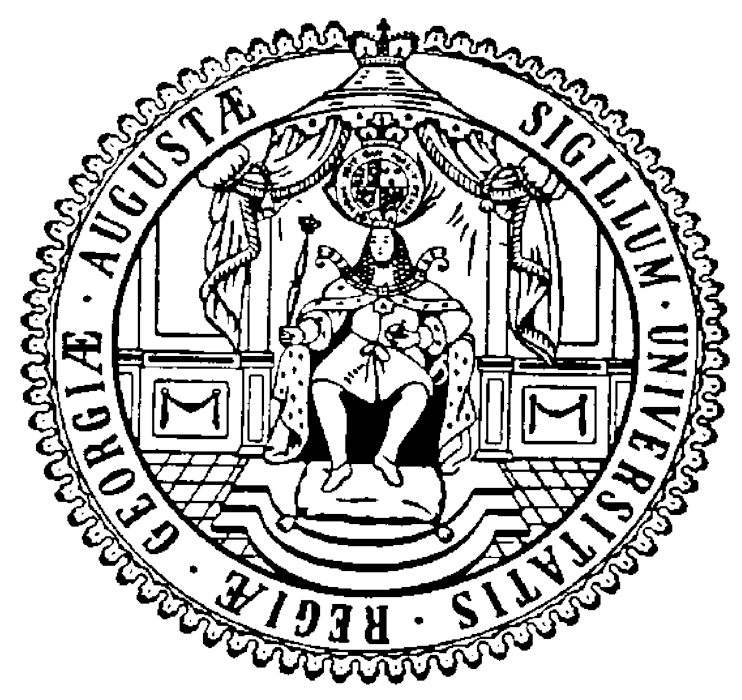

Göttingen, May 2014 


\title{
Nitrogen efficiency in semi-dwarf and normal hybrids of oilseed rape
}

\author{
Dissertation \\ to obtain the Ph.D. degree \\ in the Faculty of Agricultural Sciences, \\ Georg-August-Universität Göttingen
}

presented by

Sebastian Miersch

born in Hoyerswerda

Göttingen, May 2014 
D7

Supervisor: Prof. Dr. Heiko C. Becker

Co-supervisor: Prof. Dr. Klaus Dittert

Date of dissertation: 24.07.2014 
Dedicated to my parents and grandparents. 


\section{Acknowledgements}

The author gratefully acknowledge funding from the European Community financial participation under the Seventh Framework Programme for Research, Technological Development and Demonstration Activities, for the Integrated Project NUE-CROPS FP7-CP-IP 222645. The views expressed in this publication are the sole responsibility of the author and do not necessarily reflect the views of the European Commission. Neither the European Commission nor any person acting on behalf of the Commission is responsible for the use which might be made of the information contained herein.

I like to thank KWS SAAT AG, especially Frank Breuer, Andreas Gertz and Frank Weber for producing DH lines and testcross hybrids as well as for providing the marker data. Their excellent support in conducting the field experiments is gratefully acknowledged.

Thanks to Wolfgang Ecke for his assistance in the construction of the linkage map.

A special thanks goes to Professor Heiko C. Becker for giving me the opportunity to work on this multifaceted project. I am very grateful for his continuous scientific advises, the high degree of confidence as well as the encouragement during the last four years.

Last, but not least, I want to thank my family and friends for their constant support throughout this exciting and challenging period. 


\section{Contents}

Acknowledgements $\quad$ i

List of Tables $\quad$ iv

List of Figures

Aim of the study 1

1 Introduction 2

1.1 Agronomic relevance of Brassica napus L. . . . . . . . . . . . . . . . . 2

1.2 Nitrogen use efficiency . . . . . . . . . . . . . . . . . . . . 2

1.2.1 Nitrogen uptake . . . . . . . . . . . . . . . . . 3

1.2.2 Nitrogen utilization . . . . . . . . . . . . . . . . . . . 4

1.3 QTL mapping . . . . . . . . . . . . . . . . . . 5

$\begin{array}{ll}\text { References } & 7\end{array}$

2 Agronomic performance of semi-dwarf and normal type winter oilseed rape hybrids $\quad 9$

2.1 Introduction . . . . . . . . . . . . . . . . . . . . . . 9

2.2 Materials and Methods . . . . . . . . . . . . . . . . . . . . . . 12

2.2.1 Plant Material and Experimental Design . . . . . . . . . . . . . 12

2.2.2 Evaluated traits and Measurements . . . . . . . . . . . . 13

2.2 .3 Statistical analysis . . . . . . . . . . . . . . . . . 13

2.3 Results . . . . . . . . . . . . . . . . . . . 16

2.3.1 Agronomic performance at low nitrogen supply . . . . . . . . . 16

2.3.2 Agronomic performance at high nitrogen supply . . . . . . . . . . . 20

2.3.3 Comparison of agronomic performance at low and high nitrogen supply . . . . . . . . . . . . . . . . . . 23

2.4 Discussion . . . . . . . . . . . . . . . . . . . . . . . . . . . . . . . . . . 29

$\begin{array}{ll}\text { References } & 32\end{array}$ 
3 Nitrogen use efficiency of semi-dwarf and normal type hybrids

3.1 Introduction . . . . . . . . . . . . . . . . . . . . 34

3.2 Materials and Methods . . . . . . . . . . . . . . . . . 35

3.2.1 Plant Material and Experimental Design . . . . . . . . . . . . 35

3.2.2 Evaluated traits and Measurements . . . . . . . . . . . . . 36

3.2 .3 Statistical analysis . . . . . . . . . . . . . . . 38

3.3 Results . . . . . . . . . . . . . . . . . . . 40

3.3.1 Semi-dwarf and normal type hybrids at low nitrogen supply . . . . 40

3.3.2 Semi-dwarf and normal type hybrids at high nitrogen supply . . . . 42

3.3.3 Nitrogen uptake and nitrogen utilization . . . . . . . . . . . . 45

3.3.4 Comparison of low and high nitrogen supply . . . . . . . . . . . . 51

3.4 Discussion . . . . . . . . . . . . . . . . . . . . . 55

$\begin{array}{ll}\text { References } & 59\end{array}$

4 QTL mapping in semi-dwarf and normal type oilseed rape hybrids $\quad 61$

4.1 Introduction . . . . . . . . . . . . . . . . . . 61

4.2 Materials and Methods . . . . . . . . . . . . . . . 6 61

4.2.1 Plant material and Experimental Design . . . . . . . . . . . . . . 61

4.2.2 Genetic markers and linkage map . . . . . . . . . . . . . . . . 63

4.2 .3 Statistical analysis . . . . . . . . . . . . . . . . . 63

4.2 .4 QTL mapping . . . . . . . . . . . . . . . 64

4.3 Results . . . . . . . . . . . . . . . . . . . 66

4.3 .1 Genetic linkage map . . . . . . . . . . . . . . . . 66

4.3 .2 QTL at low nitrogen supply . . . . . . . . . . . . . 67

4.3.3 QTL at high nitrogen supply . . . . . . . . . . . . . 76

4.3 .4 Discussion . . . . . . . . . . . . . . . . . . . . . 84

$\begin{array}{ll}\text { References } & 90\end{array}$

$\begin{array}{ll}\text { Summary } & 93\end{array}$

$\begin{array}{ll}\text { Appendix A } & 95\end{array}$

$\begin{array}{ll}\text { Curriculum vitae } & 112\end{array}$ 


\section{List of Tables}

2.1 Agronomic traits of semi-dwarf and normal type hybrids at low nitrogen supply . . . . . . . . . . . . . . . . . . . . 16

2.2 Variance components of agronomic traits at low nitrogen supply . . . . . . 19

2.3 Agronomic traits of semi-dwarf and normal type hybrids at high nitrogen supply . . . . . . . . . . . . . . . . . 2 20

2.4 Variance components at high nitrogen supply . . . . . . . . . . . . 22

2.5 Seed yield, straw yield and their coefficients at low and high nitrogen supply 23

2.6 Rank correlations among agronomic traits at low and high nitrogen supply 26

2.7 Rank correlations among agronomic traits at low and high nitrogen supply 27

2.8 Variance components with and without nitrogen fertilization . . . . . . . 28

3.1 Performance of semi-dwarf and normal type hybrids at low nitrogen supply 41

3.2 Variance components at low nitrogen supply . . . . . . . . . . . . . 42

3.3 Performance of semi-dwarf and normal type hybrids at high nitrogen supply 43

3.4 Variance components at high nitrogen supply . . . . . . . . . . . . . 44

3.5 Nitrogen uptake and nitrogen uptake efficiency EOF at low and high nitrogen supply . . . . . . . . . . . . . . . . . . . . 45

3.6 Variance components for nitrogen uptake and nitrogen uptake efficiency EOF at low and high nitrogen supply . . . . . . . . . . . . . . . . 46

3.7 Parameters of nitrogen use efficiency (maturity) at low and high nitrogen supply, according to Moll et al. (1982) . . . . . . . . . . . . . . . . . 47

3.8 Variance components of parameters for nitrogen use efficiency (maturity) at low and high nitrogen supply . . . . . . . . . . . . . . . . . 48

3.9 Relative contribution of nitrogen uptake and nitrogen utilization efficiency to total genetic variation in nitrogen use efficiency, according to Moll et al.

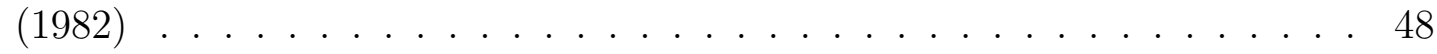

3.10 Variance components at low and high nitrogen supply . . . . . . . . . . 52

3.11 Spearman's rank correlations of phenotypic traits at low and high nitrogen supply . . . . . . . . . . . . . . . . . . 53 
3.12 Mean values and Spearman's rank correlations between low and high nitrogen supply . . . . . . . . . . . . . . . . . . . . 5 54

4.1 Genetic linkage map with length and number of markers per linkage group 66

4.2 Variance components and heritabilities at low nitrogen supply (six envi-

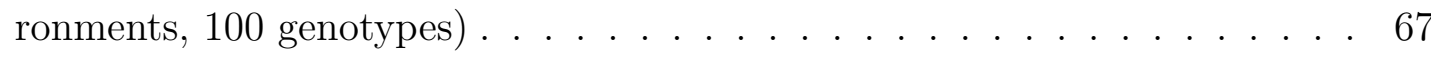

4.3 Putative QTL for agronomic traits at low nitrogen supply (six environments, 100 genotypes $) \ldots \ldots \ldots . \ldots . \ldots 68$

4.4 Putative QTL for thousand seed weight, oil content and protein content at low nitrogen supply (six environments, 100 genotypes) . . . . . . . . . 70

4.5 Putative QTL for nitrogen related traits at low nitrogen supply (four en-

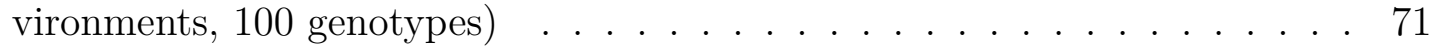

4.6 Putative QTL for agronomic traits across six environments with low nitro-

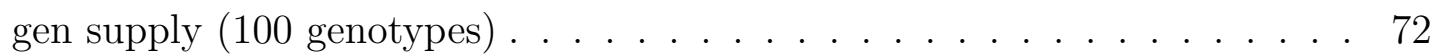

4.7 Putative QTL for thousand seed weight, oil yield, oil content and protein content across six environments with low nitrogen supply (100 genotypes) . 73

4.8 Putative QTL for nitrogen related traits across four environments with low

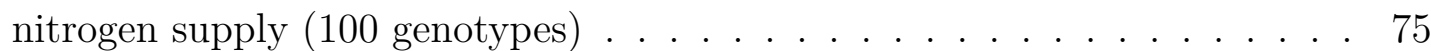

4.9 Variance components and heritabilities at high nitrogen supply (four envi-

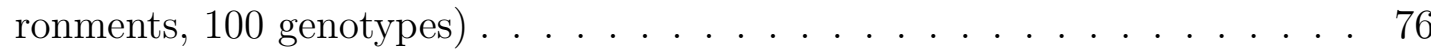

4.10 Putative QTL for agronomic traits at high nitrogen supply (four environments, 100 genotypes $\ldots \ldots \ldots$. . . . . . . . . . . 77

4.11 Putative QTL for thousand seed weight, oil content and protein content at high nitrogen supply (four environments, 100 genotypes) . . . . . . . . . 78

4.12 Putative QTL for nitrogen related traits at high nitrogen supply (two environments, 100 genotypes) . . . . . . . . . . . . . . . 80

4.13 Putative QTL for begin of flowering, plant height, seed yield, straw yield and harvest index across four environments with high nitrogen supply (100 genotypes $\ldots \ldots \ldots \ldots \ldots$. . . . . . . . . . . . . . 81

4.14 Putative QTL for thousand seed weight, oil yield, oil content and protein content across four environments with high nitrogen supply (100 genotypes) 82

4.15 Putative QTL for nitrogen affected traits across two environments with

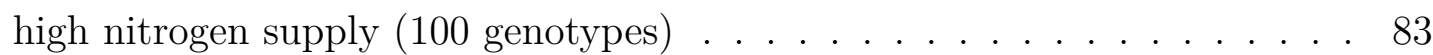

4.16 Linkage map of 'Alesi-bzh' x 'H30' population . . . . . . . . . . . . . . . . 98 


\section{List of Figures}

2.1 Violinplot of semi-dwarf and normal hybrids for seed yield across three seasons at low nitrogen supply . . . . . . . . . . . . . . . 17

2.2 Violinplot of semi-dwarf and normal hybrids for seed yield across two seasons at high nitrogen supply . . . . . . . . . . . . . . . . 21

2.3 Mean seed yields across three environments (Go12, Ei13, Go13) at low and

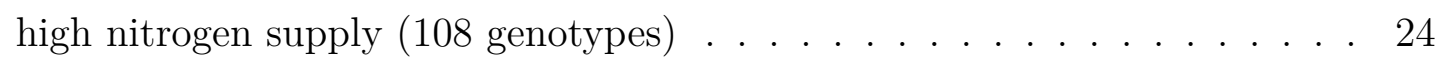

3.1 Nitrogen uptake and nitrogen utilization efficiency at low nitrogen supply . 49

3.2 Nitrogen uptake and nitrogen utilization efficiency at high nitrogen supply 50 


\section{Aim of the study}

The cultivation of winter oilseed rape is characterised by high rates of nitrogen fertilization. For economical, environmental and legislative reasons it is aspired to reduce nitrogen fertilization in oilseed rape cultivation. The development of oilseed rape cultivars with an improved nitrogen efficiency is an important factor in this context.

The major research objectives in the present study were:

- to investigate the effect of the dwarf gene $B z h$ on various physiological parameters

- to compare the agronomic performance of semi-dwarf and normal type oilseed rape hybrids at low and high nitrogen supply

- to analyse factors influencing nitrogen use efficiency

- to compare nitrogen use efficiency of semi-dwarf and normal type hybrids at low and high nitrogen supply

- to analyse genetic mechanisms controlling agronomic and nitrogen related traits

The present study is subdivided into four chapters. Chapter 1 gives an general introduction to the relevance of oilseed rape, the meaning of nitrogen use efficiency and the concept of QTL mapping. Chapter 2 contains the comparison of agronomic traits among semi-dwarf and normal type oilseed rape hybrids based on three-year field trials at low and high $\mathrm{N}$ supply. Chapter 3 focus on parameters influencing nitrogen use efficiency in semi-dwarf and normal type hybrids at low and high nitrogen supply. Chapter 4 comprises the detection of genetic mechanisms influencing agronomic and nitrogen related traits. 


\section{Introduction}

\subsection{Agronomic relevance of Brassica napus $\mathrm{L}$.}

Winter oilseed rape (Brassica napus L.) is the most grown oilseed crop in temperate regions. In 2013 the cultivated area for winter and spring types of oilseed rape and turnip in the EU-27 was about 6.73 million ha. With a cultivated area of 1.47 million ha in 2013, Germany was the most important producer of oilseed rape in the EU followed by France (1.44 million ha) and Poland (0.92 million ha) (Eurostat, 2014). Other important producing countries (mostly spring types) are China, Canada and Australia.

Most oilseed rape cultivars (80 \% in 2013) grown in Germany are hybrid varieties. Hybrid varieties are characterized by a high yield potential, a better yield stability and a more vigorous plant development compared to open pollinating varieties. Hybrids are generated by crossing two genetically different, homozygous parental lines. The resulting hybrid $\left(\mathrm{F}_{1}\right)$ is more vigorous and higher yielding compared to the parental lines. This genetic phenomenom is known as hybrid vigor or 'heterosis' (Shull, 1948).

Botanically Brassica napus L. belongs to the family Brasscicaceae with about 3.700 known species. It is the result of a spontaneous hybridisation event between the two species Brassica rapa L. (AA, $2 \mathrm{n}=2 \mathrm{x}=20)$ and Brassica oleracea L. $(\mathrm{CC}, 2 \mathrm{n}=2 \mathrm{x}=18)$ resulting in the allopolyploid hybrid Brasscia napus $\mathrm{L}$. (AACC, $2 \mathrm{n}=4 \mathrm{x}=38$ ). The genetic relationship among different Brassica species was first demonstrated with the 'Triangle of U' (Nagaharu, 1935).

Oilseed rape generated by crossing the diploid species Brassica rapa L. and Brassica oleracea L. is called 'resythesized' oilseed rape. Resynthesized genotypes are valuable to extend the genetic diversity within the breeding material by introducing alternative forms of genes (alleles) (Girke, 2002).

\subsection{Nitrogen use efficiency}

There is no generally accepted definition for nitrogen use efficiency. Nitrogen use efficiency in its broadest sense indicates how effectively a plant is able to capture and utilize nitrogen to produce biomass or grain yield (Hawkesford and Barraclough, 2011). In the present 


\section{Introduction}

study nitrogen use efficiency (NUE) is defined as seed production per unit nitrogen $(\mathrm{N})$ available in the soil, according to Moll et al. (1982).

The use of nitrogen involves several steps including uptake, assimilation, translocation and remobilization (Good et al., 2004). Each of these steps can be subdivided into many specific physiological traits and processes, encoded by multiple genes and regulatory processes (Hawkesford and Barraclough, 2011). In this study nitrogen use efficiency is split into two primary components: (1) the efficiency of absorption ( $\mathrm{N}$ uptake efficiency) and (2) the efficiency with which the absorbed $\mathrm{N}$ is utilized to produce seeds ( $\mathrm{N}$ utilization efficiency) (Moll et al., 1982).

\subsubsection{Nitrogen uptake}

Soil nitrogen availability can fluctuate greatly in both space and time due to factors such as precipitation, temperature, wind, soil type and $\mathrm{pH}$. Nitrogen uptake occurs at the root level and depends on root architecture, root functions in terms of transporters and exudates and often the presence of symbiotic associations such as mycorrhiza (Hawkesford and Barraclough, 2011).

A well developed shallow root system will be ideal for the uptake of fertilizer applications. Deeper roots are important when surface nutrients are depleted or restricted nutrient uptake due to limited surface water. In the case of high water supply deeper roots can intercept nutrients that would be potentially leached from the soil profile. The experimental assessment of size and architecture of a root system is very laborious under field conditions.

Besides root architecture transmembrane transport of nitrogen is another important factor for nitrogen uptake. The nitrogen sources taken up by higher plants are nitrate or ammonium as inorganic nitrogen sources and amino acids under particular conditions of soil composition (Masclaux-Daubresse et al., 2010). Nitrogen assimilation requires the reduction of nitrate to ammonium, followed by ammonium assimilation into amino acids.

Ammonium is taken up by different ammonium transport proteins (AMT) (Andrade and Einsle, 2007). If nitrogen is not limiting or high ammonium concentrations in the cell needs to be avoided due to toxicity, AMT-mediated transport is blocked. Nitrate is taken up by two different transport systems. They act co-ordinately to take up nitrate from the soil solution and distribute it within the whole plant (Masclaux-Daubresse et al., 2010). At high external nitrate concentration a low affinity transport system (LATS) is operating mediated by members of the NRT1 gene family. At low external nitrate concentration nitrate is taken up by a high affinity transport system (HATS) controlled by members of the NRT2 family. In Arabidopsis 53 genes were identified to belong to the NRT1 family and seven genes belonging to the NRT2 family (Masclaux-Daubresse et al., 


\section{Introduction}

2010). Depending on the species, nitrogen uptake could be negatively regulated or even in some cases totally inhibited during seed production. For example, in oilseed rape, the transition between the vegetative and reproductive phases is characterized by a drastic decrease of HATS and HATS+LATS activities (Malagoli et al., 2005).

Another important characteristic for nitrogen uptake efficiency is the availability of adequate sinks to store accumulated nitrogen (Hawkesford and Barraclough, 2011). Adequate sinks will prevent negative feedback regulation on the initial uptake processes and provide important remobilizable storage.

Due to the variety of factors involved into nitrogen uptake and their complexity it is practically not feasible to determine all of them in a single experiment. Therefore the most simple approach is to determine the amount of nitrogen taken up by a plant. This integrates the separate features of root architecture and root functions contributing to this trait (Hawkesford and Barraclough, 2011).

\subsubsection{Nitrogen utilization}

Nitrogen utilization efficiency is defined as unit of harvestable product (seed) per unit of nitrogen taken up, according to Moll et al. (1982). A key attribute to improve nitrogen utilization efficiency in oilseed rape is $\mathrm{N}$ remobilization. Nitrogen uptake after flowering is generally insufficient for the high $\mathrm{N}$ demand of seeds during the reproductive period (Masclaux-Daubresse et al., 2010). Therefore, oilseed rape remobilize N from senescing leaves, roots, stems and pod walls during the reproductive period (Rathke et al., 2006; Gombert et al., 2010). Leaf proteins and in particular photosynthetic proteins of plastids are extensively degraded during senescence, providing an enormous source of nitrogen (Masclaux-Daubresse et al., 2010).

At high nitrogen supply about $70 \%$ of seed nitrogen was remobilized from stems, leaves and pod walls of oilseed rape (Gombert et al., 2010; Malagoli et al., 2005). The contribution of remobilized nitrogen to pod nitrogen content in rice, wheat or maize grain nitrogen content is cultivar dependent, varying from 50 to $90 \%$ (Masclaux-Daubresse et al., 2010). At higher nitrogen supplies leaf senescence in oilseed rape is delayed compared to low nitrogen supply. According to Schulte auf'm Erley et al. (2007) delayed leaf senescence during grain filling enhance nitrogen use efficiency. Thus, nitrogen uptake and nitrogen remobilization is possibly delayed, too (Gombert et al., 2010).

There is evidence that plants share common nitrogen remobilization mechanisms whether they are monocotyledonous, dicotyledonous, C3 or C4 photosynthesis types (MasclauxDaubresse et al., 2010). Grain nitrogen accumulation usually appears to be regulated by the nitrogen source. Nitrogen remobilization is also environment dependent and favoured under limiting nitrate supplies. 


\section{Introduction}

\subsection{QTL mapping}

The appearance of a plant with all its observable characteristics or traits is called "phenotype'. A phenotype is determined by the expression of its genes, environmental effects and the interactions between genes and environment. Phenotypic traits controlled by one or only a few genes are often called 'Mendelian traits' and generate a limited number of expression levels.

In contrast to Mendelian traits, quantitative/complex traits are affected by multiple genes usually with small effects (Doerge 2002). Quantitative traits exhibit a continuous variation such as plant height, seed yield or oil content. Genes or chromosomal regions determining a quantitative trait are called quantitative trait loci (QTL) (Geldermann, 1975).

The process of identifying and localizing QTL along chromosomes is usually refered to as QTL mapping. Several parameters such as heritability of a trait, number of QTL affecting the trait, epistasis or interaction between QTL, genome size, marker density and variation due to type and size of a mapping population need to be considered for QTL mapping (Doerge, 2002).

One approach to conduct a QTL mapping study is to cross two homozygous parental lines to produce $\mathrm{F}_{1}$ lines which are heterozygous at all markers and QTL where the two parents differ (Doerge, 2002). Based on the $\mathrm{F}_{1}$ lines a mapping population, segregating for the trait of interest is generated. Common designs for mapping populations are $\mathrm{F}_{2}$ intercross, backcross, recombinant inbred lines or $\mathrm{F}_{1}$ derived doubled haploid lines $(\mathrm{DH})$.

In oilseed rape DH lines are generated from microspores isolated from anthers of maturing buds (Möllers et al., 1994). The microspores carry a haploid (1x) set of chromosomes. Following a colchicine treatment of microspores, the chromosomes are doubled and diploid plants (doubled haploid) are generated.

For sophisticated methods of QTL mapping such as interval mapping (IM) or composite interval mapping (CIM) it is necessary to create a genetic map. A genetic map provides a genetic representation of the chromosomes (linkage groups) on which previously identified polymorphic DNA markers are placed (Doerge, 2002). The markers are placed on the map according their genetic distance using a map function (such as the Haldane or Kosambi map functions). The accuracy of locating QTL is limited by the number of recombinants, gained from observing the genotypic states of the markers. These observed recombinants can be limited by both small sample size (genotypes) and small number of markers.

A common method for QTL mapping is composite interval mapping (CIM) described by Zeng (1994). Composite interval mapping combines the interval mapping approach (Lander and Botstein, 1989) with linear regression, including additional markers to the neighbouring pair of linked markers (Zeng, 1994). When positions for QTL are estimated, 


\section{Introduction}

the resulting maximum or peak has to surpass a specified significance threshold. The estimation of the thresholds is most commonly performed by including permutation tests (Churchill and Doerge, 1994). These tests involve a certain number of repeats (e.g. 500 or 1000) where the false positive marker-trait associations are estimated by randomisation of the phenotypic data with simultaneously constant marker values of the genotypes (Hackett, 2002). 


\section{References}

Andrade, S. L. and Einsle, O. (2007). The amt/mep/rh family of ammonium transport proteins (review). Molecular Membrane Biology, 24(5-6):357-365.

Churchill, G. A. and Doerge, R. W. (1994). Empirical threshold values for quantitative trait mapping. Genetics, 138(3):963-971.

Doerge, R. W. (2002). Mapping and analysis of quantitative trait loci in experimental populations. Nature Reviews Genetics, 3(1):43-52.

Eurostat (2014). Url : http:// www.epp.eurostat.ec.europa.eu/ portal/ page/ portal/ agriculture/ data/ maintables.html. Eurostat, 11.02.2014.

Geldermann, H. (1975). Investigations on inheritance of quantitative characters in animals by gene markers i. methods. Theoretical and Applied Genetics, 46(7):319-330.

Girke, A. (2002). Neue Genpools aus resynthetisiertem Raps (Brassica napus L.) für die Hybridzüchtung. Dissertation URL: http://webdoc. sub. gwdg. de/diss/2002/girke/girke. pdf.

Gombert, J., Le Dily, F., Lothier, J., Etienne, P., Rossato, L., Allirand, J.-M., Jullien, A., Savin, A., and Ourry, A. (2010). Effect of nitrogen fertilization on nitrogen dynamics in oilseed rape using 15N-labeling field experiment. Journal of Plant Nutrition and Soil Science, 173(6):875-884.

Good, A. G., Shrawat, A. K., and Muench, D. G. (2004). Can less yield more? is reducing nutrient input into the environment compatible with maintaining crop production? Trends in Plant Science, 9(12):597-605.

Hackett, C. A. (2002). Statistical methods for qtl mapping in cereals. Plant Molecular Biology, 48(5-6):585-599.

Hawkesford, M. J. and Barraclough, P. (2011). The Molecular And Physiological Basis Of Nutrient Use Efficiency In Crops. Wiley-Blackwell, Ames, Iowa. 


\section{REFERENCES}

Lander, E. S. and Botstein, D. (1989). Mapping mendelian factors underlying quantitative traits using rflp linkage maps. Genetics, 121(1):185-199.

Malagoli, P., Laine, P., Rossato, L., and Ourry, A. (2005). Dynamics of nitrogen uptake and mobilization in field-grown winter oilseed rape (Brassica napus) from stem extension to harvest. ii. an 15n-labelling-based simulation model of $\mathrm{n}$ partitioning between vegetative and reproductive tissues. Annals of Botany, 95(7):1187-1198.

Masclaux-Daubresse, C., Daniel-Vedele, F., Dechorgnat, J., Chardon, F., Gaufichon, L., and Suzuki, A. (2010). Nitrogen uptake, assimilation and remobilization in plants: challenges for sustainable and productive agriculture. Annals of Botany, 105(7):11411157.

Moll, R., Kamprath, E., and Jackson, W. (1982). Analysis and interpretation of factors which contribute to efficiency of nitrogen utilization. Agronomy Journal, 74(3):562-564.

Möllers, C., Iqbal, M., and Röbbelen, G. (1994). Efficient production of doubled haploid Brassica napus plants by colchicine treatment of microspores. Euphytica, 75(1-2):95104.

Nagaharu, U. (1935). Genome analysis in Brassica with special reference to the experimental formation of B. napus and peculiar mode of fertilization. Japanese Journal of Botany, 7:389-452.

Rathke, G.-W., Behrens, T., and Diepenbrock, W. (2006). Integrated nitrogen management strategies to improve seed yield, oil content and nitrogen efficiency of winter oilseed rape (Brassica napus 1.): A review. Agriculture, Ecosystems 86 Environment, 117(2):80-108.

Schulte auf'm Erley, G., Wijaya, K.-A., Ulas, A., Becker, H., Wiesler, F., and Horst, W. J. (2007). Leaf senescence and n uptake parameters as selection traits for nitrogen efficiency of oilseed rape cultivars. Physiologia Plantarum, 130(4):519-531.

Shull, G. H. (1948). What is" heterosis"? Genetics, 33(5):439.

Zeng, Z.-B. (1994). Precision mapping of quantitative trait loci. Genetics, 136(4):14571468. 


\section{Agronomic performance of semi-dwarf and normal type winter oilseed rape hybrids}

\subsection{Introduction}

Oilseed rape (Brassica napus L.) is the most important oilcrop in Europe. The cultivated area in Germany increased rapidly in the last decade to 1.47 million ha in the year 2013 (Eurostat, 2014). The economy of winter oilseed rape cultivation in Germany is primarily determined by seed yield and less by oil content (Rathke et al., 2005). One possibility to increase seed yield is to influence the distribution of assimilates within a plant. By reducing the vegetative biomass without reducing the vitality of a plant, more assimilates can be transferred into the seeds. In the end this would result in an increase of harvest index.

A reduction of vegetative biomass combined with an increase in seed yield and harvest index was already achieved in wheat and rice in the mid 20th century (Hedden, 2003). The shorter wheat and rice varieties were the prototypes of today's modern cultivars. These so called 'semi-dwarf' wheat and rice varieties were characterised by short strong stems resulting in an improved lodging resistance. In combination with high amounts of nitrogen fertilizer these new varieties led to impressive yield increases generally referred to as 'Green Revolution'. The dwarfism in both crops is caused by mutations in genes controlling the signaling pathway or biosynthesis of gibberellic acid (GA) (Hedden, 2003). Gibberellic acids form a large family of tetracyclic diterpenoid plant hormones affecting plant growth and development in higher plants. Some of the traits influenced by GA are stem and root extension, leaf expansion, seed germination and floral induction (Sun and Gubler, 2004). Two different forms of GA mutants with similar phenotypes are known. The dwarfism of GA-deficient mutants is caused by a mutated gene in the biosynthesis pathway of GA resulting in GA deficiency. By application of bioactive GAs the normal height can be restored. GA-insensitive mutants do not respond to exogenous GA treatment because they encode a mutant form of DELLA proteins. DELLA proteins affect various aspects of 
plant growth by inhibiting GA-dependent pathways. In a normal GA signaling pathway DELLA proteins are degraded. But through gain-of-function mutations in the N-terminus or loss-of-function mutations in the C-terminus the proteins are resistant to GA induced degredation and GA signaling is constitutively blocked (Peng et al., 1999).

In Brassica napus (L.) dwarf mutants were used in physiological studies by Williams and Hill (1986) and Zanewich et al. (1991). A resynthesized B. napus line was developed by crossing the dwarf Brassica rapa stock described by Zanewich et al. (1991) with a nondwarf Brassica oleracea stock (Muangprom et al., 2006). The dwarf Brassica rapa stock carried the dwarf allele of the BrGAI gene, which is a homolog of rga in Arabidopsis, $r h t$ in wheat or $d 8$ in maize. Two parents of a commercial canola hybrid were backcrossed with the resynthesized line to generate dwarf, semi-dwarf and normal hybrids. No significant differences in seed yield were observed between the three different hybrids. Due to damages by flee beetles the dwarf and semi-dwarf hyrids had a higher percentage of aborted seeds. At optimal growing conditions semi-dwarf hybrids might have higher seed yield than normal hybrids according to Muangprom et al. (2006).

Foisset et al. (1995) obtained a dwarf mutant by chemical mutagenesis of seeds from the oilseed rape cultivar 'Primor' at INRA / France. Genetic analysis of the dwarf mutant indicated that the dwarfism is controlled by a single gene named $b z h$ with additive effect. Normal growing genotypes are homogzygous $B z h / B z h$, dwarf genotypes are $b z h / b z h$ and semi-dwarfs are heterozygous Bzh/bzh. The mutated allele was transferred to different oilseed rape lines to test the agronomic performance of dwarf and semi-dwarf progenies. The authors reported a positive effect on lodging resistance and yield performance without giving further details.

A Chinese research group generated a dwarf mutant by treating seeds with neutron bombardment and chemical mutagens (Wang et al., 2004). The dwarfism in the mutant was caused by a single gene with additive effect called $n d f-1$ which is discussed to be allelic to $b z h$. Other dwarf lines were generated by introducing the dwarf trait into several elite accessions. They were used to produce ten different semi-dwarf hybrids which were tested in field trials for two years. According to Wang et al. (2004) semi-dwarf hybrids showed good agronomic performance with higher seed yield and higher thousand seed weight compared to the normal parents. Later it was shown that the $n d f-1$ mutant is a gibberellin insensitive dwarf (Li et al., 2011). Another GA insensitive dwarf mutant was obtained by treating seeds from the Chinese inbred line 'T6' with chemical mutagens (Zeng et al., 2011). The dwarfism was controlled by a single recessive gene (bnaC.dwf) mapped to linkage group N18.

Several semi-dwarf hybrid varieties using the bzh gene described by Foisset et al. (1995) have been released to the European market. The plants are shorter and branching begins 
closer to the stem base compared to normal types. Thus lodging resistance is improved which is of importance in oilseed rape cultivation (Sieling and Kage, 2008). Further benefits are reduced damages when applying plant protection agents at flowering stage, a more uniform maturation and a swifter seed harvest due to less straw.

The aim of the present experiment was to explore the effect of the dwarf gene $B z h$ described by Foisset et al. (1995), in a segregating winter oilseed rape population of semidwarf and normal hybrids. It was investigated whether the semi-dwarf growth type has positive or negative effects on agronomic traits, especially on seed yield. Furthermore the response of both growth types to different nitrogen supply levels was analysed. Special attention was paid to the question if the semi-dwarf growth type is beneficial at nitrogen deficient conditions. 


\subsection{Materials and Methods}

\subsubsection{Plant Material and Experimental Design}

A doubled-haploid (DH) population (242 lines) derived from the cross 'Alesi- $b z h \times \mathrm{x}$ H30' was produced. The 'Alesi-bzh' parent is a dwarf isogenic line derived from the German winter oilseed cultivar 'Alesi' backcrossed (BC4) to the bzh dwarf mutant described by Foisset et al. (1995). 'H30' is a normal type, resynthesized rapeseed line originating from a cross of Brasscia rapa ssp. chinensis with Brasscica napus ssp. napus var. pabularia with moderate winterhardiness (Girke, 2002). The DH population is segregating into dwarf and tall growing DH lines. All DH lines were crossed with a normal type, male sterile tester (canola quality) using the MSL ('Männliche Sterilität Lembke') hybrid system (Paulmann and Frauen, 1998). The resulting testcross hybrids (TC) segregate into semi-dwarf and normal types. In the season 2010/11 150 hybrids (75 semi-dwarf and 75 normal types) were selected based on the availability of seeds and evaluated in two adjacent field experiments.

In season 2010/11 150 TC (75 semi-dwarfs and 75 normal types) were selected based on the availability of seeds and evaluated in two adjacent experiments. One experiment was harvested at the end of flowering (EOF) (BBCH 69, Lancashire et al. (1991)) and the second experiment at seed maturity (BBCH 89). Experiments were conducted at two sites near Einbeck (Ei) (brunic aerosol) and near Göttingen (Go) (alluvial meadow soil) in Central Germany. The plot sizes were $18 \mathrm{~m}^{2}$ in Einbeck and $11.25 \mathrm{~m}^{2}$ in Göttingen with plant densities of 50 and 90 plants $/ \mathrm{m}^{2}$, respectively. Both experiments were evaluated without nitrogen fertilization (low nitrogen supply). Soil mineral nitrogen determined at the beginning of plant growth in spring was $35 \mathrm{~kg} \mathrm{~N} /$ ha in Einbeck (Ei11) and $27 \mathrm{~kg}$ $\mathrm{N} /$ ha in Göttingen (Go11). All other agronomic treatments (except fertilization) were done according to recommendations for oilseed rape cultivation in Germany. Growth types were interlaced within each block by alternately growing one strip of semi-dwarfs and one strip of normal types. Experiments were designed as split-plot with growth type as main plot factor and genotypes as subplot factor. The experimental design was identical for both environments.

In season 2011/12 experiments from season 2010/11 were repeated using 108 TC (54 semi-dwarfs and 54 normal types). The 108 TC were selected based on erucic acid content and seed yield in season 2010/11. For each growth type 27 TC with erucic acid (14 highest seed yield, 13 lowest seed yield) and the 27 TC without erucic acid (14 highest seed yield, 13 lowest seed yield) were selected. Hybrids were evaluated in two identical experiments at both sites (Göttingen and Einbeck). One experiment was harvested at the end of flowering (BBCH 69) and the second experiment at seed maturity (BBCH 89). Both experiments were conducted at two nitrogen levels: without nitrogen fertilization 
(low nitrogen supply) and fertilized with $177 \mathrm{~kg} \mathrm{~N} /$ ha (high nitrogen supply). Mineral nitrogen in the soil was determined at the beginning of plant growth in spring in Einbeck (27 kg N/ha) and Göttingen (27 kg N/ha). Both growth types were interlaced within each block and arranged in split-plot design. Genotypes within growth types were randomized in lattice design.

In season 2012/13 the 108 TC (54 semi-dwarfs and 54 normal types) were again tested at two locations (Einbeck and Göttingen). In season 2012/13 all plots were harvested at seed maturity only. Field trials were conducted at two nitrogen levels: without nitrogen fertilization (low nitrogen supply) and fertilized with $177 \mathrm{~kg} \mathrm{~N} /$ ha (high nitrogen supply). Mineral nitrogen in the soil at the beginning of plant growth in spring was determined in Göttingen (24 kg N/ha) only. Genotypes within growth types were randomized in lattice design. Both growth types were interlaced within each block and arranged in split-plot design.

Each season-site combination is considered as one environment and is addressed by location abbreviation and harvest year, such as Ei11 for Einbeck in the season 2010/2011.

\subsubsection{Evaluated traits and Measurements}

In all trials begin of flowering (days from 1st of January, $\mathrm{BBCH}$ 61) and plant height (in $\mathrm{cm}$ at $\mathrm{BBCH} 89$ ) were recorded. Seed yield at maturity was determined with a plot combine harvester. Due to a heavy hail storm seed yield could not be determined in Einbeck 2012. The straw of every plot was collected in a canvas tissue attached to the back of the harvester and weighted (except in Einbeck 2011). All plants in a plot were cut right above soil level. A straw subsample including stems and pods was taken, weighted and dried at $60{ }^{\circ} \mathrm{C}$ for $48 \mathrm{~h}$ in a drying oven. Subsequently the dried sample was weighted to calculate straw dry matter content. Thousand seed weight (TSW) was measured on a representative sample of 500 seeds. Oil, protein and moisture content in $\%$ of seed dry mater were determined with a NIRS monochromator model 6500 (NIRSystems, Inc., Silversprings, MD, USA) using calibrations (raps2011.eqa, raps2012.qa, raps2013.eqa) provided by VDLUFA Qualitätssicherung NIRS GmbH.

\subsubsection{Statistical analysis}

Analysis of variance (ANOVA), heritabilities $\left(h^{2}\right)$ and Spearman's rank correlation coefficients were calculated using PLABSTAT software (Version 3B) (Utz, 2001).

ANOVA within each nitrogen level for a single environment was calculated using the following model for a split-plot design: 
2 Agronomic performance of semi-dwarf and normal type winter oilseed rape hybrids

$$
Y_{j k l}=\mu+b_{j}+t_{k}+\epsilon_{j k}+g_{k l}+\epsilon_{j k l}
$$

in which $Y_{j k l}$ is the observation of a genotype $(l)$ within growth type $(k)$ in block $(j)$. Whole plot error is denoted by $\left(\epsilon_{j k}\right)$ and the sub-plot error is called $\left(\epsilon_{j k l}\right)$. The general mean is designated by $\mu$. The factors block and genotype were considered as random. To include the effect of different environments (year-location combination) into the ANOVA, following model for a split-plot design was used:

$$
\begin{aligned}
Y_{i j k l}= & \mu+e_{i}+t_{k}+b_{i j}+e t_{i k}+\epsilon_{i j k} \\
& +g_{k l}+e g_{i k l}+\epsilon_{i j k l}
\end{aligned}
$$

in which $Y_{i j k l}$ is the observation of a genotype $(l)$ within the growth type $(k)$ in block $(j)$ within environment $(i)$. Interaction effects between growth type and environment are denoted by $e t_{i k}$ and interactions between environment and genotype are called $e g_{i k l}$. Whole plot error is denoted by $\left(\epsilon_{i j k}\right)$ and the sub-plot error is denoted by $\left(\epsilon_{i j k l}\right)$. The factors environment, block and genotype were considered as random.

To test the effects of nitrogen levels following model for a split-split-plot design was used:

$$
\begin{aligned}
Y_{i j k l o}= & \mu+e_{i}+n_{o}+b_{i j o}+e n_{i o}+\epsilon_{i j o} \\
& +t_{k}+e t_{i k}+t n_{k o}+e t n_{i k o}+\epsilon_{i j k o} \\
& +g_{k l}+e g_{i k l}+g n_{k l o}+e g n_{i k l o}+\epsilon_{i j k l o}
\end{aligned}
$$

in which $Y_{i j k l o}$ is the observation of a genotype $(l)$ within growth type $(k)$ in block $(j)$ within nitrogen level $(o)$ at environment $(i)$. Interaction effects were tested for environment and nitrogen level $\left(e n_{i o}\right)$, environment and growth type $\left(e t_{i k}\right)$, environment and genotype $\left(e g_{i k l}\right)$, growth type and nitrogen level $\left(t n_{k o}\right)$ and genotype by nitrogen level $\left(g n_{k l o}\right)$. Threefold interactions were testes for environment by genotype by nitrogen level $\left(e g n_{i k l o}\right)$ and environment by growth type by nitrogen level $\left(e t n_{i k o}\right)$. Whole plot error is denoted by $\epsilon_{i j o}$, sub-plot error is denoted by $\epsilon_{i j k o}$ and the sub-sub-plot error is denoted by $\epsilon_{i j k l o}$. The factors environment, block and genotype were considered as random.

Broad sense heritability $\left(h^{2}\right)$ was estimated as follows: 
2 Agronomic performance of semi-dwarf and normal type winter oilseed rape hybrids

$$
h^{2}=\frac{\hat{\sigma}_{G}^{2}}{\hat{\sigma}_{G}^{2}+\frac{\hat{\sigma}_{G E}^{2}}{E}}
$$

where $\hat{\sigma}_{G}^{2}$ and $\hat{\sigma}_{G E}^{2}$ are variances of genotypes and genotypes by environment respectively; $E$ refers to number of environments.

Violin plots as described by Hintze and Nelson (1998) were generated using R software package. 


\subsection{Results}

\subsubsection{Agronomic performance at low nitrogen supply}

At low nitrogen supply both growth types showed a significant difference in plant height across all environments (Tab.2.1). The average difference in plant height was about 28

Table 2.1: Mean values and significances for agronomic traits at low nitrogen supply (108 genotypes, six environments)

\begin{tabular}{|c|c|c|c|c|c|c|c|c|}
\hline Trait & & Ei11 & Go11 & Ei12 & Go12 & Ei13 & Go13 & Mean \\
\hline \multirow{2}{*}{$\begin{array}{l}\text { Begin of flowering } \\
\text { (days) }\end{array}$} & $\mathrm{Nt}$ & 110 & 110 & 104 & 115 & 121 & 125 & 114 \\
\hline & $\mathrm{Sd}$ & $110 \mathrm{~ns}$ & $110 \mathrm{~ns}$ & $104 \mathrm{~ns}$ & $114^{*}$ & $121 \mathrm{~ns}$ & $124+$ & $113 \mathrm{~ns}$ \\
\hline \multirow{2}{*}{$\begin{array}{l}\text { Plant height } \\
(\mathrm{cm})\end{array}$} & $\mathrm{Nt}$ & 126 & 119 & 108 & 90 & 143 & 122 & 118 \\
\hline & $\mathrm{Sd}$ & $100 *$ & $92 * *$ & $72 * *$ & $70 * *$ & $110 * *$ & $93 *$ & $90 * *$ \\
\hline \multirow{2}{*}{$\begin{array}{l}\text { Seed yield } \\
\text { (dt/ha) }\end{array}$} & $\mathrm{Nt}$ & 17.0 & 12.9 & - & 10.5 & 22.5 & 30.7 & 18.3 \\
\hline & $\mathrm{Sd}$ & $18.0 *$ & $17.0^{*}$ & - & $12.8 * *$ & $22.4 \mathrm{~ns}$ & $33.9 * *$ & $20.7 *$ \\
\hline \multirow{2}{*}{$\begin{array}{l}\text { Straw yield } \\
\text { (dt/ha) }\end{array}$} & $\mathrm{Nt}$ & - & 40.1 & 18.9 & 22.9 & 46.4 & 36.4 & 32.9 \\
\hline & $\mathrm{Sd}$ & - & $34.9 * *$ & $17.7 \mathrm{~ns}$ & $19.8 * *$ & $36.1 * *$ & $32.0+$ & $28.1 *$ \\
\hline \multirow[t]{2}{*}{ Harvest index } & $\mathrm{Nt}$ & - & 0.25 & - & 0.32 & 0.33 & 0.46 & 0.34 \\
\hline & $\mathrm{Sd}$ & - & $0.33 * *$ & - & $0.39 * *$ & $0.38 * *$ & $0.52 \mathrm{~ns}$ & $0.41^{* *}$ \\
\hline \multirow{2}{*}{$\begin{array}{l}\text { Total biomass } \\
(\mathrm{dt} / \mathrm{ha})\end{array}$} & $\mathrm{Nt}$ & - & 51.9 & - & 32.5 & 58.5 & 65.9 & 55.6 \\
\hline & $\mathrm{Sd}$ & - & $53.0 \mathrm{~ns}$ & - & $33.3 \mathrm{~ns}$ & 68.9 ** & $67.1 \mathrm{~ns}$ & $52.2 \mathrm{~ns}$ \\
\hline \multirow{2}{*}{$\begin{array}{l}\text { TSW } \\
(\mathrm{g})\end{array}$} & $\mathrm{Nt}$ & 4.65 & 4.81 & 4.63 & 4.82 & 4.41 & 4.69 & 4.67 \\
\hline & $\mathrm{Sd}$ & $4.79+$ & $4.70 \mathrm{~ns}$ & $4.52 \mathrm{~ns}$ & $4.66^{* *}$ & $4.20 * *$ & $4.42 * *$ & $4.55 \mathrm{~ns}$ \\
\hline \multirow{2}{*}{$\begin{array}{l}\text { Oil content } \\
(\%)\end{array}$} & $\mathrm{Nt}$ & 52.3 & 49.5 & 48.2 & 49.2 & 50.0 & 50.7 & 50.0 \\
\hline & $\mathrm{Sd}$ & $51.6^{* *}$ & $49.2 * *$ & $47.9 \mathrm{~ns}$ & $49.4 \mathrm{~ns}$ & $49.2 \mathrm{~ns}$ & $50.4 \mathrm{~ns}$ & $49.6 \mathrm{~ns}$ \\
\hline \multirow{2}{*}{$\begin{array}{l}\text { Oil yield } \\
\text { (dt/ha) }\end{array}$} & $\mathrm{Nt}$ & 7.6 & 6.4 & - & 5.1 & 11.2 & 15.5 & 9.2 \\
\hline & $\mathrm{Sd}$ & $8.8 \mathrm{~ns}$ & $8.4^{*}$ & - & $6.3^{* *}$ & $11.0 \mathrm{~ns}$ & $17.1 * *$ & $10.3^{*}$ \\
\hline \multirow{2}{*}{$\begin{array}{l}\text { Protein content } \\
(\%)\end{array}$} & $\mathrm{Nt}$ & 16.9 & 19.3 & 20.2 & 19.0 & 17.9 & 17.4 & 18.4 \\
\hline & $\mathrm{Sd}$ & $17.02 \mathrm{~ns}$ & $19.2 \mathrm{~ns}$ & $20.0 \mathrm{~ns}$ & $18.5 * *$ & $17.9 \mathrm{~ns}$ & $17.0^{* *}$ & $18.3 \mathrm{~ns}$ \\
\hline
\end{tabular}

$* *,{ }^{*},+$ Significant difference at $0.01,0.05,0.10$ probability level, respectively; ns non-significant (Ftest from ANOVA); Ei Einbeck; Go Göttingen; Sd semi-dwarf; Nt normal type; TSW thousand seed weight

cm between growth types. In Göttingen 2012 normal types reached an average height of $90 \mathrm{~cm}$ only and the difference between both types was only $20 \mathrm{~cm}$. Differences in begin 
of flowering among both growth types were not significant across all environments (Tab. 2.2). Semi-dwarf hybrids revealed a significantly higher seed yield compared to normal types types on average across five environments with low nitrogen supply (Tab.2.1). In Einbeck 2012/13 seed yields of both growth types were nearly on the same level. The distributions of genotypes for seed yield were quite similar in 2010/11 and 2011/12 (Fig.2.1). In 2013 seed yields of normal genotypes were distributed in a wider range compared to

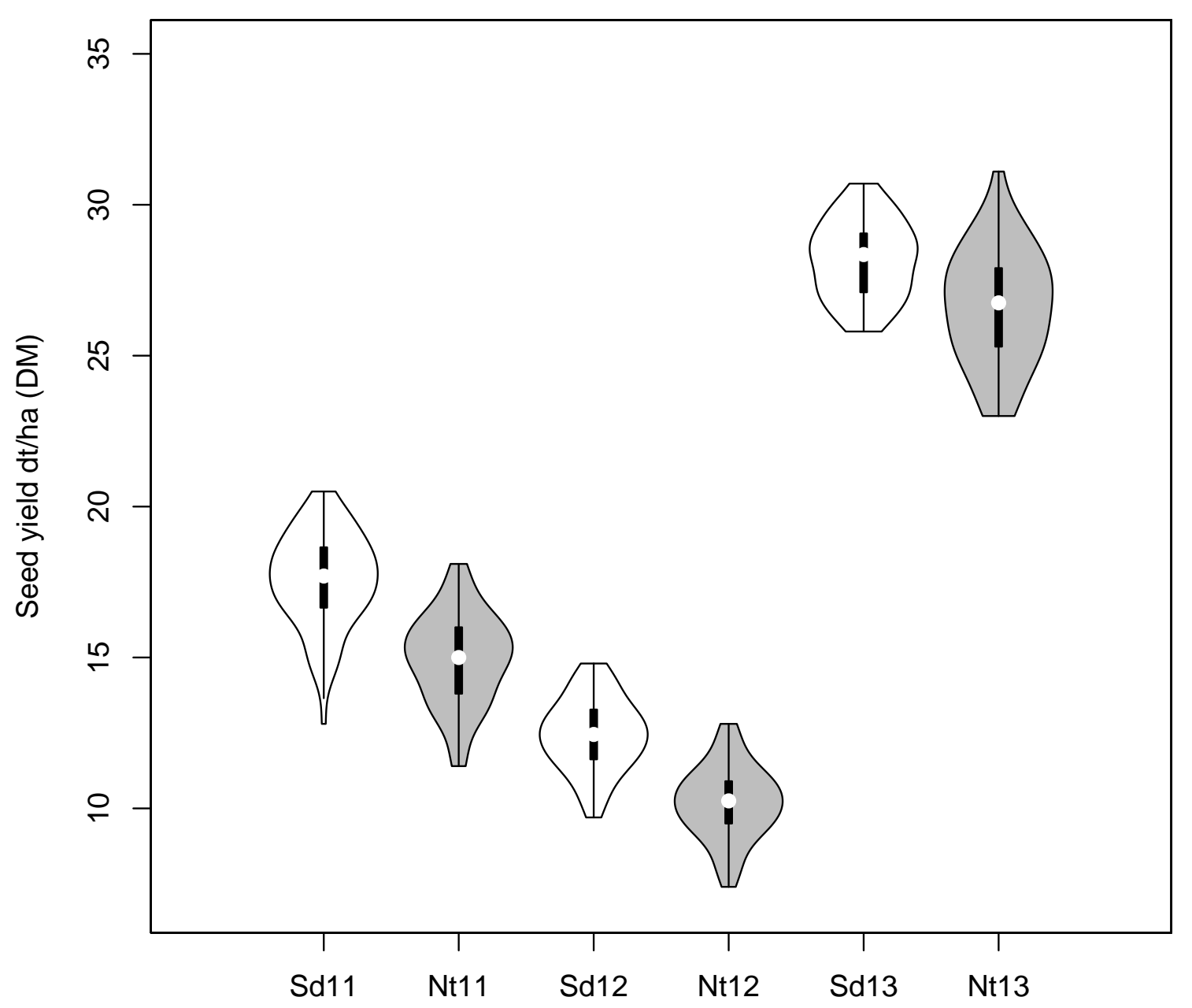

Figure 2.1: Violinplot of semi-dwarf $(\mathrm{Sd})$ and normal type (Nt) hybrids for seed yield across three seasons at low nitrogen supply.The plot is a combination of a box plot and a kernel density plot.

the semi-dwarfs. In that season the highest yielding genotype was a normal type, while in earlier years a semi-dwarf had the highest yield (Fig.2.1). Semi-dwarfs had signifi- 
cantly less straw than normal types in all environments except Einbeck 2012 (Tab.2.1). On average across five environments semi-dwarfs produced about $6 \mathrm{dt} /$ ha less straw than normal types. This resulted in a significantly higher harvest index of semi-dwarfs $(0.41)$ compared to normal types (0.34). The highest harvest indexes of normal types (0.46) and semi-dwarfs (0.52) were observed in Göttingen 2013 (Tab. 2.1).

The total biomass as sum of seed yield and straw yield, revealed no significant difference between growth types across all environments. In Einbeck 2013 semi-dwarf types had significantly higher biomass yields than normal types. Both growth types differed significantly in thousand seed weight (TSW). In all environments, except Einbeck 2011, semi-dwarfs had smaller seeds than normal types resulting in a lower TSW. Yet, in Go11 and Ei12 this difference was not significant (Tab. 2.1). Semi-dwarfs had a slightly lower oil content than normal types. A statistical significant difference in oil content among growth types was only observed in season 2010/11.

Differences in oil yield were mainly influenced by differences in seed yield due to relatively small differences in oil content among growth types. Significant differences in oil yield were only observed when seed yield differed between the growth types. In most environments no clear difference in protein content could be observed between growth types. Only in Go12 and Go13 semi-dwarf types showed a significantly lower protein content of about $0.5 \%$ compared to normal types (Tab.2.1).

Analysis of variance for low nitrogen environments revealed significant differences in plant height, seed yield, straw yield, harvest index and oil yield between growth types (Tab.2.2). Begin of flowering, total biomass at maturity, TSW, oil and protein content were not significantly affected by the growth type. Significant genotypic variation was detected for all traits except for straw yield and total biomass. All traits were significantly affected by genotype by environment interactions. Heritabilities ranged from 0.17 (straw yield) up to 0.87 (oil content). For biomass no heritability was calculated due to a negative variance component for genotypes (Tab.2.2). 
Table 2.2: Variance components of agronomic traits at low nitrogen supply in $2010 / 11,2011 / 12$ and 2012/13 (108 genotypes)

\begin{tabular}{|c|c|c|c|c|c|c|}
\hline Source & $\mathbf{E}$ & $\mathbf{T}$ & G & $\mathbf{T} \times \mathbf{E}$ & $\mathbf{G} \times \mathbf{E}$ & $\boldsymbol{h}^{2}$ \\
\hline Degrees of freedom & 5 & 1 & 106 & 5 & 530 & \\
\hline Begin of flowering (days) & $60.71^{* *}$ & $0 \quad \mathrm{~ns}$ & $0.23^{* *}$ & $0.09^{* *}$ & $0.29^{* *}$ & 0.77 \\
\hline Plant height (cm) & $274.85^{* *}$ & $402.74^{* *}$ & $4.20^{* *}$ & $16.07^{* *}$ & $7.41^{* *}$ & 0.54 \\
\hline Seed yield $(\mathrm{dt} / \mathrm{ha})^{\mathrm{a}}$ & $66.04^{* *}$ & $2.70^{*}$ & $0.78^{* *}$ & $1.09^{* *}$ & $0.83^{* *}$ & 0.54 \\
\hline Straw yield $(\mathrm{dt} / \mathrm{ha})^{\mathrm{a}}$ & $92.34^{*}$ & $10.56^{*}$ & $0.65^{\mathrm{ns}}$ & $5.39^{* *}$ & $5.86^{* *}$ & 0.17 \\
\hline $\operatorname{Biomass}(\mathrm{dt} / \mathrm{ha})^{\mathrm{b}}$ & $228.07^{* *}$ & $2.96^{\mathrm{ns}}$ & $0 \quad$ ns & $10.52^{* *}$ & $11.53^{* *}$ & 0 \\
\hline Harvest index ${ }^{b}$ & $0.68^{* *}$ & $0.23^{* *}$ & $0.02^{* *}$ & $0.005^{\mathrm{ns}}$ & $0.03^{* *}$ & 0.46 \\
\hline Thousand seed weight(g) & $0.03^{* *}$ & $0.01^{\mathrm{ns}}$ & $0.02^{* *}$ & $0.01^{* *}$ & $0.01^{* *}$ & 0.83 \\
\hline Oil content $(\%)$ & $1.67^{* *}$ & $0.04^{\mathrm{ns}}$ & $0.81^{* *}$ & $0.04^{+}$ & $0.19^{* *}$ & 0.87 \\
\hline Oil yield $(\mathrm{dt} / \mathrm{ha})^{\mathrm{a}}$ & $17.02^{* *}$ & $0.58^{*}$ & $0.25^{* *}$ & $0.30^{* *}$ & $0.21^{* *}$ & 0.59 \\
\hline Protein content (\%) & $1.47^{* *}$ & $0.01^{\mathrm{ns}}$ & $0.07^{* *}$ & $0.03^{* *}$ & $0.06^{* *}$ & 0.59 \\
\hline
\end{tabular}

${ }^{* *},{ }^{*}+{ }_{+}$Significant difference at $0.01,0.05,0.10$ probability level, respectively; ns nonsignificant (F-test from ANOVA); negative variance components were set to zero; $\mathbf{E}$ environment; $\mathbf{T}$ growth type; $\mathbf{G}$ genotype within growth type; $\boldsymbol{h}^{2}$ heritability within growth types; Biomass seed yield + straw yield;

${ }^{a}$ values for five environments;

${ }^{b}$ values for four environments 


\subsubsection{Agronomic performance at high nitrogen supply}

At high nitrogen supply both growth types started flowering at the same time or by one day delay (Go13) (Tab.2.3). In the season 2011/12 genotypes in Göttingen started flowering 11 days later than in Einbeck. Average height of semi-dwarfs across all environments was $88 \mathrm{~cm}$ with large variation between environments. Normal types had an average height of $124 \mathrm{~cm}$ and were on average about $36 \mathrm{~cm}$ taller compared to semi-dwarf types.

Table 2.3: Mean values and significance levels for agronomic traits at high nitrogen supply (108 genotypes, four environments)

\begin{tabular}{|c|c|c|c|c|c|c|}
\hline Trait & & Ei12 & Go12 & Ei13 & Go13 & Mean \\
\hline \multirow{2}{*}{$\begin{array}{l}\text { Begin of flowering } \\
\text { (days) }\end{array}$} & $\mathrm{Nt}$ & 104 & 115 & 122 & 126 & 117 \\
\hline & $\mathrm{Sd}$ & $104 \mathrm{~ns}$ & $115 \mathrm{~ns}$ & $122 \mathrm{~ns}$ & $125 * *$ & $117 \mathrm{~ns}$ \\
\hline \multirow{2}{*}{$\begin{array}{l}\text { Plant height } \\
(\mathrm{cm})\end{array}$} & $\mathrm{Nt}$ & 129 & 91 & 147 & 128 & 124 \\
\hline & $\mathrm{Sd}$ & $78 * *$ & $67 *$ & $115 * *$ & $92 * *$ & $88 * *$ \\
\hline \multirow{2}{*}{$\begin{array}{l}\text { Seed yield } \\
\text { (dt/ha) }\end{array}$} & $\mathrm{Nt}$ & - & 26.4 & 28.8 & 37.8 & 31.0 \\
\hline & $\mathrm{Sd}$ & - & $29.7 * *$ & $27.5^{* *}$ & $37.6 \mathrm{~ns}$ & $31.6 \mathrm{~ns}$ \\
\hline \multirow{2}{*}{$\begin{array}{l}\text { Straw yield } \\
(\mathrm{dt} / \mathrm{ha})\end{array}$} & $\mathrm{Nt}$ & 33.4 & 39.4 & 54.8 & 41.2 & 42.2 \\
\hline & $\mathrm{Sd}$ & $30.1^{* *}$ & $32.1 * *$ & $44.5 * *$ & $34.6 * *$ & $35.4 *$ \\
\hline \multirow{2}{*}{$\begin{array}{l}\text { Biomass } \\
\text { (dt/ha) }\end{array}$} & $\mathrm{Nt}$ & - & 65.8 & 83.3 & 79.0 & 76.0 \\
\hline & $\mathrm{Sd}$ & - & $61.8 * *$ & $72.1^{* *}$ & $72.2 * *$ & $68.7+$ \\
\hline \multirow[t]{2}{*}{ Harvest index } & $\mathrm{Nt}$ & - & 0.40 & 0.34 & 0.48 & 0.41 \\
\hline & $\mathrm{Sd}$ & - & $0.48^{* *}$ & $0.38^{* *}$ & $0.52 \mathrm{~ns}$ & $0.46^{*}$ \\
\hline \multirow{2}{*}{$\begin{array}{l}\text { TSW } \\
(\mathrm{g})\end{array}$} & $\mathrm{Nt}$ & 4.09 & 4.41 & 5.23 & 4.97 & 4.57 \\
\hline & $\mathrm{Sd}$ & $4.17 *$ & $4.13^{* *}$ & $4.54 \mathrm{~ns}$ & $4.75^{* *}$ & $4.40 \mathrm{~ns}$ \\
\hline \multirow{2}{*}{$\begin{array}{l}\text { Oil content } \\
(\%)\end{array}$} & $\mathrm{Nt}$ & 49.0 & 47.9 & 47.4 & 47.6 & 48.0 \\
\hline & $\mathrm{Sd}$ & $47.6^{* *}$ & $46.7^{* *}$ & $46.8+$ & $46.9 * *$ & $47.0^{* *}$ \\
\hline \multirow{2}{*}{$\begin{array}{l}\text { Oil yield } \\
\text { (dt/ha) }\end{array}$} & $\mathrm{Nt}$ & - & 12.6 & 13.7 & 18.0 & 14.8 \\
\hline & $\mathrm{Sd}$ & - & $13.8^{* *}$ & $12.9 * *$ & $17.6 \mathrm{~ns}$ & $14.8 \mathrm{~ns}$ \\
\hline \multirow{2}{*}{$\begin{array}{l}\text { Protein content } \\
(\%)\end{array}$} & $\mathrm{Nt}$ & 19.5 & 20.7 & 20.7 & 20.8 & 20.4 \\
\hline & $\mathrm{Sd}$ & $20.3^{* *}$ & $21.2+$ & $20.8 *$ & $20.8 \mathrm{~ns}$ & $20.7 \mathrm{~ns}$ \\
\hline
\end{tabular}

Lodging of normal types was observed in Einbeck 2013. Semi-dwarfs were not affected 
by lodging (data not shown). Significant differences in seed yield among growth types were observed in Göttingen 2012 and Einbeck 2013 (Tab.2.3). Seed yield in Göttingen 2013 was similar for both types. The distribution of genotypes for seed yield in 2012 was similar for both growth types (Fig.2.2). In 2012 the highest yielding genotypes were semi-dwarfs while in 2013 normal types produced the highest seed yield. In 2013 seed yields of normal genotypes were distributed in a wider range compared to semi-dwarfs (Fig.2.2).

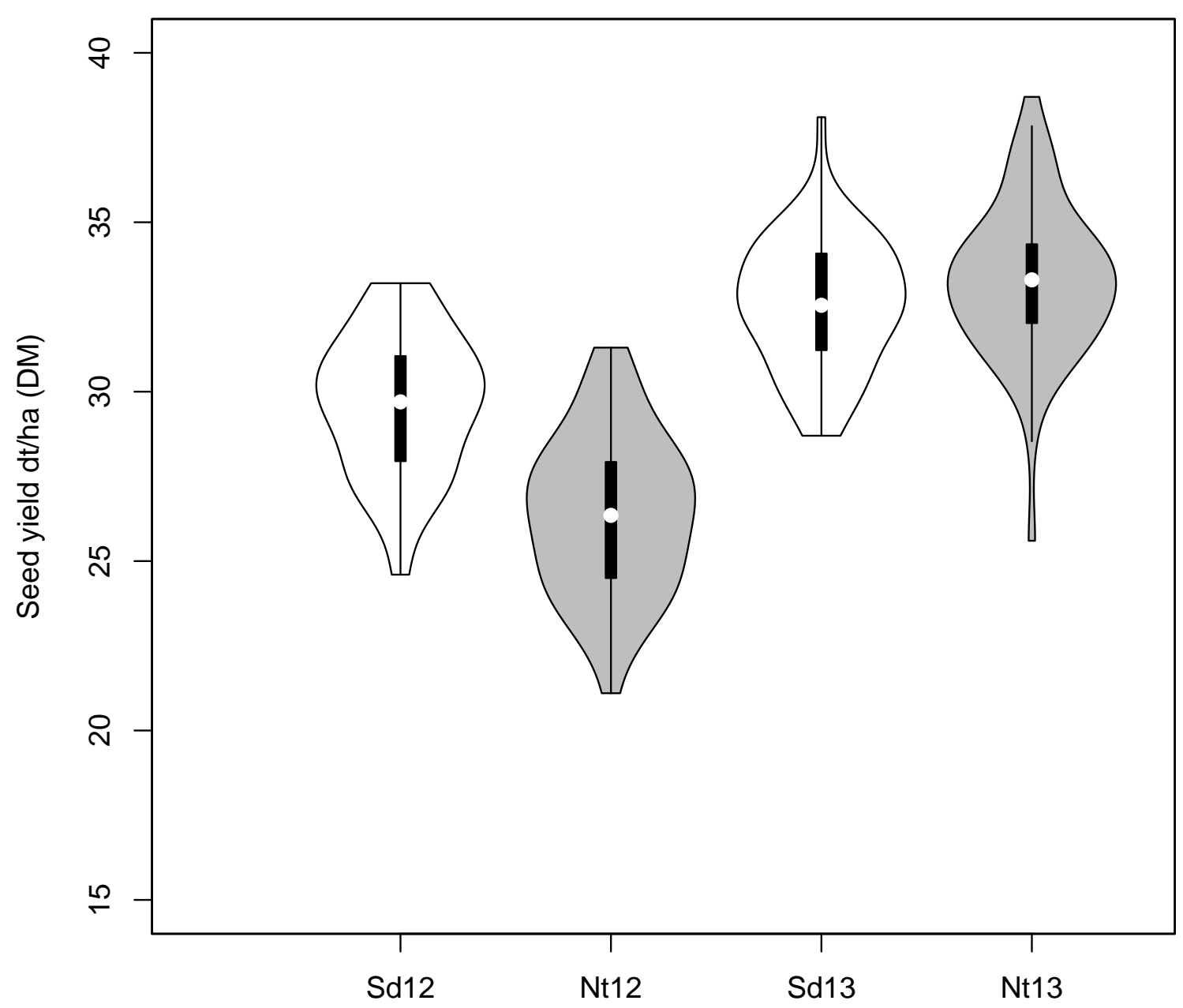

Figure 2.2: Violinplot of semi-dwarf (Sd) and normal type (Nt) hybrids for seed yield across two seasons at high nitrogen supply. The plot is a combination of a box plot and a kernel density plot.

In all environments semi-dwarf types formed significantly less straw than normal types 
(Tab.2.3). In combination with seed yield this resulted in a higher harvest index of semi-dwarfs compared to normal types. Thousand seed weight of semi-dwarf types was significantly lower compared to normal types in Göttingen 2012 and 2013. In Einbeck 2012 semi-dwarfs had significantly higher thousand seed weight. Oil content of semidwarfs was significantly reduced by $1 \%$ on average across all environments compared to normal types. Semi-dwarf types showed a significantly higher protein content in Einbeck 2012,2013 and Göttingen 2012. In Göttingen 2013 both growth types had same mean values for protein content (Tab.2.3).

The environments differed significantly for all traits (Tab.2.4). Significant differences between growth types were detected for plant height, straw yield, total biomass yield, harvest index and oil content. Seed yield and oil yield were not significantly different among growth types. Significant genotypic variations were observed for all traits. Interaction effects of growth type by environment and genotype by environment influenced all traits significantly. Heritabilities $\left(h^{2}\right)$ ranged from 0.27 for seed yield to 0.83 for thousand seed weight (Tab.2.4).

Table 2.4: Variance components of agronomic traits at high nitrogen supply in 2011/12 and 2012/13 (108 genotypes)

\begin{tabular}{|c|c|c|c|c|c|c|}
\hline Source & $\mathbf{E}$ & $\mathbf{T}$ & G & $\mathbf{T} \times \mathbf{E}$ & $\mathbf{G} \times \mathbf{E}$ & $\boldsymbol{h}^{2}$ \\
\hline Degrees of freedom & 3 & 1 & 106 & 3 & 318 & \\
\hline Begin of flowering (days) & $92.80^{* *}$ & $0 \quad \mathrm{~ns}$ & $0.18^{* *}$ & $0.16^{* *}$ & $0.44^{* *}$ & 0.56 \\
\hline Plant height (cm) & $456.81^{* *}$ & $622.62^{* *}$ & $3.74^{* *}$ & $59.63^{* *}$ & $5.29^{* *}$ & 0.54 \\
\hline Seed yield $(\mathrm{dt} / \mathrm{ha})^{\mathrm{a}}$ & $30.88^{* *}$ & $0 \quad \mathrm{~ns}$ & $0.73^{*}$ & $2.08^{+}$ & $2.10^{* *}$ & 0.27 \\
\hline Straw yield (dt/ha) & $57.36^{* *}$ & $22.18^{*}$ & $6.01^{* *}$ & $3.86^{* *}$ & $5.50^{* *}$ & 0.66 \\
\hline $\operatorname{Biomass}(\mathrm{dt} / \mathrm{ha})^{\mathrm{a}}$ & $54.44^{* *}$ & $24.30^{+}$ & $10.22^{* *}$ & $6.34^{* *}$ & $6.36^{* *}$ & 0.59 \\
\hline Harvest index ${ }^{\mathrm{a}}$ & $0.45^{* *}$ & $0.14^{*}$ & $0.37^{* *}$ & $2.97^{+}$ & $0.04^{* *}$ & 0.65 \\
\hline Thousand seed weight (g) & $0.12^{* *}$ & $0.01^{\mathrm{ns}}$ & $0.02^{* *}$ & $0.01^{* *}$ & $0.01^{* *}$ & 0.83 \\
\hline Oil content (\%) & $0.22^{*}$ & $0.51^{* *}$ & $0.42^{* *}$ & $0.06^{*}$ & $0.20^{* *}$ & 0.73 \\
\hline Oil yield (dt/ha) ${ }^{\mathrm{a}}$ & $6.82^{* *}$ & $0 \quad \mathrm{~ns}$ & $0.28^{* *}$ & $0.43^{+}$ & $0.46^{* *}$ & 0.40 \\
\hline Protein content (\%) & $0.21^{* *}$ & $0.03^{\mathrm{ns}}$ & $0.03^{* *}$ & $0.08^{* *}$ & $0.05^{*}$ & 0.33 \\
\hline
\end{tabular}

${ }^{* *},{ }^{*},+$ Significant difference at $0.01,0.05,0.10$ probability level, respectively; ns nonsignificant (F-test from ANOVA); negative variance components were set zero; $\mathbf{E}$ environment; $\mathbf{T}$ growth type; $\mathbf{G}$ genotype within growth type; $\boldsymbol{h}^{2}$ heritability within growth types; Biomass seed yield + straw yield;

${ }^{a}$ values for three environments 


\subsubsection{Comparison of agronomic performance at low and high nitrogen supply}

Nitrogen fertilization increased seed yield at all environments (Tab.2.5). Without nitrogen fertilization semi-dwarf hybrids produced between $43 \%$ (Go12) and $91 \%$ (Go13) of the seed yield achieved at fertilized conditions. Normal types produced between $40 \%$ (Go12) and $82 \%$ (Go13) of the seed yield achieved with nitrogen fertilization. In general seed yields without nitrogen fertilization in Go12 were rather low while in Go13 seed yields proved to be very high compared to other environments without nitrogen fertilization. The mean seed yield of semi-dwarf hybrids without nitrogen fertilization was reduced by $28 \%$ compared to the fertilized treatment. Normal types responded to nitrogen deficiency on average with a yield reduction of $33 \%$ compared to the fertilized treatment. The mean difference in seed yield of $5 \%$ between growth types across environments, proved to be non-significant (Tab.2.5).

Table 2.5: Seed yield, straw yield and their coefficients at low (N0) and high (N1) nitrogen supply in 2011/12 and 2012/13 (108 genotypes)

\begin{tabular}{|c|c|c|c|c|c|c|c|c|c|c|}
\hline & & \multicolumn{3}{|c|}{ Low nitrogen } & \multicolumn{3}{|c|}{ High nitrogen } & \multicolumn{3}{|c|}{ Coefficient N0:N1 } \\
\hline & & $\mathbf{N t}$ & Sd & & $\mathbf{N t}$ & Sd & & $\mathbf{N t}$ & Sd & \\
\hline \multirow{4}{*}{$\begin{array}{l}\text { Seed yield } \\
\text { (dt/ha) }\end{array}$} & Go12 & 10.4 & 12.8 & $* *$ & 26.4 & 29.7 & $* *$ & 0.40 & 0.43 & + \\
\hline & Ei13 & 22.5 & 22.4 & $\mathrm{~ns}$ & 28.5 & 27.5 & + & 0.79 & 0.82 & $*$ \\
\hline & Go13 & 30.7 & 33.9 & $* *$ & 37.8 & 37.6 & ns & 0.82 & 0.91 & ns \\
\hline & Mean & 21.2 & 23.0 & ns & 30.9 & 31.6 & ns & 0.67 & 0.72 & ns \\
\hline \multirow{5}{*}{$\begin{array}{l}\text { Straw yield } \\
(\mathrm{dt} / \mathrm{ha})\end{array}$} & $\operatorname{Ei} 12$ & 18.9 & 17.7 & $\mathrm{~ns}$ & 33.4 & 30.1 & $* *$ & 0.58 & 0.60 & $\mathrm{~ns}$ \\
\hline & Go12 & 22.9 & 19.8 & $* *$ & 39.4 & 32.1 & $* *$ & 0.58 & 0.62 & + \\
\hline & Ei13 & 46.4 & 36.1 & $* *$ & 54.8 & 44.5 & $* *$ & 0.85 & 0.83 & ns \\
\hline & Go13 & 36.4 & 32.0 & + & 41.2 & 34.6 & $* *$ & 0.89 & 0.94 & + \\
\hline & Mean & 31.1 & 26.4 & + & 42.2 & 35.4 & $*$ & 0.73 & 0.75 & $\mathrm{~ns}$ \\
\hline
\end{tabular}

$* *, *,+$ Significant difference at $0.01,0.05,0.10$ probability level, respectively; ns nonsignificant (F-test from ANOVA); Nt normal types; Sd semi-dwarfs; Ei Einbeck; Go Göttingen; all traits based on dry matter

Growth types differed significantly in straw yield at both nitrogen levels (Tab.2.5). At low nitrogen supply semi-dwarf types produced between $60 \%$ (Ei12) and $94 \%$ (Go13) of straw compared to high nitrogen supply. Normal types produced between $58 \%$ (Ei12, Go12) and $89 \%$ (Ei13) of straw compared to high nitrogen supply. Mean values for straw yield across all environments revealed no significant difference in the reduction of straw yield among growth types. In general it seems that seed yield responded stronger 
to nitrogen deficiency than straw yield.

Seed yield of semi-dwarfs at low and high nitrogen supply is correlated by $\mathrm{r}=0.54$ (Tab.2.6, Fig.2.3). Seed yield of normal types at low and high nitrogen is correlated by $\mathrm{r}$ $=0.55$. Coefficients of correlation for single traits differ between growth types.

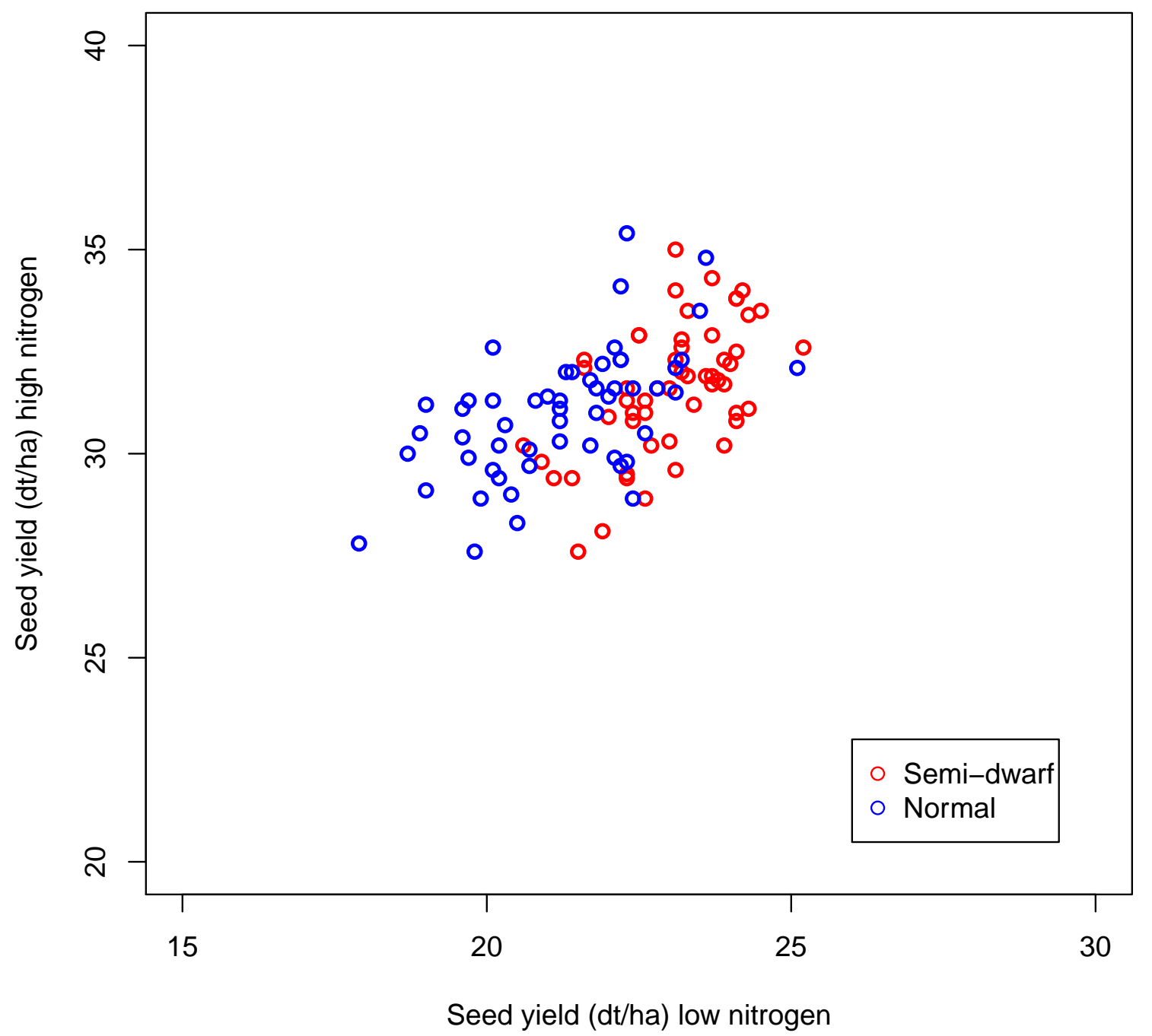

Figure 2.3: Mean seed yields across three environments (Go12, Ei13, Go13) at low and high nitrogen supply (108 genotypes) 
At low nitrogen supply seed yield of semi-dwarf hybrids was significantly negatively correlated to begin of flowering and thousand seed weight (Tab.2.7). Normal type hybrids also showed negative correlation but without significance. Significant positive correlations were observed for seed yield and harvest index as well as for seed yield and oil yield. Straw yield and plant height showed no correlation with seed yield in both types. Harvest index in both growth types was significantly negatively correlated with straw yield. Protein content in the semi-dwarfs as well as in the normal types was significantly negatively correlated with seed yield and oil content.

Seed yield of semi-dwarfs at high nitrogen supply was significantly positive correlated to plant height, straw yield and oil content (Tab.2.7). No significant correlation was observed between harvest index and seed yield. Seed yield of normal types was significantly correlated to harvest index $(\mathrm{r}=0.55)$. Normal types showed no significant correlation of plant height, straw yield and oil content with seed yield. In both types a significant negative correlation of straw yield and harvest index has been observed. Protein content in both types was negatively correlated with oil content (Tab.2.7).

The ANOVA including both nitrogen treatments revealed highly significant differences among environments for all traits except oil content (Tab.2.8). Significant differences between nitrogen fertilization levels were observed for begin of flowering, straw yield, oil content and protein content only. Seed yield revealed no significant difference between the two fertilization levels. Both growth types differed significantly for plant height, straw yield, harvest index, TSW and oil content. A significant genotypic variation was observed for all traits. Significant interactions between nitrogen fertilization and environment were observed for all traits except straw yield. Interactions between growth type and environment were significant for all traits. Significant interactions between growth type and nitrogen fertilization were observed for plant height, straw yield, oil content and protein content. Interactions of genotypes with fertilization level were observed for straw yield, total biomass and TSW. 
Table 2.6: Mean values, range and rank correlations for agronomic traits between low and high nitrogen supply (108 genotypes, four environments)

\begin{tabular}{|c|c|c|c|c|c|c|c|c|}
\hline \multirow[t]{2}{*}{ Trait } & & \multicolumn{3}{|c|}{ low nitrogen } & \multicolumn{3}{|c|}{ high nitrogen } & \multirow[t]{2}{*}{$\mathrm{r}_{\mathrm{N} 0: \mathrm{N} 1}$} \\
\hline & & Min & Max & Mean & Min & Max & Mean & \\
\hline \multirow{2}{*}{$\begin{array}{l}\text { Begin of flowering } \\
\text { (days) }\end{array}$} & $\mathrm{Nt}$ & 115 & 117 & 116 & 116 & 118 & 117 & $0.77^{* *}$ \\
\hline & $\mathrm{Sd}$ & 114 & 117 & $116 \mathrm{~ns}$ & 115 & 118 & $117 \mathrm{~ns}$ & $0.86^{* *}$ \\
\hline \multirow{2}{*}{$\begin{array}{l}\text { Plant height } \\
(\mathrm{cm})\end{array}$} & $\mathrm{Nt}$ & 109 & 120 & 116 & 119 & 130 & 124 & $0.42^{* *}$ \\
\hline & $\mathrm{Sd}$ & 80 & 95 & $86^{* *}$ & 81 & 96 & $88^{* *}$ & $0.79 * *$ \\
\hline \multirow{2}{*}{$\begin{array}{l}\text { Seed yield } \\
\text { (dt/ha) }\end{array}$} & $\mathrm{Nt}$ & 17.9 & 25.1 & 21.2 & 27.6 & 35.4 & 30.9 & $0.55^{* *}$ \\
\hline & $\mathrm{Sd}$ & 20.6 & 25.2 & $23.0 \mathrm{~ns}$ & 27.6 & 35.0 & $31.6 \mathrm{~ns}$ & $0.54 * *$ \\
\hline \multirow{2}{*}{$\begin{array}{l}\text { Straw yield } \\
\text { (dt/ha) }\end{array}$} & $\mathrm{Nt}$ & 26.6 & 36.8 & 31.1 & 37.1 & 49.1 & 42.2 & $0.33 *$ \\
\hline & $\mathrm{Sd}$ & 22.8 & 30.8 & $26.4+$ & 29.0 & 45.2 & $35.4 *$ & $0.65^{* *}$ \\
\hline \multirow{2}{*}{$\begin{array}{l}\text { Biomass }^{a} \\
(\mathrm{dt} / \mathrm{ha})\end{array}$} & $\mathrm{Nt}$ & 49.1 & 62.7 & 56.4 & 68.8 & 85.5 & 76.0 & $0.39 * *$ \\
\hline & $\mathrm{Sd}$ & 44.6 & 58.3 & $52.3 \mathrm{~ns}$ & 60.8 & 81.5 & $68.7+$ & $0.50 * *$ \\
\hline \multirow[t]{2}{*}{ Harvest index } & $\mathrm{Nt}$ & 0.32 & 0.42 & 0.37 & 0.36 & 0.46 & 0.41 & $0.49^{* *}$ \\
\hline & $\mathrm{Sd}$ & 0.37 & 0.48 & $0.43^{* *}$ & 0.36 & 0.52 & $0.46^{*}$ & $0.65 * *$ \\
\hline \multirow{2}{*}{$\begin{array}{l}\text { TSW } \\
\text { (g) }\end{array}$} & $\mathrm{Nt}$ & 4.15 & 5.05 & 4.64 & 4.26 & 5.06 & 4.57 & $0.49^{* *}$ \\
\hline & $\mathrm{Sd}$ & 4.00 & 4.87 & $4.45 * *$ & 4.02 & 4.82 & $4.40 \mathrm{~ns}$ & 0.89 ** \\
\hline \multirow{2}{*}{$\begin{array}{l}\text { Oil content } \\
(\%)\end{array}$} & $\mathrm{Nt}$ & 47.6 & 51.4 & 49.5 & 46.5 & 49.7 & 48.0 & $0.76^{* *}$ \\
\hline & $\mathrm{Sd}$ & 47.4 & 51.1 & $49.2 \mathrm{~ns}$ & 45.4 & 48.1 & $47.0^{* *}$ & $0.84 * *$ \\
\hline \multirow{2}{*}{$\begin{array}{l}\text { Oil yield } \\
\text { (dt/ha) }\end{array}$} & $\mathrm{Nt}$ & 9.1 & 12.2 & 10.6 & 13.3 & 17.2 & 14.8 & $0.62 * *$ \\
\hline & $\mathrm{Sd}$ & 9.9 & 12.9 & $11.5 \mathrm{~ns}$ & 12.4 & 16.4 & $14.8 \mathrm{~ns}$ & $0.57 * *$ \\
\hline \multirow{2}{*}{$\begin{array}{l}\text { Protein content } \\
(\%)\end{array}$} & $\mathrm{Nt}$ & 17.9 & 19.2 & 18.6 & 19.8 & 21.3 & 20.4 & $0.32 *$ \\
\hline & $\mathrm{Sd}$ & 17.4 & 19.2 & $18.3 \mathrm{~ns}$ & 20.1 & 21.3 & $20.7 \mathrm{~ns}$ & $0.53^{* *}$ \\
\hline
\end{tabular}

**,*,+ Significant difference at $0.01,0.05,0.10$ probability level, respectively; ns nonsignificant (F-test from ANOVA); $\mathbf{r}_{\text {N0:N1 }}$ Spearman's rank correlation between low and high nitrogen supply; Nt normal types; Sd semi-dwarfs; Biomass seed yield + straw yield; TSW thousand seed weight; all traits based on dry matter; (a) values across three environments (Go12, Ei13 and Go13) 
Table 2.7: Rank correlations for agronomic traits across four environments (Ei12, Go12, Ei13,Go13) at low and high nitrogen supply

\begin{tabular}{|c|c|c|c|c|c|c|c|c|c|}
\hline \multicolumn{2}{|c|}{ Low nitrogen supply } & \multirow{2}{*}{$\frac{\mathrm{BFL}}{0.35^{* *}}$} & \multirow[t]{2}{*}{ (2) } & \multirow[t]{2}{*}{ (3) } & \multirow[t]{2}{*}{ (4) } & \multirow[t]{2}{*}{ (5) } & \multirow[t]{2}{*}{ (6) } & \multirow[t]{2}{*}{ (7) } & \multirow[t]{2}{*}{ (8) } \\
\hline (2) Plant height & $\begin{array}{l}\mathrm{Nt} \\
\mathrm{Sd}\end{array}$ & & & & & & & & \\
\hline (3) Seed yield ${ }^{a}$ & $\begin{array}{l}\mathrm{Nt} \\
\mathrm{Sd}\end{array}$ & $\begin{array}{l}-0.04^{\mathrm{ns}} \\
-0.30^{*}\end{array}$ & $\begin{array}{r}-0.11^{\mathrm{ns}} \\
0.02^{\mathrm{ns}}\end{array}$ & & & & & & \\
\hline (4) Straw yield & $\begin{array}{l}\mathrm{Nt} \\
\mathrm{Sd}\end{array}$ & $\begin{array}{l}0.37^{\text {** }} \\
0.25^{\mathrm{ns}}\end{array}$ & $\begin{array}{l}0.31^{*} \\
0.33^{*}\end{array}$ & $\begin{array}{l}0.05^{\text {ns }} \\
0.09^{\text {ns }}\end{array}$ & & & & & \\
\hline (5) Harvest index ${ }^{a}$ & $\begin{array}{l}\mathrm{Nt} \\
\mathrm{Sd}\end{array}$ & $\begin{array}{l}-0.35^{*} \\
-0.37^{* *}\end{array}$ & $\begin{array}{l}-0.40^{* *} \\
-0.16^{\mathrm{ns}}\end{array}$ & $\begin{array}{l}0.68^{* *} \\
0.63^{* *}\end{array}$ & $\begin{array}{l}-0.53^{* *} \\
-0.52^{* *}\end{array}$ & & & & \\
\hline (6) TSW & $\begin{array}{l}\mathrm{Nt} \\
\mathrm{Sd}\end{array}$ & $\begin{array}{l}0.07^{\mathrm{ns}} \\
0.12^{\mathrm{ns}}\end{array}$ & $\begin{array}{r}-0.18^{\mathrm{ns}} \\
0.11^{\mathrm{ns}}\end{array}$ & $\begin{array}{l}-0.26^{\mathrm{ns}} \\
-0.30^{*}\end{array}$ & $\begin{array}{r}-0.11^{\mathrm{ns}} \\
0.09^{\mathrm{ns}}\end{array}$ & $\begin{array}{l}-0.06^{\mathrm{ns}} \\
-0.27^{\mathrm{ns}}\end{array}$ & & & \\
\hline (7) Oil content & $\begin{array}{l}\mathrm{Nt} \\
\mathrm{Sd}\end{array}$ & $\begin{array}{l}-0.07^{\mathrm{ns}} \\
-0.18^{\mathrm{ns}}\end{array}$ & $\begin{array}{l}-0.13^{\mathrm{ns}} \\
-0.15^{\mathrm{ns}}\end{array}$ & $\begin{array}{l}0.13^{\text {ns }} \\
0.21^{\text {ns }}\end{array}$ & $\begin{array}{l}-0.03^{\mathrm{ns}} \\
-0.21^{\mathrm{ns}}\end{array}$ & $\begin{array}{l}0.06^{\text {ns }} \\
0.32^{*}\end{array}$ & $\begin{array}{l}-0.17^{\mathrm{ns}} \\
-0.20^{\mathrm{ns}}\end{array}$ & & \\
\hline (8) Oil yield ${ }^{a}$ & $\begin{array}{l}\mathrm{Nt} \\
\mathrm{Sd}\end{array}$ & $\begin{array}{l}-0.08^{\mathrm{ns}} \\
-0.34^{*}\end{array}$ & $\begin{array}{l}-0.12^{\mathrm{ns}} \\
-0.05^{\mathrm{ns}}\end{array}$ & $\begin{array}{l}0.93^{* *} \\
0.92^{* *}\end{array}$ & $\begin{array}{r}0.03^{\mathrm{ns}} \\
-0.03^{\mathrm{ns}}\end{array}$ & $\begin{array}{l}0.65^{* *} \\
0.67^{* *}\end{array}$ & $\begin{array}{l}-0.32^{*} \\
-0.31^{\mathrm{ns}}\end{array}$ & $\begin{array}{l}0.44^{* *} \\
0.53^{* *}\end{array}$ & \\
\hline (9) Protein content & $\begin{array}{l}\mathrm{Nt} \\
\mathrm{Sd}\end{array}$ & $\begin{array}{l}0.14^{\mathrm{ns}} \\
0.30^{*}\end{array}$ & $\begin{array}{r}-0.04^{\mathrm{ns}} \\
0.25^{\mathrm{ns}}\end{array}$ & $\begin{array}{l}-0.36^{* *} \\
-0.40^{* *}\end{array}$ & $\begin{array}{l}0.03^{\text {ns }} \\
0 \quad \text { ns }\end{array}$ & $\begin{array}{l}-0.30^{*} \\
-0.26^{\mathrm{ns}}\end{array}$ & $\begin{array}{l}0.18^{\text {ns }} \\
0.41^{* *}\end{array}$ & $\begin{array}{l}-0.44^{* *} \\
-0.47^{* *}\end{array}$ & $\begin{array}{l}-0.49^{* *} \\
-0.52^{* *}\end{array}$ \\
\hline High nitrogen & ply & $\mathrm{BFL}$ & $(2)$ & (3) & (4) & $(5)$ & $(6)$ & (7) & (8) \\
\hline (2) Plant height & $\begin{array}{l}\mathrm{Nt} \\
\mathrm{Sd}\end{array}$ & $\begin{array}{l}0.15^{\mathrm{ns}} \\
0.52^{* *}\end{array}$ & & & & & & & \\
\hline (3) Seed yield ${ }^{a}$ & $\begin{array}{l}\mathrm{Nt} \\
\mathrm{Sd}\end{array}$ & $\begin{array}{l}0.15^{\mathrm{ns}} \\
0.09^{\mathrm{ns}}\end{array}$ & $\begin{array}{r}-0.20^{\mathrm{ns}} \\
0.41^{* *}\end{array}$ & & & & & & \\
\hline (4) Straw yield & $\begin{array}{l}\mathrm{Nt} \\
\mathrm{Sd}\end{array}$ & $\begin{array}{l}0.12^{\text {ns }} \\
0.49^{* *}\end{array}$ & $\begin{array}{l}0.07^{\text {ns }} \\
0.71^{* *}\end{array}$ & $\begin{array}{l}0.11^{\text {ns }} \\
0.33^{*}\end{array}$ & & & & & \\
\hline (5) Harvest index ${ }^{a}$ & $\begin{array}{l}\mathrm{Nt} \\
\mathrm{Sd}\end{array}$ & $\begin{array}{l}-0.02^{\mathrm{ns}} \\
-0.38^{* *}\end{array}$ & $\begin{array}{l}-0.20^{\mathrm{ns}} \\
-0.39^{* *}\end{array}$ & $\begin{array}{l}0.50^{* *} \\
0.24^{\mathrm{ns}}\end{array}$ & $\begin{array}{l}-0.71^{* *} \\
-0.77^{* *}\end{array}$ & & & & \\
\hline (6) TSW & $\begin{array}{l}\mathrm{Nt} \\
\mathrm{Sd}\end{array}$ & $\begin{array}{ll}0 & \mathrm{~ns} \\
0 & \mathrm{~ns}\end{array}$ & $\begin{array}{l}0.19^{\text {ns }} \\
0.01^{\text {ns }}\end{array}$ & $\begin{array}{l}-0.21^{\mathrm{ns}} \\
-0.07^{\mathrm{ns}}\end{array}$ & $\begin{array}{c}-0.05^{\mathrm{ns}} \\
0.28^{*}\end{array}$ & $\begin{array}{l}-0.16^{\mathrm{ns}} \\
-0.26^{\mathrm{ns}}\end{array}$ & & & \\
\hline (7) Oil content & $\begin{array}{l}\mathrm{Nt} \\
\mathrm{Sd}\end{array}$ & $\begin{array}{r}0.23^{\mathrm{ns}} \\
-0.16^{\mathrm{ns}}\end{array}$ & $\begin{array}{r}0.04^{\mathrm{ns}} \\
-0.05^{\mathrm{ns}}\end{array}$ & $\begin{array}{l}0.13^{\text {ns }} \\
0.29^{*}\end{array}$ & $\begin{array}{l}-0.05^{\mathrm{ns}} \\
-0.08^{\mathrm{ns}}\end{array}$ & $\begin{array}{l}0.13^{\text {ns }} \\
0.21^{\text {ns }}\end{array}$ & $\begin{array}{r}-0.10^{\mathrm{ns}} \\
0.10^{\mathrm{ns}}\end{array}$ & & \\
\hline (8) Oil yield ${ }^{a}$ & $\begin{array}{l}\mathrm{Nt} \\
\mathrm{Sd}\end{array}$ & $\begin{array}{l}0.19^{\text {ns }} \\
0.06^{\text {ns }}\end{array}$ & $\begin{array}{r}-0.21^{\mathrm{ns}} \\
0.35^{* *}\end{array}$ & $\begin{array}{l}0.92^{* *} \\
0.95^{* *}\end{array}$ & $\begin{array}{l}0.03^{\text {ns }} \\
0.30^{*}\end{array}$ & $\begin{array}{l}0.53^{* *} \\
0.24^{\text {ns }}\end{array}$ & $\begin{array}{l}-0.27^{*} \\
-0.01^{\mathrm{ns}}\end{array}$ & $\begin{array}{l}0.44^{* *} \\
0.52^{* *}\end{array}$ & \\
\hline (9) Protein content & $\begin{array}{l}\mathrm{Nt} \\
\mathrm{Sd}\end{array}$ & $\begin{array}{r}-0.05^{\mathrm{ns}} \\
0.22^{\mathrm{ns}}\end{array}$ & $\begin{array}{l}0.08^{\text {ns }} \\
0.03^{\text {ns }}\end{array}$ & $\begin{array}{l}-0.03^{\mathrm{ns}} \\
-0.54^{* *}\end{array}$ & $\begin{array}{l}0.23^{\text {ns }} \\
0.14^{\text {ns }}\end{array}$ & $\begin{array}{l}-0.29^{*} \\
-0.37^{* *}\end{array}$ & $\begin{array}{l}0.10^{\text {ns }} \\
0.12^{\text {ns }}\end{array}$ & $\begin{array}{l}-0.31^{*} \\
-0.49^{* *}\end{array}$ & $\begin{array}{l}-0.08^{\mathrm{ns}} \\
-0.59^{* *}\end{array}$ \\
\hline
\end{tabular}

$* *,{ }^{*},+$ Significant at $0.01,0.05,0.10$ probability level, respectively; ns non-significant; Nt normal types; Sd semi-dwarfs; BFL begin of flowering; TSW thousand seed weight; (a) values across three environments (Go12, Ei13 and Go13) 
2 Agronomic performance of semi-dwarf and normal type winter oilseed rape hybrids

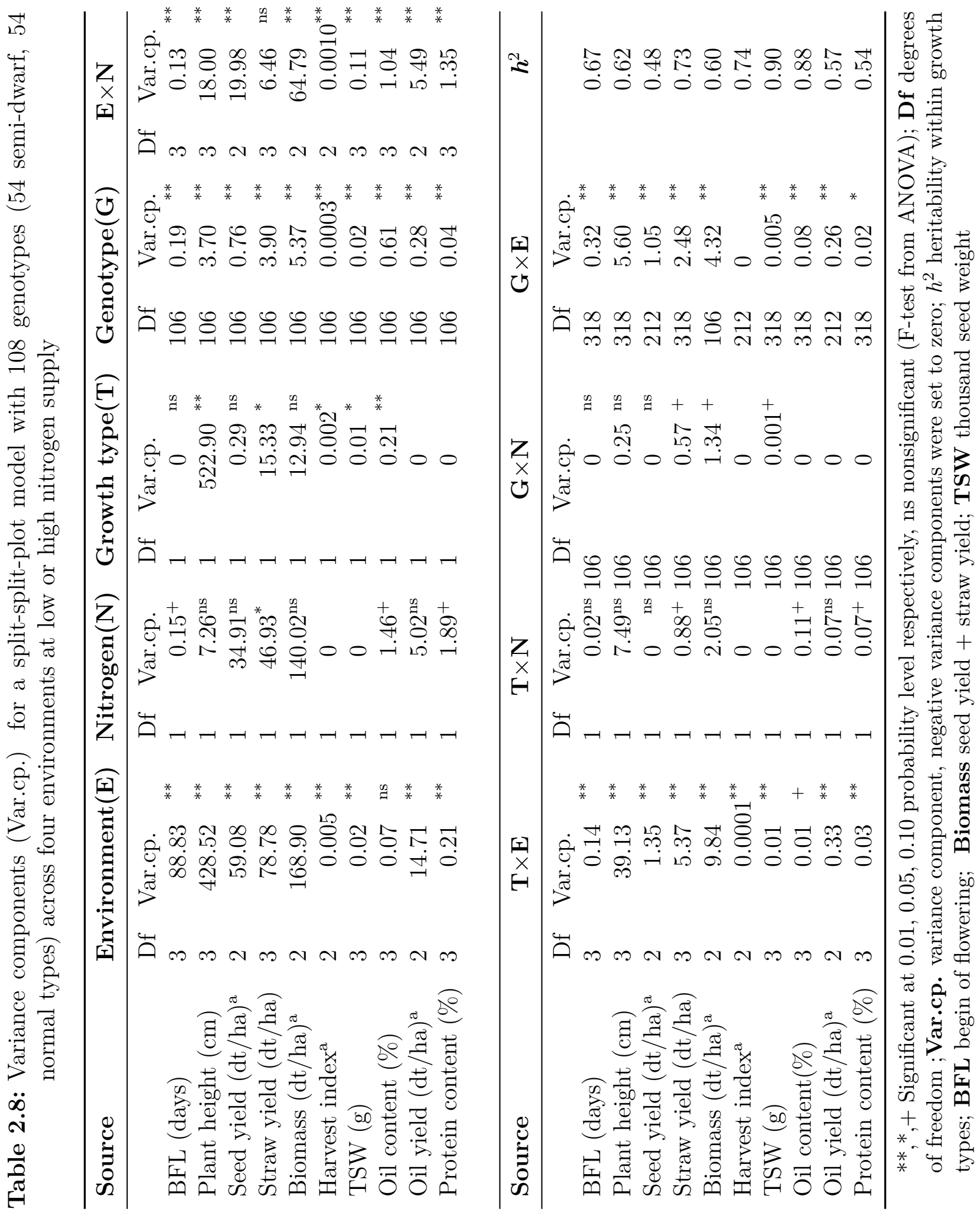




\subsection{Discussion}

In the present study the agronomic performance of semi-dwarf and normal type winter oilseed rape hybrids was compared at two contrasting nitrogen supply regimes. In Einbeck 2013 semi-dwarfs revealed a clear superiority in lodging resistance compared to normal types at high nitrogen supply (data not shown). This is in accordance with observations from Wang et al. (2004), who argued that the different branching structure of semi-dwarfs, with branches starting at lower stem sections, lead to a more even weight distribution throughout the plant stem. Genotypes within growth types varied significantly in plant height. But no semi-dwarf was taller than the shortest normal type and vice versa. Plant height of both growth types showed no significant difference between nitrogen supply levels. The average height of semi-dwarfs differed only by $2 \mathrm{~cm}$ between low and high nitrogen supply (Tab. 2.6).

At low nitrogen supply seed yield of semi-dwarf hybrids was significantly higher $(2.4$ $\mathrm{dt} / \mathrm{ha}$ ) compared to normal hybrids (Tab. 2.1). The different performance in individual environments (no difference in Einbeck 2013) is expressed as significant growth types by environment interaction (Tab. 2.2). At high nitrogen supply both growth types produced similar seed yields with a non-significant difference of 0.2 dt/ha. In Göttingen 2012 plants were relatively short compared to other environments and semi-dwarf hybrids had a significantly higher seed yield than normal types (Tab. 2.3). In Einbeck 2013 they yielded less than normal types and in Göttingen 2013, no significant difference in seed yield was observed among growth types at high nitrogen supply. The yield advantage of normal types in Einbeck 2013 (high nitrogen supply) would have been probably greater without lodging. The ANOVA for high nitrogen supply revealed a significant effect of growth type by environment and genotype by environment interactions on seed yield, resulting in a low heritability of $h^{2}=0.27$ (Tab. 2.4). To draw a meaningful conclusion about the effect of the dwarf gene on seed yield at conditions of high nitrogen supply more environments need to be tested. The comparison of seed yields at low and high nitrogen supply give the impression that normal types respond to nitrogen deficiency by a stronger reduction in seed yield than semi-dwarf types (Tab. 2.5). But results from ANOVA across both nitrogen levels revealed no significant interaction for growth type and nitrogen level (Tab. 2.8). The factors environment and nitrogen level had by far the greatest effect on seed yield (Tab. 2.8). Nevertheless the effect of nitrogen supply was not significant due to a significant environment by nitrogen supply level interaction which indicates that nitrogen fertilization had different effects in single environments. Especially the difference in seed yield between low and high nitrogen supply in Göttingen 2013 was relatively small compared to other environments. This might have been caused by high rates of nitrogen mineralization in this environment resulting in a high nitrogen supply from the soil even in 
the unfertilized experiments. Genotypes within growth types differed significantly in seed yield but revealed no interaction with nitrogen supply. Thus the ranking of genotypes for seed yield should be the same at both nitrogen supply levels and high yielding genotypes at low nitrogen supply are also superior at high nitrogen supply. However, rank correlations for seed yield between low and high nitrogen supply are rather low for both growth types (semi-dwarf $\mathrm{r}=0.54$, normal type $\mathrm{r}=0.55$ ) (Tab. 2.6). The rank shift in seed yield between low and high nitrogen levels could have been caused by experimental errors. Straw yield of semi-dwarfs at low nitrogen supply was significantly reduced compared to normal types (Tab.2.1). The relative differences in straw yield between growth types varied among environments resulting in a significant environment by growth type interaction effect (Tab. 2.2). Genotypic variation for straw yield was non-significant but genotype by environment interaction was highly significant (Tab.2.2). Heritability for straw yield at low nitrogen supply was low $\left(h^{2}=0.17\right)$ due to high experimental errors. It is often observed that experimental errors at suboptimal conditions are higher compared to optimal conditions and heritabilities are reduced. At high nitrogen supply straw yield of semi-dwarf hybrids was significantly reduced compared to normal types. Interaction between growth type and environment was significant as already observed at low nitrogen supply. Growth types and genotypes within the growth types seem to respond differently in straw yield at different nitrogen levels indicated by a significant growth type by nitrogen supply or genotype by nitrogen supply interaction, respectively (Tab. 2.8). A significant difference in straw yield between low and high nitrogen supply was also observed by Kessel et al. (2012). The authors reported no significant interaction between genotype and environment for straw yield.

Due to higher or similar seed yields and less straw yield, harvest index of semi-dwarf hybrids was significantly improved at both nitrogen levels compared to normal hybrids (Tab.2.1, Tab. 2.3). This result is contradictory to conclusions by Sieling and Kage (2008). The harvest indexes of normal hybrids at low nitrogen supply (0.34) and high nitrogen supply (0.41) in the present experiment are in accordance with results from Kessel et al. (2012), describing a harvest index of 0.42 (high nitrogen supply) and 0.36 (low nitrogen supply) for normal hybrid varieties. Correlation coefficient of semi-dwarfs for seed yield and harvest index at high nitrogen supply was only 0.24 (Tab.2.7). Normal types showed a significant correlation of 0.50 . By comparing total biomass yields of both growth types at maturity it becomes obvious that the improved harvest index of semi-dwarfs is mostly based on a reduction in straw yield. Therefore the reduction of vegetative biomass (straw) does not seem to result in an improved seed yield at high nitrogen supply. On the other hand the semi-dwarf growth type revealed no disadvantage in seed yield at high nitrogen supply either and still possesses other benefits like a swifter harvest and improved lodging 
resistance.

Wang et al. (2004) conducted field experiments over two years with ten semi-dwarf hybrids using the $n d f 1$ dwarf gene which is probably allelic to $b z h$. The authors described a good agronomic performance of semi-dwarf hybrids based on more seeds per pod and higher thousand seed weight than the normal parent. The number of pods per plant was reported to be lower compared to conventional cultivars (Wang et al., 2004). In the present experiment, thousand seed weight of semi-dwarfs was slightly lower at low and high nitrogen supply compared to normal types, but without significance at high nitrogen supply (Tab. 2.6). Considering the higher or similar seed yield of semi-dwarfs this could indicate that number of seeds per pod or number of pods is increased compared to normal types.

Protein content was significantly affected by nitrogen supply (Tab. 2.8) with higher values at high nitrogen supply compared to low nitrogen supply (Tab. 2.6). This oberservation is in accordance with other results published (Brennan et al., 2000; Rathke et al., 2005). It is known that protein and oil content are negatively correlated due to their competition for carbon compounds during carbohydrate metabolism (Bhatia and Rabson, 1976). Proteins have a lower carbohydrate content and an increased N supply intensifies the protein synthesis at the expense of fatty acid synthesis and thus reducing the oil content in seeds (Bhatia and Rabson, 1976; Rathke et al., 2005). The negative correlation of protein content and oil content had been observed at both nitrogen levels (Tab. 2.7). As a consequence of this competition oil content at high nitrogen supply was significantly reduced compared to low nitrogen supply (Tab.2.6, 2.8). Oil content of normal types at high nitrogen supply was significantly lower compared to semi-dwarfs (Tab. 2.6). At low nitrogen supply no significant difference in oil content was detected among growth types. The reason for variation in oil content between growth types at high nitrogen supply is unknown.

Based on the results of the present study, semi-dwarf hybrids seem to have a superiority in seed yield at nitrogen deficient conditions compared to normal types. At high nitrogen supply no significant difference in seed yield had been observed between both growth types but contrary results at single environments demand for further testing at more environments with high nitrogen supply. Other agronomic traits were not negatively affected by the dwarf gene $B z h$. Therefore the semi-dwarf growth type is an interesting option for rapeseed cultivation, especially for cropping systems with low nitrogen input. 


\section{References}

Bhatia, C. and Rabson, R. (1976). Bioenergetic considerations in cereal breeding for protein improvement. Science, 194(4272):1418-1421.

Brennan, R., Mason, M., and Walton, G. (2000). Effect of nitrogen fertilizer on the concentrations of oil and protein in canola (Brassica napus) seed. Journal of Plant Nutrition, 23(3):339-348.

Eurostat (2014). Url : http:// www.epp.eurostat.ec.europa.eu/ portal/ page/ portal/ agriculture/ data/ maintables.html. Eurostat, 11.02.2014.

Foisset, N., Delourme, R., Barret, P., and Renard, M. (1995). Molecular tagging of the dwarf BREIZH (Bzh) gene in Brassica napus. Theoretical and Applied Genetics, 91(5):756-761.

Hedden, P. (2003). The genes of the Green Revolution. Trends in Genetics, 19(1):5-9.

Hintze, J. L. and Nelson, R. D. (1998). Violin plots: a box plot-density trace synergism. The American Statistician, 52(2):181-184.

Kessel, B., Schierholt, A., and Becker, H. C. (2012). Nitrogen Use Efficiency in a Genetically Diverse Set of Winter Oilseed Rape (L.). Crop Science, 52(6):2546-2554.

Lancashire, P. D., Bleiholder, H., Boom, T., Langelüddeke, P., Stauss, R., Weber, E., and Witzenberger, A. (1991). A uniform decimal code for growth stages of crops and weeds. Annals of Applied Biology, 119(3):561-601.

Li, H., Wang, Y., Li, X., Gao, Y., Wang, Z., Zhao, Y., and Wang, M. (2011). A GAinsensitive dwarf mutant of Brassica napus L. correlated with mutation in pyrimidine box in the promoter of GID1. Molecular Biology Reports, 38(1):191-197.

Muangprom, A., Mauriera, I., and Osborn, T. C. (2006). Transfer of a dwarf gene from Brassica rapa to oilseed B. napus, effects on agronomic traits, and development of a 'perfect' marker for selection. Molecular Breeding, 17(2):101-110. 


\section{REFERENCES}

Paulmann, W. and Frauen, M. (1998). Erfahrungsbericht zur Entwicklung und Saatguterzeugung von restaurierten Winterraps-Hybridsorten. Bericht über die 48 . Tagung der Arbeitsgemeinschaft der Saatzuchtleiter, BAL Gumpenstein, 48:25-27.

Peng, J., Richards, D. E., Hartley, N. M., Murphy, G. P., Devos, K. M., Flintham, J. E., Beales, J., Fish, L. J., Worland, A. J., Pelica, F., et al. (1999). 'Green revolution' genes encode mutant gibberellin response modulators. Nature, 400(6741):256-261.

Rathke, G.-W., Christen, O., and Diepenbrock, W. (2005). Effects of nitrogen source and rate on productivity and quality of winter oilseed rape (Brassica napus L.) grown in different crop rotations. Field Crops Research, 94(2):103-113.

Sieling, K. and Kage, H. (2008). The potential of semi-dwarf oilseed rape genotypes to reduce the risk of N leaching. The Journal of Agricultural Science, 146(01):77-84.

Sun, T.-P. and Gubler, F. (2004). Molecular mechanism of gibberellin signaling in plants. Annual Review of Plant Biology, 55:197-223.

Utz, H. (2001). Plabstat - ein Computerprogramm zur statistischen Analyse von pflanzenzüchterischen Experimenten. Institut für Pflanzenzüchtung, Saatgutforschung und Populationsgenetik der Universität Hohenheim.

Wang, M., Zhao, Y., Chen, F., and Yin, X. (2004). Inheritance and potentials of a mutated dwarfing gene ndf1 in Brassica napus. Plant Breeding, 123(5):449-453.

Zanewich, K. P., Rood, S. B., Southworth, C. E., and Williams, P. H. (1991). Dwarf mutants of Brassica: Responses to applied gibberellins and gibberellin content. Journal of Plant Growth Regulation, 10(1-4):121-127.

Zeng, X., Zhu, L., Chen, Y., Qi, L., Pu, Y., Wen, J., Yi, B., Shen, J., Ma, C., Tu, J., et al. (2011). Identification, fine mapping and characterisation of a dwarf mutant (bnaC. dwf) in Brassica napus. Theoretical and Applied Genetics, 122(2):421-428. 


\section{Nitrogen use efficiency of semi-dwarf and normal type hybrids}

\subsection{Introduction}

Germany produced about 3.41 million tons of oilseed rape oil in 2012 (UFOP, 2012). Most of the oil is used for the production of biofuels and technical oils. In 2009 the European Union (EU) introduced the Renewable Energy Directive (RED 2009/28/EG) with the objective to increase the use of biofuels. To meet the new regulatory standards only biofuels with a reduction of $35 \%$ in greenhouse gas (GHG) emission compared to conventional fossil fuels are allowed. This percentage will increased to at least $50 \%$ by 2017.

The vast majority of GHG emissions from biofuels based on oilseed rape oil are caused by cultivation and processing of oilseed rape. More than $82 \%$ of GHG emissions in the cultivation of winter oilseed rape is caused by $\mathrm{N}$-fertilization $(42 \%)$ and $\mathrm{N}_{2} \mathrm{O}$ emissions in the field (40.8\%) (Schiemenz and Gurgel, 2013).

In field trials in Northern Germany Schiemenz and Gurgel (2013) investigated the effect of a reduction in GHG emissions to $50 \%$ compared to fossil fuels on the cultivation of winter oilseed rape. In a typical crop rotation winter wheat is followed by oilseed rape. For a oilseed rape yield of $50 \mathrm{dt} / \mathrm{ha} 247 \mathrm{~kg} \mathrm{~N} /$ ha are required. To meet future EU regulations nitrogen fertilization would have to be reduced to $83 \mathrm{~kg} N / \mathrm{ha}$. As a consequence oilseed rape yield would decrease to $38 \mathrm{dt} / \mathrm{ha}$ (Schiemenz and Gurgel, 2013). Although it is unlikely that farmers respond to the new regulations only by reducing nitrogen fertilization, the scenario illustrates the future challenge of maintaining current seed yields while using less mineral nitrogen fertilizer than today. This challenge could be met by the development of winter oilseed rape cultivars with an improved nitrogen use efficiency. In the present study nitrogen use efficiency is defined as seed production per unit nitrogen available in the soil. According to Moll et al. (1982) it is subdivided into the proportion of available nitrogen that is taken up by the plant (nitrogen uptake efficiency) and the efficiency with which the absorbed nitrogen is utilized to produce seeds (nitrogen utilization efficiency). 
Genetic variation for nitrogen uptake efficiency and nitrogen utilization efficiency between European winter oilseed rape cultivars and breeding lines was detected in several studies (Berry et al., 2010; Kessel et al., 2012; Schulte auf'm Erley et al., 2011). At low nitrogen conditions nitrogen uptake proved to be more important for seed yield than nitrogen utilization. With increasing nitrogen supply nitrogen utilization become more important (Berry et al., 2010; Kessel et al., 2012). Interactions between genotype and nitrogen level have been observed as well. That means that genotypes selected for high yield at high nitrogen conditions might not be high yielding under low nitrogen conditions (Berry et al., 2010; Kessel et al., 2012).

The objective of this study was to compare the nitrogen use efficiency of semi-dwarf and normal-type winter oilseed rape hybrids. Semi-dwarf types are of special interest, because they might need less nitrogen per unit seed yield than normal types, due to the reduced formation of vegetative biomass. To evaluate the response to nitrogen deficiency, genotypes were tested at low and high nitrogen conditions. Furthermore, parameters influencing nitrogen use efficiency at low and high nitrogen supply were investigated.

\subsection{Materials and Methods}

\subsubsection{Plant Material and Experimental Design}

A doubled-haploid (DH) population (242 lines) derived from the cross 'Alesi- $b z h \times \mathrm{H} 30$ ' was produced. The 'Alesi- $b z h$ ' parent is a dwarf isogenic line derived from the German winter oilseed cultivar 'Alesi' backcrossed (BC4) to the bzh dwarf mutant described by Foisset et al. (1995). 'H30' is a normal type, resynthesized rapeseed line originating from a cross of Brasscia rapa ssp. chinensis with Brasscica napus ssp. napus var. pabularia with moderate winterhardiness (Girke, 2002). The DH population is segregating into dwarf and tall growing DH lines. All DH lines were crossed with a normal type, male sterile tester (canola quality) using the MSL ('Männliche Sterilität Lembke') hybrid system (Paulmann and Frauen, 1998). The resulting testcross hybrids (TC) segregate into semi-dwarf and normal types.

In season 2010/11 150 TC (75 semi-dwarfs and 75 normal types) were selected based on the availability of seeds and evaluated in two adjacent experiments. One experiment was harvested at the end of flowering (EOF) (BBCH 69, Lancashire et al. (1991)) and the second experiment at seed maturity (BBCH 89). Experiments were conducted at two sites near Einbeck (Ei) (brunic aerosol) and near Göttingen (Go) (alluvial meadow soil) in Central Germany. The plot sizes were $18 \mathrm{~m}^{2}$ in Einbeck and $11.25 \mathrm{~m}^{2}$ in Göttingen with plant densities of 50 and 90 plants $/ \mathrm{m}^{2}$, respectively. Both experiments were evaluated without nitrogen fertilization (low nitrogen supply). Soil mineral nitrogen determined at 
the beginning of plant growth in spring was $35 \mathrm{~kg} \mathrm{~N} /$ ha in Einbeck (Ei11) and $27 \mathrm{~kg}$ $\mathrm{N} /$ ha in Göttingen (Go11). All other agronomic treatments (except fertilization) were done according to recommendations for oilseed rape cultivation in Germany. Growth types were interlaced within each block by alternately growing one strip of semi-dwarfs and one strip of normal types. Experiments were designed as split-plot with growth type as main plot factor and genotypes as subplot factor. The experimental design was identical for both environments.

In season 2011/12 experiments from season 2010/11 were repeated using 108 TC (54 semi-dwarfs and 54 normal types). The $108 \mathrm{TC}$ were selected based on erucic acid content and seed yield in season 2010/11. For each growth type 27 TC with erucic acid (14 highest seed yield, 13 lowest seed yield) and the 27 TC without erucic acid (14 highest seed yield, 13 lowest seed yield) were selected. Hybrids were evaluated in two identical experiments at both sites (Göttingen and Einbeck). One experiment was harvested at the end of flowering (BBCH 69) and the second experiment at seed maturity (BBCH 89). Both experiments were conducted at two nitrogen levels: without nitrogen fertilization (low nitrogen supply) and fertilized with $177 \mathrm{~kg} \mathrm{~N} /$ ha (high nitrogen). Mineral nitrogen in the soil was determined at the beginning of plant growth in spring in Einbeck $(27 \mathrm{~kg} \mathrm{~N} / \mathrm{ha}$ ) and Göttingen (27 kg N/ha). Both growth types were interlaced within each block and arranged in split-plot design. Genotypes within growth types were randomized in lattice design.

Each season-site combination is considered as one environment and is addressed by location abbreviation and harvest year, such as Ei11 for Einbeck in the season 2010/2011.

\subsubsection{Evaluated traits and Measurements}

The following measurements and calculations were done for every single plot in the experiments. Begin of flowering in days from 1st of January was recorded at BBCH 61, when $10 \%$ of the plants flowered. Plant height in $\mathrm{cm}$ was measured at grain maturity $\mathrm{BBCH}$ 89). Biomass yield was determined in the first experiment by harvesting whole plots with a combine harvester at EOF. The plots were cut right above soil level and biomass yield was weighted. A subsample of fresh plant material of every plot was weighed and dried at $105^{\circ} \mathrm{C}$ for $72 \mathrm{~h}$ in a dry oven. Dried biomass samples was weighed again to calculate dry matter content in the biomass. The dried biomass samples were milled (particle sizes of about $0.2 \mathrm{~mm}$ ) for nitrogen analysis.

In the second experiment seed yield was determined with a combine harvester at maturity (BBCH 89). At the same time the straw of every plot was collected in a canvas tissue attached to the back of the combine harvester and weighted (except in Einbeck 2011). Therefore all plants in a plot were cut right above soil level by the harvester. A straw 
subsample including stems and pod walls was taken, weighed and dried at $60{ }^{\circ} \mathrm{C}$ for $48 \mathrm{~h}$ in a dry oven. The dried subsample was weighted to calculate straw dry matter content and subsequently milled (particle sizes of $0.2 \mathrm{~mm}$ ). Due to a heavy hail storm in Einbeck 2012, seed yield could not be determined at this location.

Nitrogen content was determined by analysing approximately $16 \mathrm{mg}$ grinded material by the Dumas based combustion method using a CN Elemental analyser, type vario EL (Elementar Analysensysteme $\mathrm{GmbH}$ ) as described in the manual (Anonymous 1992). Thousand seed weight (TSW) was measured on a representative sample of 500 seeds. Oil, protein and moisture content in $\%$ at seed dry matter basis were determined with a NIRS monochromator model 6500 (NIRSystems, Inc., Silversprings, MD, USA) using calibrations (raps2010.eqa, raps2011.eqa, raps2012.eqa) provided by VDLUFA Qualitätssicherung NIRS GmbH. Nitrogen yield in $\mathrm{kg} \mathrm{N} /$ ha at end of flowering was calculated on basis of biomass dry matter yield and nitrogen content in the biomass. Nitrogen yield at grain maturity was calculated as the sum of nitrogen in the straw and nitrogen in the seeds. Nitrogen yield of the straw ( $\mathrm{kg} \mathrm{N} / \mathrm{ha}$ ) was calculated on basis of straw dry matter yield and nitrogen content in the straw. Nitrogen yield in the grain $(\mathrm{kg}$ $\mathrm{N} / \mathrm{ha}$ ) was calculated on the basis of seed dry matter yield ( $\mathrm{kg} / \mathrm{ha})$ and nitrogen content in the seeds (\%), obtained by dividing the NIRS determined protein content in the seeds (\%) by the factor 6.25. Nitrogen harvest index was calculated dividing nitrogen in the seeds by total nitrogen yield at grain maturity.

Nitrogen use efficiency is defined as seed production per unit of nitrogen available in the soil (Moll et al., 1982). According to (Moll et al., 1982) nitrogen use efficiency, nitrogen uptake efficiency and nitrogen utilization efficiency were calculated using the following equations:

Nitrogen use efficiency $=$ Seed yield $(\mathrm{kg} / \mathrm{ha}) /$ total nitrogen supply $(\mathrm{kg} \mathrm{N} / \mathrm{ha})$

Nitrogen uptake efficiency $=$ Nitrogen fixed in the plant at maturity $(\mathrm{kg} \mathrm{N} / \mathrm{ha}) /$ total nitrogen supply (kg N/ha)

Nitrogen utilization efficiency $=$ Seed yield $(\mathrm{kg} / \mathrm{ha}) /$ Nitrogen fixed in the plant at maturity $(\mathrm{kg} \mathrm{N} / \mathrm{ha})$

Nitrogen supply at the unfertilized treatment was determined in each replication by the highest amount of total nitrogen taken up by a genotype at maturity. The nitrogen supply at fertilised treatment was determined by the mean value of nitrogen supply for both unfertilized replications plus the amount of nitrogen fertilised. The total amount 
of nitrogen fixed in a plant at maturity is the sum of nitrogen in straw and nitrogen in seeds. The relative contributions of nitrogen uptake and nitrogen utilization efficiency to variation in overall nitrogen use efficiency were calculated according to Moll et al. (1982).

\subsubsection{Statistical analysis}

Analysis of variance (ANOVA), heritabilities $\left(h^{2}\right)$ and Spearman's rank correlation coefficients were calculated using PLABSTAT software (Version 3B) (Utz 2011).

ANOVA within each N-level for a single environment was done using the following model for a split-plot design:

$$
Y_{j k l}=\mu+b_{j}+t_{k}+\epsilon_{j k}+g_{k l}+\epsilon_{j k l}
$$

in which $Y_{j k l}$ is the observation of a genotype $\left(g_{l}\right)$ within growth type $\left(t_{k}\right)$ in block $\left(b_{j}\right)$. The effect of the genotype within growth type is denoted by $\left(g_{k l}\right)$. Whole plot error is denoted by $\epsilon_{j k}$ and the sub-plot error is called $\epsilon_{j k l}$. The general mean is designated by $\mu$. The factors block and genotype were considered as random.

To include the effect of different environments (year-location combination) into the ANOVA, following model for a split-plot design was used:

$$
\begin{aligned}
Y_{i j k l}= & \mu+e_{i}+t_{k}+b_{i j}+e t_{i k}+\epsilon_{i j k} \\
& +g_{k l}+e g_{i k l}+\epsilon_{i j k l}
\end{aligned}
$$

in which $Y_{i j k l}$ is the observation of a genotype $\left(g_{l}\right)$ within the growth type $\left(t_{k}\right)$ in block $\left(b_{j}\right)$ within environment $\left(e_{i}\right)$. Interaction effects between growth type and environment are denoted by $e t_{i k}$ and interactions between environment and genotype are called $e g_{i k l}$. Whole plot error is denoted by $\epsilon_{i j k}$ and the sub-plot error is denoted by $\epsilon_{i j k l}$. The general mean is denoted by $\mu$. The factors environment, block and genotype were considered as random. 
3 Nitrogen use efficiency of semi-dwarf and normal type hybrids

To test the effects of nitrogen levels, following model for a split-split-plot design was used:

$$
\begin{aligned}
Y_{i j k l o}= & \mu+e_{i}+n_{o}+b_{i j o}+e n_{i o}+\epsilon_{i j o} \\
& +t_{k}+e t_{i k}+t n_{k o}+e t n_{i k o}+\epsilon_{i j k o} \\
& +g_{k l}+e g_{i k l}+g n_{k l o}+e g n_{i k l o}+\epsilon_{i j k l o}
\end{aligned}
$$

in which $Y_{i j k l o}$ is the observation of a genotype $\left(g_{l}\right)$ within the growth type $\left(t_{k}\right)$ in block $\left(b_{j}\right)$ within nitrogen level $\left(n_{o}\right)$ at environment $\left(e_{i}\right)$. Interaction effects were tested for environment and nitrogen level $\left(e n_{i o}\right)$, environment and growth type $\left(e t_{i k}\right)$, environment and genotype $\left(e g_{i k l}\right)$, growth type and nitrogen level $\left(t n_{k o}\right)$ and genotype by nitrogen level $\left(g n_{k l o}\right)$. Threefold interactions were testes for environment by genotype by nitrogen level $\left(e g n_{i k l o}\right)$ and environment by growth type by nitrogen level $\left(e t n_{i k o}\right)$. Whole plot error is denoted by $\epsilon_{i j o}$, sub-plot error is denoted by $\epsilon_{i j k o}$ and the sub-sub-plot error is denoted by $\epsilon_{i j k l o}$. The factors environment, block and genotype were considered as random.

Broad sense heritability $\left(h^{2}\right)$ was estimated as follows:

$$
h^{2}=\frac{\hat{\sigma}_{G}^{2}}{\hat{\sigma}_{G}^{2}+\frac{\hat{\sigma}_{G E}^{2}}{E}}
$$

where $\hat{\sigma}_{G}^{2}$ and $\hat{\sigma}_{G E}^{2}$ are variances of genotypes and genotypes by environment respectively; $E$ refers to number of environments. 


\subsection{Results}

\subsubsection{Semi-dwarf and normal type hybrids at low nitrogen supply}

At low nitrogen supply semi-dwarf hybrids produced significantly less biomass by end of flowering compared to normal bybrids (Tab.3.1, Tab. 3.2). The ANOVA for biomass yield EOF at low nitrogen supply detected no significant variation between genotypes within growth types, but a highly significant interaction of growth type and genotype with the factor environment (Tab. 3.2).

Both growth types took up comparable quantities of nitrogen (Nitrogen yield EOF) at low nitrogen supply by end of flowering (Tab. 3.1). The largest difference between both types of about $6 \mathrm{~kg} \mathrm{~N} /$ ha was observed in Go11. The ANOVA did not reveal a significant variation in nitrogen yield EOF among growth types or genotypes within growth types (Tab.3.2). Interaction effects of growth type by environment and genotype by environment were significant. Due to similar amounts of nitrogen taken up until end of flowering and less biomass, semi-dwarfs had higher nitrogen contents in the biomass, compared to the normal types (Tab.3.1). No significant variation in nitrogen content EOF had been detected among the genotypes at low nitrogen supply (Tab.3.2).

At maturity semi-dwarf types formed significantly less straw compared to normal types (Tab.3.1). The single genotypes showed strong interaction effects for straw yield with the environments, resulting in a low heritability of 0.06 (Tab.3.2). No significant variation in nitrogen content of straw was observed between the two growth types (Tab.3.1). Genotypes within growth types differed significantly in nitrogen content of straw and showed also a significant interaction with environments (Tab.3.2). Due to lower straw yield and similar nitrogen content of straw semi-dwarf types contained about $1.5 \mathrm{~kg} / \mathrm{ha}$ less nitrogen in straw than normal types (Tab.3.1).

The mean seed yield of semi-dwarf types at low nitrogen supply was $2.4 \mathrm{dt} /$ ha higher compared to normal types (Tab.3.1). Nevertheless, the effect was not significant (Tab.3.2). Genotypes within growth types showed significant variation for nitrogen yield in seeds but no significant difference between growth types. Total nitrogen yield at maturity was calculated only for Go11 and Go12. The difference of about $7 \mathrm{~kg} \mathrm{~N} /$ ha among growth types was not significant (Tab.3.1). In Go11 both growth types fixed less nitrogen in biomass at maturity compared to end of flowering. In Go12 the amount of nitrogen at maturity was higher compared to end of flowering. Semi-dwarf hybrids had a higher nitrogen harvest index due to less nitrogen in straw and more nitrogen in seeds (Tab.3.1). 
Table 3.1: Performance of semi-dwarf (Sd) and normal type (Nt) hybrids at low nitrogen supply in 2010/11 and 2011/12 (108 genotypes, four environments)

\begin{tabular}{|c|c|c|c|c|c|c|c|c|c|c|c|}
\hline \multirow{3}{*}{$\begin{array}{l}\text { Trait } \\
\begin{array}{l}\text { Beginn of flowering } \\
\text { (days) }\end{array}\end{array}$} & & \multicolumn{2}{|c|}{ Ei11 } & \multicolumn{2}{|c|}{ Go11 } & \multicolumn{2}{|c|}{ Ei12 } & \multicolumn{2}{|c|}{ Go12 } & \multicolumn{2}{|c|}{ Mean } \\
\hline & $\mathrm{Nt}$ & 110 & & 110 & & 104 & & 115 & & 110 & \\
\hline & $\mathrm{Sd}$ & 110 & ns & 110 & ns & 104 & ns & 114 & $*$ & 110 & ns \\
\hline \multirow{2}{*}{$\begin{array}{l}\text { Plant height } \\
(\mathrm{cm})\end{array}$} & $\mathrm{Nt}$ & 126 & & 119 & & 108 & & 90 & & 110.8 & \\
\hline & $\mathrm{Sd}$ & 100 & $* *$ & 92 & $* *$ & 72 & $* *$ & 70 & $* *$ & 83.5 & $* *$ \\
\hline \multirow{2}{*}{$\begin{array}{l}\text { Biomass EOF } \\
(\mathrm{dt} / \mathrm{ha})\end{array}$} & $\mathrm{Nt}$ & 36.7 & & 59.3 & & 17.1 & & 17.1 & & 32.6 & \\
\hline & $\mathrm{Sd}$ & 34.1 & $*$ & 48.3 & $\mathrm{~ns}$ & 12.2 & $* *$ & 14.5 & $* *$ & 27.3 & + \\
\hline \multirow{2}{*}{$\begin{array}{l}\text { Seed yield } \\
\text { (dt/ha) }\end{array}$} & $\mathrm{Nt}$ & 17.0 & & 12.9 & & - & & 10.5 & & 13.5 & \\
\hline & $\mathrm{Sd}$ & 18.0 & ns & 17.0 & $*$ & - & & 12.8 & $* *$ & 15.9 & ns \\
\hline \multirow{2}{*}{$\begin{array}{l}\text { Straw yield } \\
(\mathrm{dt} / \mathrm{ha})\end{array}$} & $\mathrm{Nt}$ & - & & 40.1 & & 18.9 & & 22.9 & & 27.3 & \\
\hline & $\mathrm{Sd}$ & - & & 34.9 & $* *$ & 17.7 & ns & 19.8 & $* *$ & 24.2 & + \\
\hline \multirow{2}{*}{$\begin{array}{l}\text { Nitrogen content EOF } \\
(\%)\end{array}$} & $\mathrm{Nt}$ & 1.66 & & 1.53 & & 1.77 & & 1.60 & & 1.64 & \\
\hline & $\mathrm{Sd}$ & 1.81 & + & 1.75 & $\mathrm{~ns}$ & 2.11 & $* *$ & 1.86 & $* *$ & 1.89 & $* *$ \\
\hline \multirow{2}{*}{$\begin{array}{l}\text { Nitrogen content straw } \\
(\%)\end{array}$} & $\mathrm{Nt}$ & - & & 0.50 & & 0.61 & & 0.51 & & 0.54 & \\
\hline & $\mathrm{Sd}$ & - & & 0.53 & $* *$ & 0.60 & ns & 0.50 & $\mathrm{~ns}$ & 0.54 & ns \\
\hline \multirow{2}{*}{$\begin{array}{l}\text { Nitrogen content seed } \\
(\%)\end{array}$} & $\mathrm{Nt}$ & 2.70 & & 3.09 & & 3.17 & & 3.04 & & 3.01 & \\
\hline & $\mathrm{Sd}$ & 2.72 & + & 3.07 & $\mathrm{~ns}$ & 3.26 & ns & 2.95 & $* *$ & 2.99 & ns \\
\hline \multirow{2}{*}{$\begin{array}{l}\text { Nitrogen yield EOF } \\
(\mathrm{kg} \mathrm{N} / \mathrm{ha})\end{array}$} & $\mathrm{Nt}$ & 61.1 & & 90.3 & & 26.7 & & 27.3 & & 52.2 & \\
\hline & $\mathrm{Sd}$ & 62.4 & ns & 84.2 & $* *$ & 29.1 & $* *$ & 27.4 & ns & 49.9 & ns \\
\hline \multirow{2}{*}{$\begin{array}{l}\text { Nitrogen yield straw } \\
(\mathrm{kg} \mathrm{N} / \mathrm{ha})\end{array}$} & $\mathrm{Nt}$ & - & & 20.5 & & 13.7 & & 11.7 & & 14.5 & \\
\hline & $\mathrm{Sd}$ & - & & 18.7 & $*$ & 7.9 & + & 9.8 & $* *$ & 12.9 & $* *$ \\
\hline \multirow{2}{*}{$\begin{array}{l}\text { Nitrogen yield seed } \\
(\mathrm{kg} \mathrm{N} / \mathrm{ha})\end{array}$} & $\mathrm{Nt}$ & 46.0 & & 39.9 & & - & & 31.7 & & 39.2 & \\
\hline & $\mathrm{Sd}$ & 48.8 & ns & 52.1 & * & - & & 37.7 & $*$ & 46.2 & ns \\
\hline \multirow{2}{*}{$\begin{array}{l}\text { Nitrogen yield total } \\
(\mathrm{kg} \mathrm{N} / \mathrm{ha})\end{array}$} & $\mathrm{Nt}$ & - & & 60.6 & & - & & 43.4 & & 52.0 & \\
\hline & $\mathrm{Sd}$ & - & & 70.9 & + & - & & 47.4 & $*$ & 59.2 & ns \\
\hline \multirow[t]{2}{*}{ Nitrogen harvest index } & $\mathrm{Nt}$ & - & & 0.66 & & - & & 0.73 & & 0.70 & \\
\hline & $\mathrm{Sd}$ & - & & 0.74 & $* *$ & - & & 0.79 & $*$ & 0.77 & $* *$ \\
\hline
\end{tabular}

$* *, *,+$ Significant difference at 0.01, 0.05, 0.10 probability level, respectively; ns non-significant (F-test from ANOVA); Ei Einbeck; Go Göttingen; Sd semi-dwarf; Nt normal type; EOF end of flowering 
Table 3.2: Variance components of agronomic and nitrogen related traits at low nitrogen supply in 2010/11 and 2011/12 (108 genotypes)

\begin{tabular}{|c|c|c|c|c|c|c|c|c|c|c|}
\hline Source & $\mathbf{E}$ & $\mathbf{T}$ & & $G$ & & $\mathbf{T} \times \mathbf{F}$ & & $\mathbf{G} \times \mathbf{F}$ & & \multirow[t]{2}{*}{$\boldsymbol{h}^{2}$} \\
\hline Degrees of freedom & 3 & 1 & & 106 & & 3 & & 318 & & \\
\hline Begin of flowering (days) & $19.08^{* *}$ & 0 & & 0.28 & ** & 0 & & 0.27 & $* *$ & 0.71 \\
\hline Plant height $(\mathrm{cm})$ & $222.97^{* *}$ & 367.18 & $* *$ & 3.98 & ** & 24.18 & ** & 4.78 & $* *$ & 0.42 \\
\hline Biomass EOF (dt/ha) & $342.96^{* *}$ & 12.08 & + & 0.69 & ns & 7.61 & ** & 7.96 & $* *$ & 0.15 \\
\hline Seed yield $(\mathrm{dt} / \mathrm{ha})^{\mathrm{a}}$ & $8.64^{* *}$ & 2.56 & ns & 0.83 & ** & 0.94 & ns & 1.00 & $* *$ & 0.47 \\
\hline Straw yield $(\mathrm{dt} / \mathrm{ha})^{\mathrm{b}}$ & $91.97+$ & 4.31 & + & 0.36 & ns & 1.73 & ** & 4.96 & $* *$ & 0.06 \\
\hline Nitrogen content EOF (\%) & $0.01^{* *}$ & 0.03 & $* *$ & 0.001 & ns & 0.003 & $*$ & 0.003 & ns & 0.09 \\
\hline Nitrogen content straw $(\%)^{\mathrm{b}}$ & $0.002^{\text {ns }}$ & 0 & & 0.0003 & & 0.0003 & ** & $0.000^{\circ}$ & & 0.22 \\
\hline Nitrogen content seed (\%) & $0.04^{* *}$ & 0.0001 & & 0.002 & * & 0.001 & * & 0.001 & ** & 0.51 \\
\hline Nitrogen yield EOF (kg N/ha) & $838.17^{* *}$ & 0.92 & ns & 1.70 & ns & 5.64 & ** & 22.71 & $* *$ & 0.08 \\
\hline Nitrogen yield straw $(\mathrm{kg} \mathrm{N} / \mathrm{ha})^{\mathrm{b}}$ & $21.34^{+}$ & 1.15 & $* *$ & 0.10 & ns & 0.06 & ns & 2.10 & $* *$ & 0.04 \\
\hline Nitrogen yield seed $(\mathrm{kg} \mathrm{N} / \mathrm{ha})^{\mathrm{a}}$ & $47.40^{* *}$ & 20.50 & ns & 5.45 & ** & 9.00 & ns & 7.99 & $* *$ & 0.42 \\
\hline Nitrogen yield total $(\mathrm{kg} \mathrm{N} / \mathrm{ha})^{\mathrm{c}}$ & $199.61^{*}$ & 20.70 & ns & 7.29 & + & 8.04 & + & 21.46 & $* *$ & 0.22 \\
\hline Nitrogen harvest index ${ }^{c}$ & $0.17^{+}$ & 0.23 & $* *$ & 0.02 & + & 0 & & 0.01 & ns & 0.26 \\
\hline
\end{tabular}

${ }^{* *},{ }^{*},+$ Significant difference at 0.01, 0.05, 0.10 probability level, respectively; ns non-significant (F-test from ANOVA); negative variance components were set to zero; $\mathbf{E}$ environment; $\mathbf{T}$ growth type; $\mathbf{G}$ genotype within growth type; $\boldsymbol{h}^{2}$ heritability within growth types; EOF end of flowering;

${ }^{a}$ values for three environments (Ei11, Go11, Go12)

${ }^{b}$ values for three environments (Go11, Ei12, Go12)

${ }^{c}$ values for two environments (Go11, Go12)

\subsubsection{Semi-dwarf and normal type hybrids at high nitrogen supply}

At high nitrogen supply both growth types differed in biomass yield at EOF in average by about $9 \mathrm{dt} / \mathrm{ha}$ (Tab.3.3). This difference proved to be non-significant. But interaction effects of growth types and environment were significant (Tab.3.4).

Results for nitrogen yield EOF in high nitrogen environments were contradictory (Tab.3.3). In Einbeck 2012 normal hybrids took up nearly $20 \mathrm{~kg}$ N/ha more than semidwarf hybrids. In Göttingen 2012 semi-dwarf hybrids took up about $5 \mathrm{~kg} \mathrm{~N} /$ ha more compared to normal hybrids. The difference in average nitrogen yield between both environments was up to $60 \mathrm{~kg} \mathrm{~N} /$ ha (Tab.3.3). Therefore the ANOVA revealed a significant growth type by environment interaction but no significant variation between growth types (Tab. 3.4). Variation in nitrogen yield EOF between genotypes was also significant. Semi-dwarfs had significantly higher nitrogen contents in the biomass EOF (Tab.3.3). At maturity semi-dwarf hybrids formed on average $5.3 \mathrm{dt} /$ ha less straw compared to normal hybrids. The ANOVA revealed this difference between growth types as non-significant. 
3 Nitrogen use efficiency of semi-dwarf and normal type hybrids

Table 3.3: Performance of semi-dwarf (Sd) and normal type (Nt) at high nitrogen supply in 2011/12 (108 genotypes, two environments)

\begin{tabular}{|c|c|c|c|c|c|c|c|}
\hline Trait & & Einb & & Götti & gen & Mea & \\
\hline $\begin{array}{l}\text { Beginn of flowering } \\
\text { (days) }\end{array}$ & $\begin{array}{l}\mathrm{Nt} \\
\mathrm{Sd}\end{array}$ & $\begin{array}{l}104 \\
104\end{array}$ & $\mathrm{~ns}$ & $\begin{array}{l}115 \\
115\end{array}$ & ns & $\begin{array}{l}109 \\
109\end{array}$ & $\mathrm{~ns}$ \\
\hline $\begin{array}{l}\text { Plant height } \\
(\mathrm{cm})\end{array}$ & $\begin{array}{l}\mathrm{Nt} \\
\mathrm{Sd}\end{array}$ & $\begin{array}{c}129 \\
78\end{array}$ & $* *$ & $\begin{array}{l}91 \\
67\end{array}$ & $*$ & $\begin{array}{c}109.9 \\
72.8\end{array}$ & ns \\
\hline $\begin{array}{l}\text { Biomass EOF } \\
(\mathrm{dt} / \mathrm{ha})\end{array}$ & $\begin{array}{l}\mathrm{Nt} \\
\mathrm{Sd}\end{array}$ & $\begin{array}{l}45.0 \\
30.5\end{array}$ & $* *$ & $\begin{array}{l}42.4 \\
38.5\end{array}$ & ns & $\begin{array}{l}43.7 \\
34.5\end{array}$ & ns \\
\hline $\begin{array}{l}\text { Seed yield } \\
\text { (dt/ha) }\end{array}$ & $\begin{array}{l}\mathrm{Nt} \\
\mathrm{Sd}\end{array}$ & - & & $\begin{array}{l}26.4 \\
29.7\end{array}$ & $* *$ & $\begin{array}{l}26.4 \\
29.7\end{array}$ & $* *$ \\
\hline $\begin{array}{l}\text { Straw yield } \\
(\mathrm{dt} / \mathrm{ha})\end{array}$ & $\begin{array}{l}\mathrm{Nt} \\
\mathrm{Sd}\end{array}$ & $\begin{array}{l}33.4 \\
30.1\end{array}$ & $* *$ & $\begin{array}{l}39.4 \\
32.1\end{array}$ & $* *$ & $\begin{array}{l}36.4 \\
31.1\end{array}$ & ns \\
\hline $\begin{array}{l}\text { Nitrogen content EOF } \\
(\%)\end{array}$ & $\begin{array}{l}\mathrm{Nt} \\
\mathrm{Sd}\end{array}$ & $\begin{array}{l}2.38 \\
2.83\end{array}$ & $* *$ & $\begin{array}{l}3.35 \\
3.81\end{array}$ & $* *$ & $\begin{array}{l}2.86 \\
3.32\end{array}$ & $* *$ \\
\hline $\begin{array}{l}\text { Nitrogen content straw } \\
(\%)\end{array}$ & $\begin{array}{l}\mathrm{Nt} \\
\mathrm{Sd}\end{array}$ & $\begin{array}{l}0.50 \\
0.56\end{array}$ & $* *$ & $\begin{array}{l}0.78 \\
0.85\end{array}$ & $* *$ & $\begin{array}{c}0.64 \\
0.7\end{array}$ & $* *$ \\
\hline $\begin{array}{l}\text { Nitrogen content seed } \\
(\%)\end{array}$ & $\begin{array}{l}\mathrm{Nt} \\
\mathrm{Sd}\end{array}$ & $\begin{array}{l}3.12 \\
3.24\end{array}$ & $* *$ & $\begin{array}{l}3.31 \\
3.39\end{array}$ & $\begin{array}{l}+ \\
* *\end{array}$ & $\begin{array}{l}3.21 \\
3.31\end{array}$ & + \\
\hline $\begin{array}{l}\text { Nitrogen yield EOF } \\
(\mathrm{kg} \mathrm{N} / \mathrm{ha})\end{array}$ & $\begin{array}{l}\mathrm{Nt} \\
\mathrm{Sd}\end{array}$ & $\begin{array}{c}106.7 \\
86.0\end{array}$ & $*$ & $\begin{array}{l}141.3 \\
146.4\end{array}$ & ns & $\begin{array}{l}124.0 \\
116.2\end{array}$ & ns \\
\hline $\begin{array}{l}\text { Nitrogen yield straw } \\
\text { (kg N/ha) }\end{array}$ & $\begin{array}{l}\mathrm{Nt} \\
\mathrm{Sd}\end{array}$ & $\begin{array}{l}16.5 \\
16.8\end{array}$ & ns & $\begin{array}{l}30.7 \\
27.4\end{array}$ & $* *$ & $\begin{array}{l}23.6 \\
22.1\end{array}$ & ns \\
\hline $\begin{array}{l}\text { Nitrogen yield seed } \\
(\mathrm{kg} \mathrm{N} / \mathrm{ha})\end{array}$ & $\begin{array}{l}\mathrm{Nt} \\
\mathrm{Sd}\end{array}$ & - & & $\begin{array}{c}87.3 \\
100.3\end{array}$ & $* *$ & $\begin{array}{c}87.3 \\
100.3\end{array}$ & $* *$ \\
\hline $\begin{array}{l}\text { Nitrogen yield total } \\
(\mathrm{kg} \mathrm{N} / \mathrm{ha})\end{array}$ & $\begin{array}{l}\mathrm{Nt} \\
\mathrm{Sd}\end{array}$ & $\begin{array}{l}- \\
-\end{array}$ & & $\begin{array}{l}118.0 \\
127.7\end{array}$ & $* *$ & $\begin{array}{l}118.0 \\
127.7\end{array}$ & $* *$ \\
\hline Nitrogen harvest index & $\begin{array}{l}\mathrm{Nt} \\
\mathrm{Sd}\end{array}$ & $\begin{array}{l}- \\
-\end{array}$ & & $\begin{array}{l}0.74 \\
0.79\end{array}$ & $* *$ & $\begin{array}{l}0.74 \\
0.79\end{array}$ & $* *$ \\
\hline
\end{tabular}

$* *, *,+$ Significant difference at $0.01,0.05,0.10$ probability level, respectively; ns non-significant (F-test from ANOVA); Sd semi-dwarf; Nt normal type; EOF end of flowering 
Nitrogen content of straw varied significantly among environments, growth types and genotypes within growth types (Tab.3.4). The amount of nitrogen fixed in the straw showed no significant variation between growth types and genotypes, but significant interactions of both factors with environments.

Seed yield at high nitrogen levels could only be measured in Göttingen 2012. It revealed a significantly higher seed yield of semi-dwarfs compared to normal hybrids (Tab.3.3). Due to higher seed yields and higher nitrogen content of seeds semi-dwarf hybrids had a significantly higher nitrogen yield of seeds (Tab.3.3). Total nitrogen yield at maturity revealed a significant difference between growth types of about $10 \mathrm{~kg} N /$ ha in Göttingen 2012. Compared to the values for nitrogen yield EOF in Göttingen 2012 this is a reduction of about $20 \mathrm{~kg} \mathrm{~N} /$ ha from the end of flowering to maturity in both growth types (Tab.3.3).

Table 3.4: Variance components of agronomic and nitrogen related traits at high nitrogen supply in 2011/12 (108 genotypes)

\begin{tabular}{|c|c|c|c|c|c|c|}
\hline Source & $\mathbf{E}$ & $\mathbf{T}$ & $\mathrm{G}$ & $\mathbf{T} \times \mathbf{E}$ & $\mathbf{G} \times \mathbf{E}$ & $h^{2}$ \\
\hline Degrees of freedom & 1 & 1 & 106 & 1 & 106 & \\
\hline Begin of flowering (days) & $56.83^{* *}$ & 0 & $0.34^{* *}$ & $0.16^{*}$ & $0.52^{* *}$ & 0.49 \\
\hline Plant height (cm) & $290.52^{* *}$ & $599.63^{\mathrm{ns}}$ & $3.74^{*}$ & $172.80^{* *}$ & $7.43^{* *}$ & 0.36 \\
\hline Biomass EOF (dt/ha) & 0 & $28.26^{\mathrm{ns}}$ & $2.14^{*}$ & $27.43^{* *}$ & $1.20^{\mathrm{ns}}$ & 0.30 \\
\hline Seed yield $(\mathrm{dt} / \mathrm{ha})^{\mathrm{a}}$ & - & $5.26^{* *}$ & $2.66^{* *}$ & & - & 0.55 \\
\hline Straw yield (dt/ha) & $5.55^{\mathrm{ns}}$ & $11.82^{\mathrm{ns}}$ & $2.96^{* *}$ & $3.77^{* *}$ & $1.87^{*}$ & 0.44 \\
\hline Nitrogen content EOF (\%) & $46.50^{*}$ & $10.34^{* *}$ & 0 & 0 & $0.86^{* *}$ & - \\
\hline Nitrogen content straw (\%) & $4.03^{* *}$ & $0.22^{* *}$ & $0.10^{*}$ & 0 & $0.22^{\mathrm{ns}}$ & 0.32 \\
\hline Nitrogen content seed $(\%)$ & $1.31^{*}$ & $0.50^{+}$ & $0.13^{* *}$ & $0.03^{\mathrm{ns}}$ & $0.14^{* *}$ & 0.40 \\
\hline Nitrogen yield EOF (kg N/ha) & $1096.46^{*}$ & 0 & $16.47^{+}$ & $162.54^{* *}$ & $0.67^{\mathrm{ns}}$ & 0.25 \\
\hline Nitrogen yield straw (kg N/ha) & $73.39^{*}$ & 0 & $1.72^{\mathrm{ns}}$ & $3.18^{* *}$ & $7.32^{* *}$ & 0.22 \\
\hline Nitrogen yield seed $(\mathrm{kg} \mathrm{N} / \mathrm{ha})^{\mathrm{a}}$ & - & $84.67^{* *}$ & $30.99^{* *}$ & - & - & 0.56 \\
\hline Nitrogen yield total $(\mathrm{kg} \mathrm{N} / \mathrm{ha})^{\mathrm{a}}$ & - & $46.07^{* *}$ & $57.63^{* *}$ & - & - & 0.59 \\
\hline Nitrogen harvest index ${ }^{a}$ & - & $0.11^{* *}$ & $0.07^{* *}$ & & - & 0.72 \\
\hline
\end{tabular}

${ }^{* *},{ }^{*},+$ Significant difference at $0.01,0.05,0.10$ probability level, respectively; ns non-significant (Ftest from ANOVA); negative variance components were set to zero; $\mathbf{E}$ environment; $\mathbf{T}$ growth type; $\mathbf{G}$ genotype within growth type; $\boldsymbol{h}^{2}$ heritability within growth types; EOF end of flowering; ${ }^{a}$ values for Göttingen 2011/12 only 


\subsubsection{Nitrogen uptake and nitrogen utilization}

At low nitrogen supply in the first experiment (harvest EOF) nitrogen uptake (kg N/ha) and nitrogen uptake efficiency were non-significantly different between growth types or genotypes within growth types (Tab. 3.5, Tab. 3.6). Nitrogen uptake and nitrogen uptake efficiency were significantly influenced by interactions with environments. At high nitrogen supply genotypes differed significantly in nitrogen uptake and nitrogen uptake efficiency. Both traits were significantly affected by interactions of environments with growth type.

Table 3.5: Nitrogen uptake and nitrogen uptake efficiency EOF at low and high nitrogen supply (108 genotypes, Einbeck and Göttingen 2010/11 and 2011/12)

\begin{tabular}{lcccc}
\hline & \multicolumn{2}{c}{ Semi-dwarf } & \multicolumn{2}{c}{ Normal type } \\
Trait & Env. Min Max Mean & Min Max Mean \\
\hline
\end{tabular}

\section{Low nitrogen supply}

\begin{tabular}{lcrrrrrr}
$\begin{array}{l}\text { Nitrogen uptake EOF } \\
\text { (kg N/ha) }\end{array}$ & Ei11 & 43.4 & 86.3 & 62.4 & 43.9 & 96.3 & 61.1 \\
& Go11 & 55.1 & 114.0 & 84.2 & 66.0 & 117.3 & 90.3 \\
& Ei12 & 17.0 & 38.8 & 25.7 & 22.0 & 39.4 & 30.1 \\
& Go12 & 13.2 & 36.3 & 27.4 & 21.0 & 32.7 & 27.3 \\
& Mean & & & 49.9 & & & 52.2 \\
Nitrogen uptake & & & & & & & \\
efficiency EOF & Ei11 & 0.42 & 0.82 & 0.59 & 0.42 & 0.92 & 0.58 \\
& Go11 & 0.38 & 0.78 & 0.58 & 0.45 & 0.79 & 0.62 \\
& Ei12 & 0.36 & 0.79 & 0.53 & 0.45 & 0.82 & 0.63 \\
& Go12 & 0.33 & 0.85 & 0.65 & 0.50 & 0.78 & 0.65 \\
& Mean & & & 0.59 & & & 0.62 \\
\hline High nitrogen supply & & & & & & & \\
Nitrogen uptake EOF & Ei12 & 66.8 & 120.2 & 85.9 & 78.1 & 156.1 & 106.7 \\
(kg N/ha) & Go12 & 126.1 & 186.7 & 146.4 & 126.9 & 163.0 & 141.3 \\
& Mean & & & 116.2 & & & 124.0 \\
Nitrogen uptake & Ei12 & 0.30 & 0.53 & 0.38 & 0.35 & 0.69 & 0.47 \\
efficiency EOF & Go12 & 0.58 & 0.85 & 0.67 & 0.58 & 0.74 & 0.64 \\
& Mean & & & 0.52 & & & 0.56 \\
\hline
\end{tabular}

Env environment; Ei Einbeck; Go Göttingen; EOF end of flowering 
Table 3.6: Variance components for nitrogen uptake and nitrogen uptake efficiency EOF at low and high nitrogen supply (108 genotypes, Einbeck and Göttingen 2010/11 and 2011/12)

\begin{tabular}{lcccccc}
\hline \multicolumn{1}{c}{ Source } & $\mathbf{E}$ & $\mathbf{T}$ & $\mathbf{G}$ & $\mathbf{T} \times \mathbf{E}$ & $\mathbf{G} \times \mathbf{E}$ & $\boldsymbol{h}^{2}$ \\
\hline Low nitrogen supply & & & & & & \\
& 3 & 1 & 106 & 3 & 318 & \\
Degrees of freedom & $338.17^{* *}$ & $0.92^{\text {ns }}$ & $1.70^{\text {ns }}$ & $5.64^{* *}$ & $22.71^{* *}$ & 0.08 \\
Nitrogen uptake EOF & 0 & $0.01^{\text {ns }}$ & $0.02^{\text {ns }}$ & $0.11^{* *}$ & $0.27^{* *}$ & 0.08
\end{tabular}

\section{High nitrogen supply}

\begin{tabular}{lrrrrrrr} 
Degrees of freedom & 1 & 1 & 106 & 1 & \multicolumn{2}{c}{106} & \\
\cline { 1 - 2 } & $1096.46^{*}$ & 0 & $16.47^{+}$ & $162.55^{* *}$ & 0.6 & ns & 0.25 \\
Nitrogen uptake efficiency EOF & $2.55^{*}$ & 0 & $0.03^{+}$ & $0.32^{* *}$ & $0.002^{\mathrm{ns}}$ & 0.25
\end{tabular}

\footnotetext{
${ }^{* *}, *,+$ Significant difference at $0.01,0.05,0.10$ probability level, respectively; ns non-significant (Ftest from ANOVA); negative variance components were set to zero; E environment; $\mathbf{T}$ growth type; $\mathbf{G}$ genotype within growth type; $\boldsymbol{h}^{2}$ heritability within growth types; EOF end of flowering
}

For the estimation of nitrogen uptake and nitrogen utilization parameters at maturity data from Go11 and Go12 was analysed. The means for nitrogen uptake at low nitrogen supply differed non-significantly between growth types (Tab. 3.7, 3.8). At high nitrogen supply semi-dwarf hybrids took up significantly more nitrogen than normal hybrids. Nitrogen uptake efficiency was significantly different between growth types at both nitrogen levels with higher values for semi-dwarfs. Nitrogen utilization efficiency of semi-dwarfs was also significantly higher at both nitrogen levels compared to normal hybrids. Semidwarf hybrids proved to be superior in nitrogen use efficiency at both nitrogen levels, compared to normal hybrids. (Tab. 3.7, 3.8)

The analysis of relative contributions of nitrogen uptake efficiency and nitrogen utilization efficiency to nitrogen use efficiency revealed that in both growth types, and at both nitrogen levels, nitrogen uptake efficiency contributes largely to variation in nitrogen use efficiency (Tab.3.9). Nitrogen utilization efficiency contributed more to nitrogen use efficiency in the semi-dwarf hybrids compared to normal hybrids (Tab.3.9). 
Table 3.7: Parameters of nitrogen use efficiency (maturity) at low and high nitrogen supply, according to Moll et al. (1982)(108 genotypes, Göttingen 2010/11 and 2011/12)

\begin{tabular}{|c|c|c|c|c|c|c|c|}
\hline \multirow[b]{2}{*}{ Trait } & \multirow[b]{2}{*}{ Env. } & \multicolumn{3}{|c|}{ Semi-dwarf } & \multicolumn{3}{|c|}{ Normal type } \\
\hline & & Min. & Max. & Mean & Min. & Max. & Mean \\
\hline \multicolumn{8}{|c|}{ Low nitrogen supply } \\
\hline \multirow{3}{*}{$\begin{array}{l}\text { Nitrogen uptake } \\
(\mathrm{kg} \mathrm{N} / \mathrm{ha})\end{array}$} & Go11 & 49.0 & 88.7 & 70.9 & 40.7 & 98.0 & 60.6 \\
\hline & Go12 & 41.8 & 68.6 & 47.4 & 37.5 & 69.9 & 43.4 \\
\hline & Mean & & & 59.2 & & & 52.0 \\
\hline \multirow{3}{*}{$\begin{array}{l}\text { Nitrogen uptake } \\
\text { efficiency }\end{array}$} & Go11 & 0.51 & 0.93 & 0.75 & 0.44 & 0.98 & 0.64 \\
\hline & Go12 & 0.60 & 0.94 & 0.82 & 0.52 & 0.88 & 0.75 \\
\hline & Mean & & & 0.78 & & & 0.70 \\
\hline \multirow{3}{*}{$\begin{array}{l}\text { Nitrogen utilization } \\
\text { efficiency }\end{array}$} & Go11 & 19.6 & 26.5 & 24.0 & 17.2 & 24.8 & 21.5 \\
\hline & Go12 & 23.1 & 28.2 & 26.9 & 20.2 & 24.6 & 24.1 \\
\hline & Mean & & & 25.5 & & & 22.8 \\
\hline \multirow{3}{*}{$\begin{array}{l}\text { Nitrogen use } \\
\text { efficiency }\end{array}$} & Go11 & 11.4 & 23.0 & 18.1 & 9.6 & 19.5 & 13.8 \\
\hline & Go12 & 17.1 & 26.3 & 22.0 & 13.2 & 22.7 & 18.1 \\
\hline & Mean & & & 20.1 & & & 15.9 \\
\hline \multirow[b]{2}{*}{ Trait } & & \multicolumn{3}{|c|}{ Semi-dwarf } & \multicolumn{3}{|c|}{ Normal type } \\
\hline & Env. & Min. & Max. & Mean & Min. & Max. & Mean \\
\hline \multicolumn{8}{|c|}{ High nitrogen supply } \\
\hline $\begin{array}{l}\text { Nitrogen uptake } \\
(\mathrm{kg} \mathrm{N} / \mathrm{ha})\end{array}$ & Go12 & 110.3 & 160.4 & 127.7 & 94.2 & 148.5 & 118.0 \\
\hline $\begin{array}{l}\text { Nitrogen uptake } \\
\text { efficiency }\end{array}$ & Go12 & 0.67 & 0.97 & 0.77 & 0.57 & 0.90 & 0.72 \\
\hline $\begin{array}{l}\text { Nitrogen utilization } \\
\text { efficiency }\end{array}$ & Go12 & 18.8 & 25.5 & 23.3 & 20.4 & 24.8 & 22.2 \\
\hline $\begin{array}{l}\text { Nitrogen use } \\
\text { efficiency }\end{array}$ & Go12 & 10.3 & 13.6 & 12.6 & 6.3 & 13.8 & 11.2 \\
\hline
\end{tabular}

Env environment; Ei Einbeck; Go Göttingen 
Table 3.8: Variance components of parameters for nitrogen use efficiency (maturity) at low and high nitrogen supply (108 genotypes, Göttingen 2010/11 and 2011/12)

\begin{tabular}{lcccccc}
\hline \multicolumn{1}{c}{ Source } & $\mathbf{E}$ & $\mathbf{T}$ & $\mathbf{G}$ & $\mathbf{T} \times \mathbf{E}$ & $\mathbf{G} \times \mathbf{E}$ & $\boldsymbol{h}^{2}$ \\
\hline Low nitrogen supply & & & & & & \\
Degrees of freedom & 1 & 1 & 106 & 1 & 106 & \\
Nitrogen uptake (kg N/ha) & $199.61^{*}$ & $20.70^{\text {ns }}$ & $7.29^{+}$ & $8.04^{+}$ & $21.46^{* *}$ & 0.22 \\
Nitrogen uptake efficiency & $0.39^{* *}$ & $0.38^{+}$ & $0.13^{*}$ & $0.02^{\text {ns }}$ & $0.27^{* *}$ & 0.29 \\
Nitrogen utilization efficiency & $3.44^{*}$ & $3.50^{* *}$ & $0.34^{*}$ & 0 & $0.34^{+}$ & 0.32 \\
Nitrogen use efficiency & $8.38^{* *}$ & $8.55^{* *}$ & $1.48^{* *}$ & 0 & $1.68^{* *}$ & 0.42 \\
& & & & & &
\end{tabular}

\section{High nitrogen supply}

Degrees of freedom 106

Nitrogen uptake (kg N/ha)

Nitrogen uptake efficiency

Nitrogen utilization efficiency

Nitrogen use efficiency

\begin{tabular}{cccccc}
\multicolumn{7}{c}{1} & 106 & & & \\
- & $22.13^{* *}$ & $57.63^{* *}$ & - & - & 0.59 \\
- & $0.08^{* *}$ & $0.10^{* *}$ & - & - & 0.59 \\
- & $0.32^{*}$ & $0.80^{* *}$ & - & - & 0.64 \\
- & $0.95^{* *}$ & $0.48^{* *}$ & - & - & 0.55
\end{tabular}

${ }^{* *, *},+$ Significant difference at $0.01,0.05,0.10$ probability level, respectively; ns non-significant (F-test from ANOVA); negative variance components were set to zero; $\mathbf{E}$ environment; $\mathbf{T}$ growth type; $\mathbf{G}$ genotype within growth type; $\boldsymbol{h}^{2}$ heritability within growth types

Table 3.9: Relative contribution of nitrogen uptake and nitrogen utilization efficiency to total genetic variation in nitrogen use efficiency, according to Moll et al. (1982)

\begin{tabular}{lcccc}
\hline \multicolumn{1}{c}{ Growth type } & \multicolumn{2}{c}{ Low nitrogen supply } & \multicolumn{2}{c}{ High nitrogen supply } \\
\hline & $\begin{array}{c}\text { Uptake } \\
\text { efficiency }\end{array}$ & $\begin{array}{c}\text { Utilization } \\
\text { efficiency }\end{array}$ & $\begin{array}{c}\text { Uptake } \\
\text { efficiency }\end{array}$ & $\begin{array}{c}\text { Utilization } \\
\text { efficiency }\end{array}$ \\
Göttingen 2010/11 & & & & - \\
Normal type & 0.90 & 0.10 & - & - \\
Semi-dwarf & 0.75 & 0.25 & - & 0.13 \\
Göttingen 2011/12 & & & & 0.87 \\
Normal type & 0.72 & 0.28 & 0.74 & 0.26 \\
Semi-dwarf & 0.72 & 0.28 & & \\
& & & & \\
\hline
\end{tabular}


The proportion of nitrogen uptake and nitrogen utilization at low nitrogen supply is visualized in Fig. 3.1. The highest yielding genotypes within growth types are characterized by high amounts of nitrogen uptake and/or high nitrogen utilization efficiencies (Fig. 3.1). The relationship between nitrogen uptake and nitrogen utilization at high

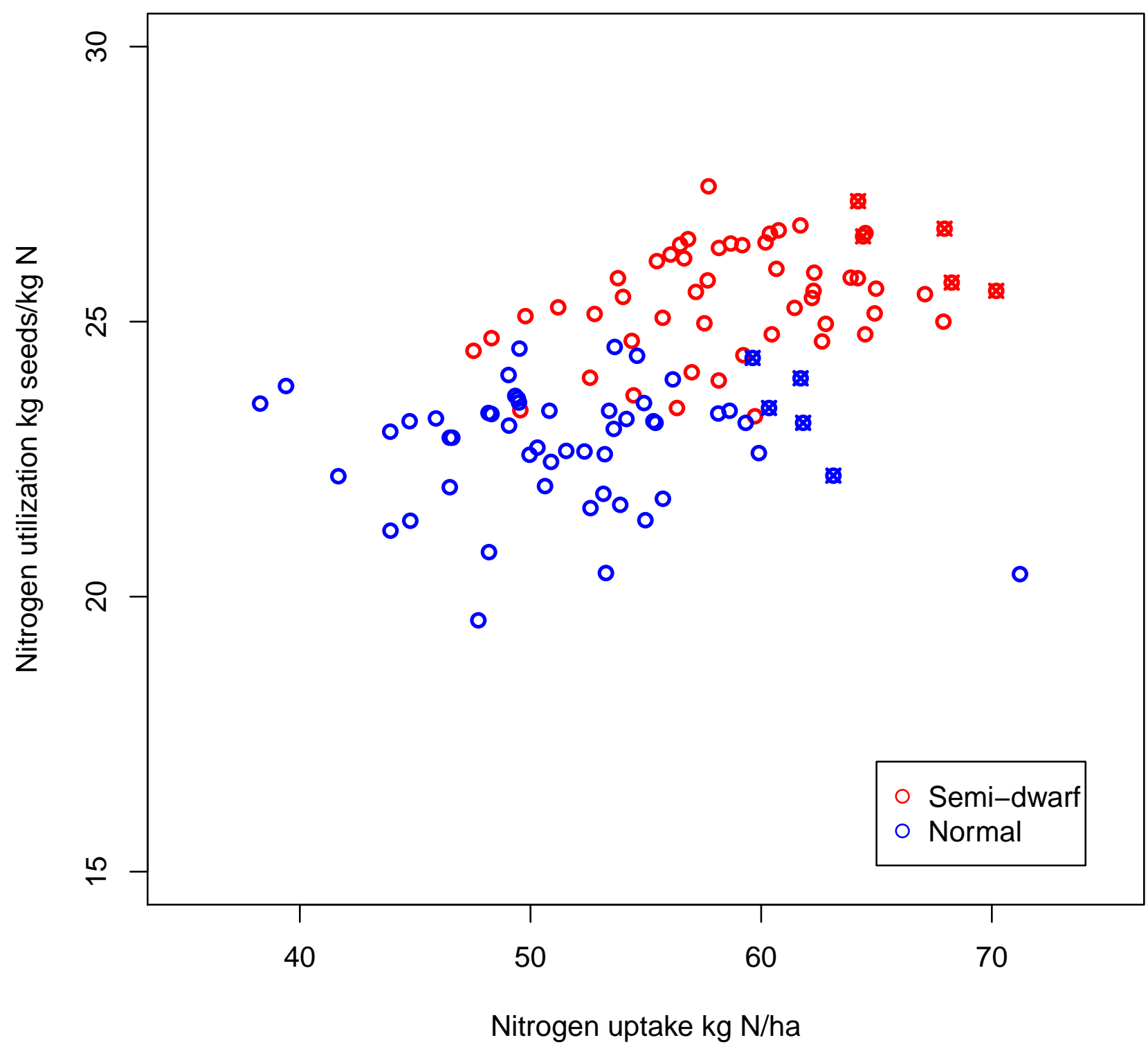

Figure 3.1: Nitrogen uptake and nitrogen utilization efficiency of 108 genotypes at low nitrogen supply (Göttingen 2010/11 and 2011/12). The five genotypes with the highest seed yields in each group, are marked with crosses

nitrogen supply revealed a similar pattern. Genotypes with the highest seed yield in both 
growth types are characterized by high amounts of nitrogen uptake and/or high nitrogen utilization efficiencies (Fig. 3.2).

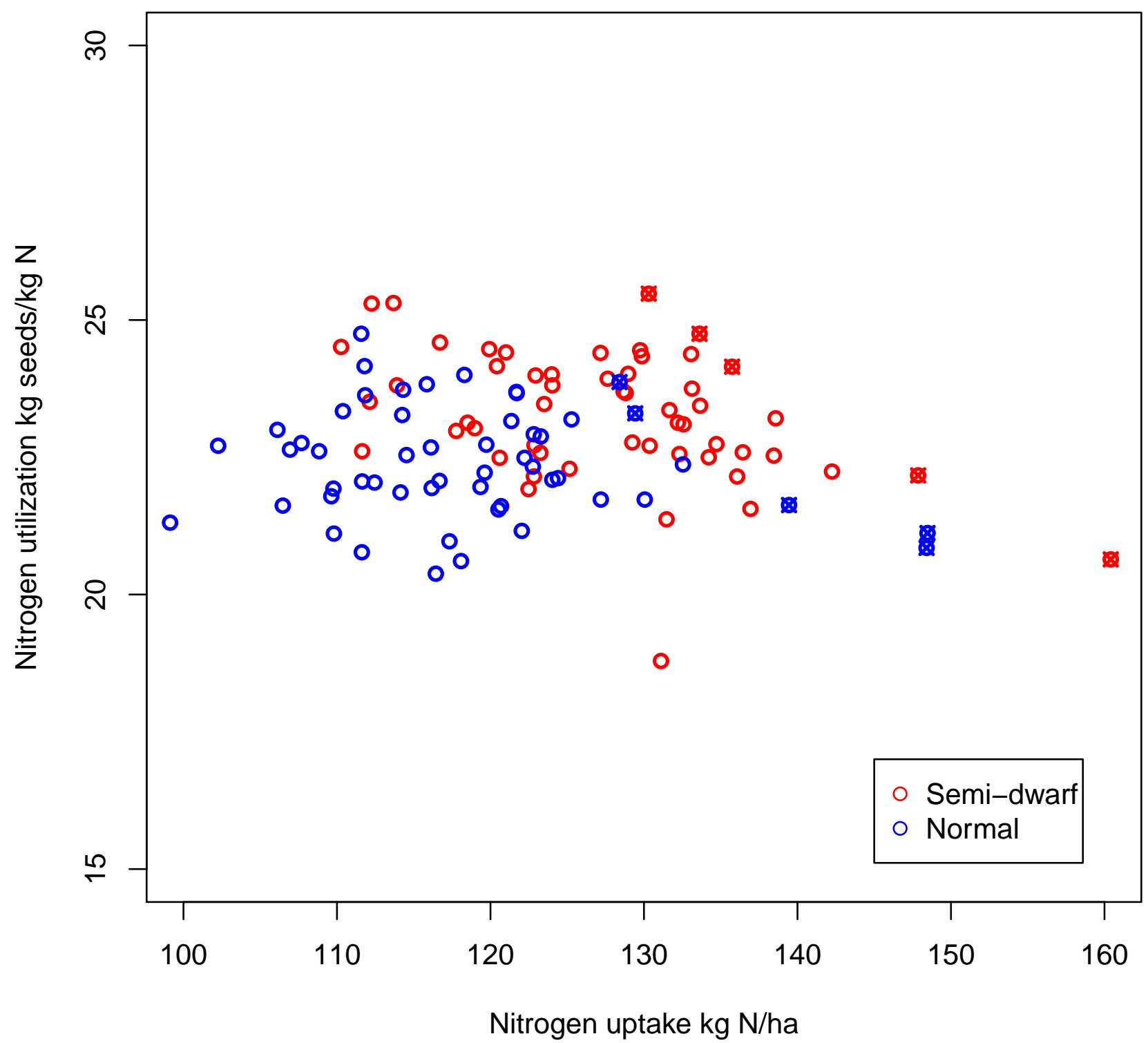

Figure 3.2: Nitrogen uptake and nitrogen utilization efficiency of 108 genotypes at high nitrogen supply (Einbeck and Göttingen 2011/12). The five genotypes with the highest seed yields in each group, are marked with crosses 


\subsubsection{Comparison of low and high nitrogen supply}

ANOVA across nitrogen levels revealed a significant effect of nitrogen fertilization on BFL, Biomass EOF, seed yield, straw yield, nitrogen yield of seeds and the total amount of nitrogen at maturity (Nitrogen yield total) (Tab. 3.10). Nitrogen uptake efficiency and nitrogen utilization efficiency differed significantly between nitrogen levels. No effect of nitrogen fertilization was detected for plant height, nitrogen content of straw, nitrogen content of seeds and nitrogen harvest index. Growth types differed significantly in seed yield and responded significantly different to nitrogen fertilization (TN interaction).

Genotypic variation was detected for all traits except nitrogen content EOF (Tab. 3.10). A significant interaction of genotypes and nitrogen level was observed for seed yield, nitrogen yield of seeds, total amount of nitrogen fixed at maturity (Nitrogen yield total), nitrogen harvest index, nitrogen uptake efficiency and nitrogen utilization efficiency. All traits were significantly affected by genotype by environment interactions, except nitrogen yield EOF. Heritabilities ranged from 0.27 (Nitrogen yield EOF) to 0.77 (Nitrogen utilization efficiency). At both nitrogen levels seed yield of semi-dwarf and normal type hybrids was positively correlation with nitrogen uptake and nitrogen uptake efficiency (Tab. 3.11). Nitrogen utilization efficiency was not correlated with seed yield of semi-dwarf hybrids but showed a weak significant positive correlation with seed yield of normal hybrids at both nitrogen levels . The amount of nitrogen fixed by the end of flowering was not correlated with seed yield. At low nitrogen supply straw yield was positively correlated to seed yield. Nitrogen utilization efficiency of normal hybrids correlated positively with seed yield at low nitrogen supply. Nitrogen utilization efficiency was negatively correlated to nitrogen content of straw at both nitrogen levels.

Correlations for individual traits at low and high nitrogen supply were rather low (Tab. 3.12). Seed yield of normal hybrids was correlated with $r=0.60$ between low and high nitrogen supply. Seed yield of semi-dwarfs was correlated with $r=0.46$. No correlation among the two nitrogen levels was observed for nitrogen content EOF, nitrogen content straw and nitrogen yield EOF. 
Table 3.10: Variance components of agronomic traits and nitrogen affected traits at low and high nitrogen supply (108 genotypes, Einbeck and Göttingen 2011/12)

\begin{tabular}{|c|c|c|c|c|c|}
\hline Source & $\mathbf{E}$ & $\mathbf{N}$ & $\mathbf{T}$ & G & $\mathbf{E} \times \mathbf{N}$ \\
\hline Degrees of freedom & 1 & 1 & 1 & 106 & 1 \\
\hline Beginn of flowering (days) & $56.83^{* *}$ & $0.02^{* *}$ & 0 & $0.29^{* *}$ & 0 \\
\hline Plant height $(\mathrm{cm})$ & $146.88^{* *}$ & 0 & $475.65^{\mathrm{ns}}$ & $4.32^{* *}$ & $48.59^{* *}$ \\
\hline Biomass EOF (dt/ha) & 0 & $284.93^{*}$ & $15.80^{\text {ns }}$ & $0.91^{*}$ & 0 \\
\hline Seed yield $(\mathrm{dt} / \mathrm{ha})^{\mathrm{a}}$ & - & $134.71^{* *}$ & $3.84^{* *}$ & $1.66^{* *}$ & - \\
\hline Straw yield (dt/ha) & $0.57 \mathrm{~ns}$ & $96.72^{*}$ & $5.75^{\mathrm{ns}}$ & $2.11^{* *}$ & 0 \\
\hline Nitrogen content EOF (\%) & $7.39^{*}$ & $60.97^{\mathrm{ns}}$ & $7.41^{* *}$ & $0.06^{\mathrm{ns}}$ & $33.43^{*}$ \\
\hline Nitrogen content straw (\%) & $0.43^{* *}$ & 0 & $0.04^{* *}$ & $0.06^{* *}$ & $3.65^{* *}$ \\
\hline Nitrogen content seed (\%) & $0.01 \mathrm{~ns}$ & 0 & 0 & $0.08^{* *}$ & $3.58^{* *}$ \\
\hline Nitrogen yield EOF (kg N/ha) & $268.88^{*}$ & $3985.42^{\mathrm{ns}}$ & 0 & $5.61^{+}$ & $563.93^{*}$ \\
\hline Nitrogen yield straw (kg N/ha) & $16.67^{+}$ & $53.66^{\mathrm{ns}}$ & $0.37^{\mathrm{ns}}$ & $1.29^{* *}$ & $34.30^{+}$ \\
\hline Nitrogen yield seed $(\mathrm{kg} \mathrm{N} / \mathrm{ha})^{\mathrm{a}}$ & - & $1747.70^{* *}$ & $44.73^{* *}$ & $15.78^{* *}$ & - \\
\hline Nitrogen yield total $(\mathrm{kg} \mathrm{N} / \mathrm{ha})^{\mathrm{a}}$ & - & $2995.64^{*}$ & $23.23^{* *}$ & $23.67^{* *}$ & - \\
\hline Nitrogen harvest index ${ }^{\mathrm{a}}$ & - & 0 & $0.15^{* *}$ & $0.06^{* *}$ & - \\
\hline Nitrogen uptake efficiency ${ }^{\mathrm{a}}$ & - & $3.41^{*}$ & $0.15^{* *}$ & $0.15^{* *}$ & - \\
\hline Nitrogen utilization efficiency ${ }^{\mathrm{a}}$ & - & $3.42^{+}$ & $1.64^{* *}$ & $0.92^{* *}$ & - \\
\hline Source & $\mathbf{E} \times \mathbf{T}$ & $\mathbf{T} \times \mathbf{N}$ & $\mathbf{G} \times \mathbf{N}$ & $\mathbf{G} \times \mathbf{E}$ & $h^{2}$ \\
\hline Degrees of freedom & 1 & 1 & 106 & 106 & \\
\hline Beginn of flowering & $0.08^{* *}$ & & 0 & $0.49^{* *}$ & 0.51 \\
\hline Plant height $(\mathrm{cm})$ & $118.38^{* *}$ & $13.60^{\mathrm{ns}}$ & $0.97^{\mathrm{ns}}$ & $4.64^{* *}$ & 0.53 \\
\hline Biomass EOF (dt/ha) & $10.51^{* *}$ & $3.11^{\mathrm{ns}}$ & $0.65^{\mathrm{ns}}$ & $1.34^{* *}$ & 0.30 \\
\hline Seed yield $(\mathrm{dt} / \mathrm{ha})^{\mathrm{a}}$ & - & $0.21^{* *}$ & $0.45^{*}$ & - & 0.73 \\
\hline Straw yield (dt/ha) & $2.09^{* *}$ & $2.15^{\mathrm{ns}}$ & $0.22^{\mathrm{ns}}$ & $0.58^{+}$ & 0.58 \\
\hline Nitrogen content EOF (\%) & $0.002^{\mathrm{ns}}$ & $0.47^{*}$ & 0 & $0.36^{*}$ & 0.08 \\
\hline Nitrogen content straw (\%) & 0 & $0.16^{* *}$ & $0.04^{\mathrm{ns}}$ & $0.08^{* *}$ & 0.40 \\
\hline Nitrogen content seed (\%) & $0.07^{* *}$ & $0.61^{* *}$ & 0 & $0.06^{*}$ & 0.39 \\
\hline Nitrogen yield EOF (kg N/ha) & $57.47^{* *}$ & 0 & $4.75^{\mathrm{ns}}$ & $2.92^{\mathrm{ns}}$ & 0.27 \\
\hline Nitrogen yield straw (kg N/ha) & $1.28^{* *}$ & 0 & 0 & $2.13^{* *}$ & 0.41 \\
\hline Nitrogen yield seed $(\mathrm{kg} \mathrm{N} / \mathrm{ha})^{\mathrm{a}}$ & - & $12.53^{* *}$ & $7.64^{* *}$ & - & 0.70 \\
\hline Nitrogen yield total $(\mathrm{kg} \mathrm{N} / \mathrm{ha})^{\mathrm{a}}$ & - & $7.71^{* *}$ & $19.00^{* *}$ & - & 0.67 \\
\hline Nitrogen harvest index ${ }^{\mathrm{a}}$ & - & $0.62^{*}$ & $0.02^{* *}$ & - & 0.74 \\
\hline Nitrogen uptake efficiency ${ }^{\mathrm{a}}$ & - & $0.02^{*}$ & $0.09^{* *}$ & - & 0.71 \\
\hline Nitrogen utilization efficiency ${ }^{\mathrm{a}}$ & - & $0.95^{* *}$ & $0.27^{* *}$ & - & 0.77 \\
\hline
\end{tabular}

${ }^{* *},{ }^{*},+$ Significant difference at $0.01,0.05,0.10$ probability level, respectively; ns non-significant (F-test from ANOVA); negative variance components were set to zero; E environment; $\mathbf{N}$ nitrogen supply level; $\mathbf{T}$ growth type; $\mathbf{G}$ genotype within growth type; $\boldsymbol{h}^{2}$ heritability within growth types; EOF end of flowering;

${ }^{a}$ values for Göttingen 2011/12 only 
Table 3.11: Spearman's rank correlations of agronomic and nitrogen affected traits at low and high nitrogen supply

\begin{tabular}{|c|c|c|c|c|c|c|c|c|}
\hline \multicolumn{2}{|l|}{ Low nitrogen supply ${ }^{a}$} & $\begin{array}{l}\text { Seed } \\
\text { yield }\end{array}$ & $(2)$ & (3) & (4) & (5) & (6) & (7) \\
\hline \multirow[t]{2}{*}{ (2) Straw yield } & $\mathrm{Sd}$ & $0.47^{* *}$ & & & & & & \\
\hline & $\mathrm{Nt}$ & $0.57^{* *}$ & & & & & & \\
\hline \multirow[t]{2}{*}{ (3) Nitrogen total EOF } & $\mathrm{Sd}$ & $0.17^{\mathrm{ns}}$ & $0.22^{\mathrm{ns}}$ & & & & & \\
\hline & $\mathrm{Nt}$ & $0.15^{\mathrm{ns}}$ & $0.28^{*}$ & & & & & \\
\hline \multirow[t]{2}{*}{ (4) Nitrogen seed } & $\mathrm{Sd}$ & $0.64^{* *}$ & $0.73^{* *}$ & $0.28^{*}$ & & & & \\
\hline & $\mathrm{Nt}$ & $0.99^{* *}$ & $0.57^{* *}$ & $0.19^{\mathrm{ns}}$ & & & & \\
\hline \multirow[t]{2}{*}{ (5) Nitrogen straw } & $\mathrm{Sd}$ & $0.64^{* *}$ & $0.60^{* *}$ & $0.16^{\mathrm{ns}}$ & $0.35^{* *}$ & & & \\
\hline & $\mathrm{Nt}$ & $0.50^{* *}$ & $0.81^{* *}$ & $0.27^{*}$ & $0.51^{* *}$ & & & \\
\hline \multirow[t]{2}{*}{ (6) Nitrogen uptake } & $\mathrm{Sd}$ & $0.75^{* *}$ & $0.82^{* *}$ & $0.29^{*}$ & $0.94^{* *}$ & $0.61^{* *}$ & & \\
\hline & $\mathrm{Nt}$ & $0.92^{* *}$ & $0.75^{* *}$ & $0.25^{\mathrm{ns}}$ & $0.93^{* *}$ & $0.77^{* *}$ & & \\
\hline \multirow{2}{*}{$\begin{array}{l}\text { (7) Nitrogen utilization } \\
\text { efficiency }\end{array}$} & $\mathrm{Sd}$ & $0.06^{\mathrm{ns}}$ & $0.30^{*}$ & $0.10^{\mathrm{ns}}$ & $0.53^{* *}$ & $-0.38^{* *}$ & $0.33^{*}$ & \\
\hline & $\mathrm{Nt}$ & $0.40^{* *}$ & $-0.24^{\mathrm{ns}}$ & $-0.27^{*}$ & $0.35^{* *}$ & $-0.47^{* *}$ & $0.09^{\mathrm{ns}}$ & \\
\hline \multirow{2}{*}{$\begin{array}{l}\text { (8) Nitrogen uptake } \\
\text { efficiency }\end{array}$} & $\mathrm{Sd}$ & $0.73^{* *}$ & $0.80^{* *}$ & $0.22^{\mathrm{ns}}$ & $0.94^{* *}$ & $0.56^{* *}$ & $0.98^{* *}$ & $0.35^{* *}$ \\
\hline & $\mathrm{Nt}$ & $0.92^{* *}$ & $0.72^{* *}$ & $0.18^{\mathrm{ns}}$ & $0.93^{* *}$ & $0.72^{* *}$ & $0.98^{* *}$ & $0.12^{\text {ns }}$ \\
\hline \multicolumn{2}{|l|}{ High nitrogen supply b } & $\begin{array}{l}\text { Seed } \\
\text { yield }\end{array}$ & (2) & (3) & (4) & (5) & (6) & (7) \\
\hline
\end{tabular}

(2) Straw yield

Sd $\quad 0.17^{\text {ns }}$

$\mathrm{Nt}-0.15^{\mathrm{ns}}$

(3) Nitrogen total EOF

Sd $\quad 0.14^{\mathrm{ns}}-0.03^{\mathrm{ns}}$

$\mathrm{Nt} \quad 0.09^{\mathrm{ns}} \quad 0.03^{\mathrm{ns}}$

(4)Nitrogen seed

Sd $\quad 0.96^{* *} \quad 0.17^{\mathrm{ns}} \quad 0.08^{\mathrm{ns}}$

$\mathrm{Nt} \quad 0.97^{* *}-0.11^{\mathrm{ns}} \quad 0.06^{\mathrm{ns}}$

(5) Nitrogen straw

$\begin{array}{llll}\text { Sd } & 0.19^{\text {ns }} & 0.75^{* *}-0.04^{\text {ns }} & 0.22^{\text {ns }} \\ \text { Nt } & 0.11^{\text {ns }} & 0.67^{* *}-0.05^{\text {ns }} & 0.18^{\text {ns }}\end{array}$

(6) Nitrogen uptake

$\begin{array}{llllll}\text { Sd } & 0.77^{* *} & 0.53^{* *} & 0.09^{\text {ns }} & 0.81^{* *} & 0.71^{* *} \\ \text { Nt } & 0.85^{* *} & 0.17^{\text {ns }} & 0.02^{\text {ns }} & 0.90^{* *} & 0.54^{* *}\end{array}$

(7) Nitrogen utilization

Sd $\quad 0.22^{\text {ns }}-0.61^{* *} \quad 0.20^{\text {ns }}$

$0.11^{\text {ns }}-0.85^{* *}-0.39^{* *}$ efficiency

$\mathrm{Nt} \quad 0.35^{*}-0.62^{* *}$

$0.10^{\mathrm{ns}}$

$0.22^{\mathrm{ns}}-0.81^{* *}-0.11^{\mathrm{ns}}$

(8) Nitrogen uptake

Sd $0.78^{* *} \quad 0.54^{* *} \quad 0.09^{\mathrm{ns}}$

$0.81^{* *} \quad 0.70^{* *} \quad 1.00^{* *}-0.37^{* *}$ efficiency

$\mathrm{Nt} \quad 0.86^{* *} \quad 0.14^{\mathrm{ns}} \quad 0.02^{\mathrm{ns}}$

$0.91^{* *} \quad 0.51^{* *} \quad 1.00^{* *}-0.08^{\mathrm{ns}}$

$* *, *,+$ Significant difference at 0.01, 0.05, 0.10 probability level respectively; ns non-significant; Sd semi-dwarfs; Nt normal types; a Göttingen 2010/11 and 2011/12; b Göttingen 2011/12;

EOF end of flowering 
Table 3.12: Mean values of agronomic and nitrogen related traits at low and high nitrogen supply. Spearman's rank correlations between the two nitrogen levels (108 genotypes, Göttingen 2011/12)

\begin{tabular}{|c|c|c|c|c|c|c|}
\hline \multirow{3}{*}{$\begin{array}{l}\text { Trait } \\
\begin{array}{l}\text { Beginn of flowering } \\
\text { (days) }\end{array}\end{array}$} & & \multicolumn{2}{|c|}{$\begin{array}{l}\text { Low nitrogen } \\
\text { supply }\end{array}$} & \multicolumn{2}{|c|}{$\begin{array}{l}\text { High nitrogen } \\
\text { supply }\end{array}$} & \multirow{2}{*}{$\begin{array}{c}\begin{array}{c}\text { Correlation } \\
\text { coefficient }\end{array} \\
0.59^{* *}\end{array}$} \\
\hline & $\mathrm{Nt}$ & 109 & & 109 & & \\
\hline & $\mathrm{Sd}$ & 109 & ns & 109 & ns & $0.66^{* *}$ \\
\hline \multirow{2}{*}{$\begin{array}{l}\text { Plant height } \\
(\mathrm{cm})\end{array}$} & $\mathrm{Nt}$ & 99 & & 110 & & $0.44 * *$ \\
\hline & $\mathrm{Sd}$ & 71 & $\mathrm{~ns}$ & 73 & $\mathrm{~ns}$ & $0.24 \mathrm{~ns}$ \\
\hline \multirow{2}{*}{$\begin{array}{l}\text { Biomass EOF } \\
(\mathrm{dt} / \mathrm{ha})\end{array}$} & $\mathrm{Nt}$ & 17.1 & & 43.7 & & $0.36 * *$ \\
\hline & $\mathrm{Sd}$ & 13.3 & $\mathrm{~ns}$ & 34.5 & ns & $0.39 * *$ \\
\hline \multirow{2}{*}{$\begin{array}{l}\text { Seed yield } \\
\text { (dt/ha) }\end{array}$} & $\mathrm{Nt}$ & 10.5 & & 26.4 & & $0.60 * *$ \\
\hline & $\mathrm{Sd}$ & 12.8 & $* *$ & 29.7 & $* *$ & $0.46^{* *}$ \\
\hline \multirow{2}{*}{$\begin{array}{l}\text { Straw yield } \\
(\mathrm{dt} / \mathrm{ha})\end{array}$} & $\mathrm{Nt}$ & 11.5 & & 36.4 & & $0.28 *$ \\
\hline & $\mathrm{Sd}$ & 10.1 & ns & 31.1 & ns & $0.47 * *$ \\
\hline \multirow{2}{*}{$\begin{array}{l}\text { Nitrogen content EOF } \\
(\%)\end{array}$} & $\mathrm{Nt}$ & 1.68 & & 2.86 & & $0.19 \mathrm{~ns}$ \\
\hline & $\mathrm{Sd}$ & 2.00 & $* *$ & 3.32 & $* *$ & $0.20 \mathrm{~ns}$ \\
\hline \multirow{2}{*}{$\begin{array}{l}\text { Nitrogen content straw } \\
(\%)\end{array}$} & $\mathrm{Nt}$ & 0.56 & & 0.64 & & $0.24 \mathrm{~ns}$ \\
\hline & $\mathrm{Sd}$ & 0.55 & + & 0.70 & $* *$ & $0.18 \mathrm{~ns}$ \\
\hline \multirow{2}{*}{$\begin{array}{l}\text { Nitrogen content seed } \\
(\%)\end{array}$} & $\mathrm{Nt}$ & 3.13 & & 3.21 & & $0.41 * *$ \\
\hline & $\mathrm{Sd}$ & 3.08 & $\mathrm{~ns}$ & 3.31 & + & $0.35 * *$ \\
\hline \multirow{2}{*}{$\begin{array}{l}\text { Nitrogen yield EOF } \\
\text { (kg N/ha) }\end{array}$} & $\mathrm{Nt}$ & 28.7 & & 124.0 & & $0.07 \mathrm{~ns}$ \\
\hline & $\mathrm{Sd}$ & 26.6 & ns & 116.2 & ns & $0.15 \mathrm{~ns}$ \\
\hline \multirow{2}{*}{$\begin{array}{l}\text { Nitrogen yield straw } \\
(\mathrm{kg} \mathrm{N} / \mathrm{ha})\end{array}$} & $\mathrm{Nt}$ & 11.5 & & 23.6 & & $0.31 *$ \\
\hline & $\mathrm{Sd}$ & 10.1 & $\mathrm{~ns}$ & 22.1 & ns & $0.30 *$ \\
\hline \multirow{2}{*}{$\begin{array}{l}\text { Nitrogen yield seed } \\
\text { (kg N/ha) }\end{array}$} & $\mathrm{Nt}$ & 31.7 & & 87.3 & & $0.53 * *$ \\
\hline & $\mathrm{Sd}$ & 37.7 & $*$ & 100.3 & $* *$ & $0.46^{* *}$ \\
\hline \multirow{2}{*}{$\begin{array}{l}\text { Nitrogen yield total } \\
\text { (kg N/ha) }\end{array}$} & $\mathrm{Nt}$ & 43.3 & & 118.0 & & $0.47 * *$ \\
\hline & $\mathrm{Sd}$ & 47.4 & $*$ & 127.7 & $* *$ & $0.33^{*}$ \\
\hline \multirow[t]{2}{*}{ Nitrogen harvest index } & $\mathrm{Nt}$ & 0.73 & & 0.74 & & $0.40 * *$ \\
\hline & $\mathrm{Sd}$ & 0.79 & $*$ & 0.79 & $* *$ & $0.42 * *$ \\
\hline \multirow[t]{2}{*}{ Nitrogen uptake efficiency } & $\mathrm{Nt}$ & 0.75 & & 0.50 & & $0.47^{* *}$ \\
\hline & $\mathrm{Sd}$ & 0.82 & + & 0.54 & $* *$ & $0.36^{* *}$ \\
\hline \multirow[t]{2}{*}{ Nitrogen utilization efficiency } & $\mathrm{Nt}$ & 24.09 & & 22.24 & & $0.51^{* *}$ \\
\hline & $\mathrm{Sd}$ & 26.89 & $* *$ & 23.26 & $*$ & $0.46^{* *}$ \\
\hline
\end{tabular}

**,*,+ Significant difference at $0.01,0.05,0.10$ probability level, respectively; ns non-significant; EOF end of flowering 


\subsection{Discussion}

Nitrogen use efficiency can be subdivided into nitrogen uptake efficiency and nitrogen utilization efficiency. Nitrogen uptake efficiency was calculated as the ratio of total nitrogen taken up by a genotype at maturity and available nitrogen. The only source of nitrogen for plants at low nitrogen conditions is the so called 'mineralized nitrogen'. Mineralized nitrogen is the results of organic matter decomposition by soil microbes. The intensity of nitrogen mineralization strongly depends on temperature, moisture and aeriation in the soil as well as on the amount of organic matter. Therefore an exact quantification of available nitrogen in the soil is quite difficult. In the present experiment the available amount of nitrogen was defined individually for each replication within each environment as the highest amount of nitrogen taken up by a genotype at end of flowering or maturity, respectively.

\section{Variation in nitrogen at the end of flowering and maturity}

At low nitrogen supply in Göttingen 2011, the total nitrogen uptake at maturity was lower than the nitrogen uptake at end of flowering (Tab. 3.1). The average difference in the nitrogen uptake of genotypes between the two experiments (harvest EOF or maturity) was $30 \mathrm{~kg} \mathrm{~N} /$ ha for normal types and $13 \mathrm{~kg} \mathrm{~N} /$ ha for semi-dwarf types. The same pattern was observed at high nitrogen supply in Göttingen 2012 with a difference in total nitrogen uptake between the two harvest dates of about $20 \mathrm{~kg} \mathrm{~N} /$ ha for both types (Tab. 3.3).

Oilseed rape looses its leaves between end of flowering and maturity. The decline in total nitrogen in Göttingen 2011 and Göttingen 2012 could have been caused by nitrogen loss through leaf shedding. Ulas et al. (2013) reported nitrogen loss rates through leaf shedding of $3.7 \mathrm{~kg} \mathrm{~N} / \mathrm{ha}$ at N0 (no nitrogen fertilization) and $13.4 \mathrm{~kg} \mathrm{~N} /$ ha at N240 (240 $\mathrm{kg} \mathrm{N} /$ ha fertilized). Gombert et al. (2010) reported that leaves and stems of oilseed rape are the major storage organs for nitrogen until flowering stage. As soon as reproductive organs develop, the nitrogen stored in leaves and stems is remobilized and pods become the most important nitrogen sink in the plant. The first basal leaves were dropped before pod development. Thus stems acted as a nitrogen buffer and became the main sink of remobilized nitrogen from leaves. However the proportion of remobilized nitrogen allocated to the stem decreased with increasing nitrogen supply. The nitrogen concentration of dropped leaves increased with rising nitrogen level (Gombert et al., 2010). An increase in nitrogen concentration of dropped leaves with rising nitrogen supply was also observed by Kessel (2000). Gombert et al. (2010) assumed a sink limitation for remobilized nitrogen from leaves, causing higher nitrogen concentrations in dropped leafs. Furthermore the authors concluded that the time course of nitrogen uptake seems to have a stronger impact on the efficiency of nitrogen remobilization than the overall nitrogen supply. This 
conclusion is confirmed when comparing the present observations in Göttingen 2012 at low and high nitrogen supply. At low nitrogen supply (Go12) both growth types took up about $27 \mathrm{~kg} /$ ha of mineralized nitrogen by end of flowering and continued nitrogen uptake after flowering (Tab. 3.1). At high nitrogen supply both growth types took up already $140 \mathrm{~kg} \mathrm{~N} /$ ha by end of flowering but lost about $20 \mathrm{~kg} \mathrm{~N} /$ ha until maturity (Tab. 3.3).

\section{Nitrogen uptake and nitrogen uptake efficiency}

At harvest EOF nitrogen uptake and nitrogen uptake efficiency showed no significant difference between the growth types at low and high nitrogen supply (Tab. 3.6). But both traits were significantly influenced by interactions between growth type and environment at both nitrogen levels. Results from the harvest at maturity revealed that semi-dwarfs had a significantly higher nitrogen uptake efficiency than normal types at low and high nitrogen supply. Nitrogen uptake proved to be non-significantly different between growth types at low nitrogen supply but significantly different at high nitrogen supply (Tab. 3.8). Based on the observations for harvest at EOF the positive effect of the semi-dwarf type on nitrogen uptake and nitrogen uptake efficiency at maturity could be a result of less nitrogen loss through leaf shedding compared to normal types. For a reliable conclusion more environments need to be tested due to the strong interaction effects of growth type with environments.

Heritabilities for nitrogen uptake and nitrogen uptake efficiency at low and high nitrogen supply were low at both harvest dates due to significant genotype by environment interactions and high experimental errors. Heritabilities at high nitrogen supply are probably overestimated due to only one environment.

Nitrogen uptake efficiency at maturity in the semi-dwarf types correlated with seed yield at low nitrogen supply $(r=0.73)$ and high nitrogen supply $(r=0.78)$. The same was true for normal types with $r=0.92$ at low nitrogen and $r=0.86$ at high nitrogen supply (Tab. 3.11). Schulte auf'm Erley et al. (2011) analysed a set of 17 winter oilseed rape lines and hybrids and found significant correlations of nitrogen uptake with seed yield of $r=0.78$ at low nitrogen supply and $r=0.65$ at high nitrogen supply. In the interpretation of correlation coefficients for nitrogen uptake, nitrogen uptake efficiency and nitrogen utilization efficiency with seed yield, it shall be considered that they could be overestimated, due to use of seed yield in the estimation of all three components.

\section{Nitrogen utilization efficiency and nitrogen use efficiency}

Semi-dwarf hybrids revealed a significantly higher nitrogen utilization efficiency at low and high nitrogen supply compared to normal types (Tab. 3.7, 3.8). The difference in nitrogen utilization efficiency between growth types was much more pronounced at low than at 
high nitrogen supply. Seed yield of normal types was positively correlated with nitrogen utilization efficiency at low $(r=0.40)$ and high nitrogen supply $(r=0.35)$ (Tab.3.11). Nitrogen utilization efficiency in the semi-dwarfs was not significantly correlated with seed yield. The average nitrogen utilization efficiency of $22.8 \mathrm{~kg}$ seeds $/ \mathrm{kg} \mathrm{N}$ (Tab. 3.7) for normal type hybrids at low nitrogen supply in the present study is in accordance with results from Berry et al. (2010), reporting nitrogen utilization efficiencies of $19.5 \mathrm{~kg}$ seed/ $\mathrm{kg} \mathrm{N}$ to $23.1 \mathrm{~kg}$ seeds $/ \mathrm{kg} \mathrm{N}$ for normal hybrids at low nitrogen supply. At both nitrogen levels, nitrogen utilization efficiency was significantly negatively correlated with the amount of nitrogen of straw. This means that genotypes with less straw and/or lower nitrogen contents in the straw are favorable in terms of nitrogen utilization efficiency (Tab. 3.11). A significant genotypic variation for nitrogen utilization efficiency was observed in both growth types and at both nitrogen levels (Tab. 3.8).

Semi-dwarfs proved to have a significantly higher nitrogen use efficiency at low and high nitrogen supply (Tab. 3.7). The relative contributions of nitrogen uptake efficiency and nitrogen utilization efficiency to the genetic variation in nitrogen use efficiency were calculated according to Moll et al. (1982). At both nitrogen levels nitrogen uptake efficiency was the most important parameter for genetic variation in nitrogen use efficiency (Tab. 3.9). These results are contrary to other studies for nitrogen use efficiency in winter oilseed rape where nitrogen utilization efficiency was more important with increased nitrogen supply (Kessel, 2000; Schulte auf'm Erley et al., 2011). Nitrogen uptake efficiency and nitrogen utilization efficiency at low nitrogen supply were correlated by $r=0.35$ in the semi-dwarf types and $r=0.12$ in normal types.

\section{Selection for nitrogen use efficiency}

Schulte auf'm Erley et al. (2011) resumed, when nitrogen is the limiting factor and when nitrogen taken up is already used at maximum efficiency, additional $\mathrm{N}$ is of overwhelming importance for seed yield. This finding could be confirmed in the present study because high yielding genotypes at low nitrogen supply are among the ones with highest nitrogen uptake rates (Fig. 3.1). Based on the results of this study a breeder should select primarily for high nitrogen uptake efficiency to gain genotypes with superior seed yield at low nitrogen supply. The selection should be conducted at low nitrogen conditions due to the low correlation for nitrogen uptake efficiency between low and high nitrogen supply (Tab. 3.12). Determination of nitrogen uptake efficiency is quite laborious especially in larger scales. Due to the correlation with nitrogen uptake efficiency, seed yield is a parameter to select for high nitrogen uptake rates and efficiencies at low nitrogen conditions.

However, nitrogen use efficiency is the combination of nitrogen uptake and nitrogen utilization efficiency. Thus, seed yield represents the combination of these two separate traits. 
Small improvements or even negative trends in one trait (most likely nitrogen uptake), may be hidden by gains in the other (utilization efficiency) (Hawkesford and Barraclough, 2011). Genotypes with lower nitrogen uptake rates can still achieve high seed yields by having a higher nitrogen utilization efficiency (Fig. 3.2). Therefore, selecting for yield alone may not select for optimal nitrogen uptake or utilization characteristics (Hawkesford and Barraclough, 2011). Based on the low (low nitrogen) or negative phenotypic correlation (high nitrogen) between nitrogen uptake efficiency and nitrogen utilization efficiency a selection for genotypes with high nitrogen uptake efficiency and high nitrogen utilization efficiency seems to be challenging (Tab. 3.11). The semi-dwarf growth type could be a solution to this problem. Due to less straw and less nitrogen fixed in the straw semi-dwarfs had a higher nitrogen utilization efficiency compared to normal types. This seems to be of special importance at nitrogen deficient conditions where semi-dwarf types had significantly higher seed yields than normal types.

This experiment has shown that nitrogen uptake efficiency is significantly correlated to seed yield at low and high nitrogen supply and confirmed results from other studies in winter oilseed rape (Berry et al., 2010; Schulte auf'm Erley et al., 2011; Kessel et al., 2012). At low and high nitrogen supply levels nitrogen uptake efficiency was more important to nitrogen use efficiency than nitrogen utilization efficiency. This is in clear contrast to results from Kessel et al. (2012). A significant genetic variation with strong interactions of genotype with environments was detected for nitrogen uptake efficiency and nitrogen utilization efficiency. The amount of nitrogen fixed by a genotype at end of flowering proved to be not correlated with seed yield. This confirms observations from Berry et al. (2010). 


\section{References}

Berry, P., Spink, J., Foulkes, M., and White, P. (2010). The physiological basis of genotypic differences in nitrogen use efficiency in oilseed rape (Brassica napus L.). Field Crops Research, 119(2):365-373.

Foisset, N., Delourme, R., Barret, P., and Renard, M. (1995). Molecular tagging of the dwarf BREIZH (Bzh) gene in Brassica napus. Theoretical and Applied Genetics, 91(5):756-761.

Gombert, J., Le Dily, F., Lothier, J., Etienne, P., Rossato, L., Allirand, J.-M., Jullien, A., Savin, A., and Ourry, A. (2010). Effect of nitrogen fertilization on nitrogen dynamics in oilseed rape using 15N-labeling field experiment. Journal of Plant Nutrition and Soil Science, 173(6):875-884.

Hawkesford, M. J. and Barraclough, P. (2011). The Molecular And Physiological Basis Of Nutrient Use Efficiency In Crops. Wiley-Blackwell, Ames, Iowa.

Kessel, B. (2000). Genetische Variation und Verbung der Stickstoff-Effizienz bei Winterraps (Brassica napus L.). Cuvillier Verlag Göttingen.

Kessel, B., Schierholt, A., and Becker, H. C. (2012). Nitrogen use efficiency in a genetically diverse set of winter oilseed rape (L.). Crop Science, 52(6):2546-2554.

Lancashire, P. D., Bleiholder, H., Boom, T., Langelüddeke, P., Stauss, R., Weber, E., and Witzenberger, A. (1991). A uniform decimal code for growth stages of crops and weeds. Annals of Applied Biology, 119(3):561-601.

Moll, R., Kamprath, E., and Jackson, W. (1982). Analysis and interpretation of factors which contribute to efficiency of nitrogen utilization. Agronomy Journal, 74(3):562-564.

Paulmann, W. and Frauen, M. (1998). Erfahrungsbericht zur Entwicklung und Saatguterzeugung von restaurierten Winterraps-Hybridsorten. Bericht über die 48 . Tagung der Arbeitsgemeinschaft der Saatzuchtleiter, BAL Gumpenstein, 48:25-27. 


\section{REFERENCES}

Schiemenz, K. and Gurgel, A. (2013). Anbauversuche zur Senkung der THG-Emissionen in landwirtschaftlichen Produktionsverfahren. http://www.duesse.de/znr/pdfs/2013/2013-11-28-biokraftstoffe-03.pdf.

Schulte auf'm Erley, G., Behrens, T., Ulas, A., Wiesler, F., and Horst, W. J. (2011). Agronomic traits contributing to nitrogen efficiency of winter oilseed rape cultivars. Field Crops Research, 124(1):114-123.

Ulas, A., Behrens, T., Wiesler, F., Horst, W. J., and Schulte auf'm Erley, G. (2013). Does genotypic variation in nitrogen remobilisation efficiency contribute to nitrogen efficiency of winter oilseed-rape cultivars (Brassica napus L.) ? Plant and Soil, 371(1-2):463-471. 


\section{QTL mapping in semi-dwarf and normal type oilseed rape hybrids}

\subsection{Introduction}

Many agronomic traits are quantitatively controlled by several genes with different effects. The use of molecular marker for quantitative trait locus (QTL) analysis proved to be a powerful genetic approach to dissect complex traits (Paran and Zamir, 2003). One of the most complex traits is seed yield. Shi et al. (2009) identified more than 400 genomic regions directly or indirectly related to seed yield in oilseed rape. Forty-seven of these QTL were relevant for seed yield. It was demonstrated that many QTL for seed yield and yield related traits clustered into unique QTL with pleiotropic effect. However, only a few QTL studies in oilseed rape were conducted at different nitrogen levels (Gül, 2003; Miro, 2010).

The aim of this experiment is to detect genetic mechanisms controlling agronomic and nitrogen related traits at low and high nitrogen supply.

\subsection{Materials and Methods}

\subsubsection{Plant material and Experimental Design}

A doubled-haploid (DH) population (242 DH lines) derived from the cross 'Alesi-bzh' $\mathrm{x}$ 'H30' was produced. 'Alesi- $b z h$ ' is a dwarf isogenic line derived from the German winter oilseed cultivar 'Alesi' backcrossed (BC4) to the bzh dwarf mutant described by (Foisset et al., 1995). 'H30' is a normal type, resynthesized rapeseed line originating from a cross of Brassica rapa ssp.chinensis with Brassica napus ssp. napus var. pabularia with moderate winterhardiness (Girke, 2002). The DH population is segregating into dwarf and normal type lines. Furthermore, DH lines segregate for erucic acid content due to one erucic acid gene of the resynthesized parent 'H30'. All DH lines were crossed with a normal type, male sterile tester (canola quality) using the MSL ('Männliche Sterilität Lembke') hybrid system (Paulmann and Frauen, 1998). The resulting testcross hybrids (TC) segregate 
into semi-dwarf and normal types.

In season 2010/11 150 TC (75 semi-dwarfs and 75 normal types) were selected based on the availability of seeds and evaluated in two adjacent experiments. One experiment was harvested at the end of flowering (EOF) (BBCH 69, Lancashire et al. (1991)) and the second experiment at seed maturity (BBCH 89). Experiments were conducted at two sites near Einbeck (Ei) (brunic aerosol) and near Göttingen (Go) (alluvial meadow soil) in Central Germany. The plot sizes were $18 \mathrm{~m}^{2}$ in Einbeck and $11.25 \mathrm{~m}^{2}$ in Göttingen with plant densities of 50 and 90 plants $/ \mathrm{m}^{2}$, respectively. Both experiments were evaluated at low nitrogen (N0) supply, without additional nitrogen fertilization. Soil mineral nitrogen determined at the beginning of plant growth in spring was $35 \mathrm{~kg} \mathrm{~N} / \mathrm{ha}$ in Einbeck (Ei11) and $27 \mathrm{~kg} \mathrm{~N} /$ ha in Göttingen (Go11). All other agronomic treatments (except fertilization) were done according to recommendations for oilseed rape cultivation in Germany. Growth types were interlaced within each block by alternately growing one strip of semi-dwarfs and one strip of normal types. Experiments were designed as split-plot with growth type as main plot factor and genotypes as subplot factor. The experimental design was identical for both environments.

In season 2011/12 experiments from season 2010/11 were repeated using 108 TC (54 semi-dwarfs and 54 normal types). The $108 \mathrm{TC}$ were selected based on erucic acid content and seed yield in season 2010/11. For each growth type 27 TC with erucic acid (14 highest seed yield, 13 lowest seed yield) and the 27 TC without erucic acid (14 highest seed yield, 13 lowest seed yield) were selected. Hybrids were evaluated in two identical experiments at both sites (Göttingen and Einbeck). One experiment was harvested at the end of flowering (BBCH 69) and the second experiment at seed maturity (BBCH 89). Both experiments were conducted with two levels of nitrogen supply: low nitrogen supply (without nitrogen fertilization) and high nitrogen supply (fertilized with $177 \mathrm{~kg} \mathrm{~N} / \mathrm{ha}$ ). Mineral nitrogen in the soil was determined at the beginning of plant growth in spring in Einbeck $(27 \mathrm{~kg}$ N/ha) and Göttingen (27 kg N/ha). Both growth types were interlaced within each block and arranged in split-plot design. Genotypes within growth types were randomized in lattice design.

In season 2012/13 the 108 TC (54 semi-dwarfs and 54 normal types) were tested at two locations (Einbeck and Göttingen). In season 2012/13 all plots were harvested at seed maturity only. Field trials were conducted at two levels of nitrogen supply: low nitrogen supply (without nitrogen fertilization) and high nitrogen supply (fertilized with $177 \mathrm{~kg} \mathrm{~N} / \mathrm{ha}$ ). Mineral nitrogen in the soil at the beginning of plant growth in spring was determined in Göttingen ( $24 \mathrm{~kg} \mathrm{~N} / \mathrm{ha}$ ) only. Genotypes within growth types were randomized in lattice design. Both growth types were interlaced within each block and arranged in split-plot design. 
4 QTL mapping in semi-dwarf and normal type oilseed rape hybrids

Each season-site combination is considered as one environment and is addressed by location abbreviation and harvest year, such as Ei11 for Einbeck in the season 2010/2011.

\subsubsection{Genetic markers and linkage map}

In total $139 \mathrm{DH}$ lines (out of 150) used to produce TC were genotyped. In season 2011/12 and 2012/13 genotypic information was available for 100 (out of the 108 DH lines) used for TC production.

Genotyping was conducted using simple sequence repeat (SSR) and single nucleotide polymorphism (SNP) marker. The SSR marker (primer) labeled with prefix 'BRAS' and 'CB' were developed by Celera AgGen Brassica Consortium (Piquemal et al., 2005). SSR primer named with prefix 'MR' were developed by the Georg-August-Universität Göttingen (Uzunova and Ecke, 1999). The SNP marker are coded with prefix 'ra'. Complete marker data was provided by KWS SAAT AG.

The genome of Brassica napus contains homologous regions in the $\mathrm{A}$ and $\mathrm{C}$ genome, due to the amphidiploid structure of Brassica napus (Schranz et al., 2006). Therefore, some SSR primer pairs amplify more than one locus. These primer pairs are labelled with an additional letter at the end to distinguish different loci.

Genetic linkage map was constructed with MAPMAKER / EXP 3.0b (Lander et al., 1987). A pearl-script that automates the mapping process by controlling MAPMAKER / EXP 3.0b was used (Ecke, personal communication). Recombination frequencies were converted by Kosambi mapping function into genetic distances given in centi Morgan (cM) (Kosambi, 1943). A subset of markers was used to construct a 'high fidelity' map with marker orders supported by a minimum LOD of 3.0 and a maximum genetic distance of $35 \mathrm{cM}$ between adjacent markers on a linkage group (LG). Remaining markers were fitted into the high fidelity map by 'order' and 'try' command. A $\chi^{2}$ test $(\mathrm{P}=0.05)$ was used to check for deviations from Mendelian segregation ratios (1:1 or 3:1) at each marker locus. Linkage groups were named according to the AC nomenclature (Choi et al., 2007). Linkage groups A01 - A10 correspond to the A-genome chromosomes derived from Brassica rapa and C01 - C09 correspond to the C-genome chromosomes from Brassica oleracea.

Linkage groups with marker names and position in $\mathrm{cM}$ were drawn using MapChart 2.2 (Voorrips, 2002).

\subsubsection{Statistical analysis}

Analyses of variance (ANOVA) and heritabilities $\left(h^{2}\right)$ were calculated using PLABSTAT software (Version 3B) (Utz, 2001). 
ANOVA within each N-level was performed across environments using the following model:

$$
Y_{i j k}=\mu+e_{i}+b_{i j}+g_{k}+e g_{i k}+\epsilon_{i j k}
$$

where $Y_{i j k}$ is the observation of a genotype $(k)$ at environment $(i)$ in block $(j)$ within environment $(i)$. The interaction effect of environment and genotype is denoted by $e g_{i k}$. The error is denoted by $\left(\epsilon_{i j k}\right)$. The general mean is designated by $\mu$. The factors environment, block and genotype were considered as random.

\subsubsection{QTL mapping}

Location of putative QTL and estimation of their genetic effects was calculated by composite interval mapping (CIM) (Zeng, 1994) implemented in Windows QTL Cartographer 2.5 (Wang et al., 2006). According to Cowen (1988) it is appropriate to use an additive genetic model to analyse TC progenies. According to Schön et al. (1994) the corresponding model can be written as:

$$
Y_{i}=\mu_{P 1}+k_{j} a+\epsilon_{j}
$$

where $Y_{i}$ is the phenotypic trait value of TC line $\mathrm{j}, \mu_{P 1}$ mean phenotypic trait value of TC carrying the allele from parent 1 ('Alesi-bzh') at the QTL, $k_{j}$ indicator variable depending on the parental genotype at the QTL: 0 if parental DH line carries allele from parent 1 or 1 if parental DH line carries allele from parent 2 ('H30'). The average effect of substituting allele from P1 by allele of P2 at the QTL is designated with $a$. The variation of the trait not controlled by the QTL is indicated by $\epsilon_{j}$.

The software Windows QTL Carthographer 2.5 was used for QTL mapping (Wang et al., 2006). The CIM procedure use markers as cofactors to eliminate effects of other QTL located in other regions of the same chromosome that harbours a putative QTL (Rifkin, 2012). Including cofactors reduce the confidence interval of the putative QTL position and increase the power of QTL detection. Default values of 5 control markers and $10 \mathrm{cM}$ for window size were used as parameters for 'Model-6'. The window size will exclude a region of $10 \mathrm{cM}$ on either side of the markers flanking the test site The flanking regions are tightly linked to the testing site and would eliminate the signal from the test site itself. The threshold LOD score for detecting a significant QTL was determined 
4 QTL mapping in semi-dwarf and normal type oilseed rape hybrids

individually for every trait by permutation analysis (500 permutations). The confidence interval of a QTL is determined by the interval in which the LOD decreases by 1.0 relative to the maximum LOD score (most likely position of a QTL). QTL on one linkage group with overlapping confidence intervals between years and/or traits were considered as the same QTL.

QTL mapping was performed with mean values for 17 traits from individual environments and means across environments for each nitrogen level. The traits analysed were described in detail in chapter 2 and chapter 3. 
4 QTL mapping in semi-dwarf and normal type oilseed rape hybrids

\subsection{Results}

\subsubsection{Genetic linkage map}

A total of 541 (432 SNP, 109 SSR) polymorphic marker loci were identified in the 'Alesibzh $\mathrm{x}$ H30' population. A proportion of 55 markers (39 SNP, 16 SSR) showed a significant deviation $(\mathrm{P}=0.05)$ from the expected segregation ratio. The final linkage map includes 437 markers (392 SNP, 45 SSR) distributed on 22 linkage groups (LGs) with a total map length of $1301 \mathrm{cM}$ (Kosambi). The number and density of markers differed considerably between the LGs, ranging from 2 markers on LG 22 up to 52 on LG C06 (Tab. 4.1). In total 157 marker loci co-segregated with other markers on the map. Twenty-one LGs could be assigned to the 19 chromosomes of Brassica napus. Two linkage groups (LG C04 and LG C05) are split into two subgroups. The full linkage map is shown in the appendix A.

The linkage groups $A 01-A 10$ represent the A-genome (Brassica rapa), while LG C01 - C09 belong to the C-genome (Brassica oleracea) (Choi et al., 2007). The small LG 22 with two markers only, could not be assigned to any of the 19 chromosomes of Brassica napus. The SNP marker (SNP-bzhrga1) inside the dwarf gene Bzh was mapped to the distal part of LG A06 (3 cM). This is in accordance with other linkage maps (Breuer personal communication).

Table 4.1: Genetic linkage map with length and number of markers per linkage group

\begin{tabular}{lrrlrr}
\hline $\begin{array}{c}\text { Linkage } \\
\text { group }\end{array}$ & $\begin{array}{c}\text { Length } \\
{[\mathbf{c M}]}\end{array}$ & $\begin{array}{c}\text { Number of } \\
\text { marker }\end{array}$ & $\begin{array}{c}\text { Linkage } \\
\text { group }\end{array}$ & $\begin{array}{c}\text { Length } \\
{[\mathbf{c M}]}\end{array}$ & $\begin{array}{c}\text { Number of } \\
\text { marker }\end{array}$ \\
\hline & & & & & \\
A01 & 75.3 & 25 & C01 & 71.9 & 28 \\
A02 & 44.1 & 12 & C02 & 8.0 & 4 \\
A03 & 135.3 & 36 & C03 & 79.2 & 22 \\
A04 & 27.1 & 8 & C04a & 29.8 & 4 \\
A05 & 98.1 & 29 & C04b & 63.0 & 15 \\
A06 & 90.8 & 32 & C05a & 44.4 & 15 \\
A07 & 70.4 & 38 & C05b & 13.6 & 6 \\
A08 & 19.7 & 11 & C06 & 110.9 & 52 \\
A09 & 80.7 & 18 & C07 & 54.5 & 22 \\
A10 & 59.7 & 12 & C08 & 38.4 & 15 \\
LG22 & 6.9 & 2 & C09 & 79.1 & 20 \\
\hline
\end{tabular}

centi Morgan (cM) 


\subsubsection{QTL at low nitrogen supply}

\section{QTL at individual environments with low nitrogen supply}

Analysis of variance (ANOVA) revealed significant genotypic variation for all traits, except protein content, nitrogen uptake EOF and nitrogen uptake efficiency EOF (Tab. 4.2). Significant genotype by environment interactions were detected for all traits, except nitrogen harvest index. Heritabilities ranged from 0.11 (Nitrogen uptake EOF) to 0.74 (Nitrogen utilization and Nitrogen use efficiency). The heritability for seed yield was rather low $\left(h^{2}=0.20\right)$.

Six QTL in four individual environments were detected for begin of flowering. The high-

Table 4.2: Variance components and heritabilities at low nitrogen supply (six environments, 100 genotypes)

\begin{tabular}{|c|c|c|c|c|c|}
\hline Source & $\mathbf{E}$ & $\mathrm{B}$ & $\mathrm{G}$ & $\mathbf{G} \times \mathbf{E}$ & $h^{2}$ \\
\hline Df & 5 & 6 & 99 & 495 & \\
\hline Begin of flowering (days) & $60.52 * *$ & $0.02 * *$ & $0.13 * *$ & $0.44 * *$ & 0.56 \\
\hline Plant height $(\mathrm{cm})$ & $147.48 * *$ & $0.26+$ & $72.82 * *$ & $153.30 * *$ & 0.72 \\
\hline Seed yield $(\mathrm{dt} / \mathrm{ha})^{\mathrm{a}}$ & $64.64 * *$ & $0.32 * *$ & $0.26+$ & $3.21 * *$ & 0.20 \\
\hline Straw yield $(\mathrm{dt} / \mathrm{ha})^{\mathrm{a}}$ & $90.60 *$ & $20.38 * *$ & $4.29 * *$ & $10.74 * *$ & 0.51 \\
\hline Harvest index $\mathrm{b}$ & $0.67 * *$ & $0.03^{* *}$ & $0.05 * *$ & $0.11^{* *}$ & 0.57 \\
\hline Thousand seed weight (g) & $0.03^{* *}$ & $0.01 * *$ & $0.01 * *$ & $0.03 * *$ & 0.60 \\
\hline Oil content $(\%)$ & $1.70^{* *}$ & $0.15^{* *}$ & $0.39 * *$ & $0.60 * *$ & 0.67 \\
\hline Protein content $(\%)$ & $1.49^{* *}$ & $0.05^{* *}$ & $0.01 \mathrm{~ns}$ & $0.14 * *$ & 0.14 \\
\hline Nitrogen uptake EOF $(\mathrm{kg} \mathrm{N} / \mathrm{ha})^{\mathrm{b}}$ & $828.28 * *$ & $4.62 * *$ & $2.51 \mathrm{~ns}$ & $25.20 * *$ & 0.11 \\
\hline Nitrogen uptake maturity $(\mathrm{kg} \mathrm{N} / \mathrm{ha})^{a}$ & $198.23 *$ & $14.82 * *$ & $18.04 * *$ & $28.31 * *$ & 0.38 \\
\hline Nitrogen content straw $(\%)^{\mathrm{c}}$ & $0.26 *$ & $0.03 * *$ & 0 & $0.04 *$ & - \\
\hline Nitrogen harvest index ${ }^{\mathrm{d}}$ & $0.17+$ & $0.03 * *$ & $0.13 * *$ & $0.01 \mathrm{~ns}$ & 0.73 \\
\hline Nitrogen uptake efficiency EOF ${ }^{b}$ & $0.05 \mathrm{~ns}$ & $0.15^{* *}$ & $0.03 \mathrm{~ns}$ & $0.31 * *$ & 0.13 \\
\hline Nitrogen uptake efficiency ${ }^{d}$ & $0.40^{* *}$ & 0 & $0.33 * *$ & $0.31 * *$ & 0.49 \\
\hline Nitrogen utilization efficiency ${ }^{d}$ & $350.66 *$ & $34.11 * *$ & $209.98 * *$ & $31.11 *$ & 0.74 \\
\hline Nitrogen use efficiency ${ }^{d}$ & $862.95 * *$ & $7.88+$ & $594.54 * *$ & $169.93^{* *}$ & 0.74 \\
\hline
\end{tabular}

$* *, *,+$ Significant difference at $0.01,0.05,0.10$ probability level respectively; ns non-significant (F-test from ANOVA), negative variance components were set to zero, $\mathbf{E}$ environment, $\mathbf{B}$ block within environment, $\mathbf{G}$ genotype, $\boldsymbol{h}^{2}$ heritability, EOF end of flowering,

${ }^{a}$ five environments,

${ }^{b}$ four environments,

${ }^{c}$ three environments,

${ }^{d}$ two environments

est proportion of explained phenotypic variance was detected in Göttingen 2013 (78 \%) (Tab. 4.3). At the QTL on A07, C06 and C07 the allele from 'Alesi-bzh' delayed begin of flowering. At the other three QTL the allele had the opposite effect. 
4 QTL mapping in semi-dwarf and normal type oilseed rape hybrids

Table 4.3: Putative QTL for agronomic traits at low nitrogen supply (six environments, 100 genotypes)

\begin{tabular}{|c|c|c|c|c|c|c|c|}
\hline Env. & QTL & LG & $\mathrm{CI}[\mathrm{cM}]$ & Pos. $[\mathrm{cM}]$ & LOD & Effect & $\mathbf{R}^{2}$ \\
\hline \multicolumn{8}{|c|}{ Begin of flowering [days] } \\
\hline Ei13 & $B F L-A 01$ & A 01 & $19.4-36.1$ & 32.5 & 4.32 & 0.35 & 0.14 \\
\hline Ei13 & $B F L-A 03$ & A03 & $62.3-74.4$ & 68.8 & 3.15 & 0.28 & 0.09 \\
\hline Go13 & $B F L-A 06$ & A06 & $1.4-5.2$ & 3.0 & 39.24 & 0.53 & 0.78 \\
\hline Go11 & $B F L-A 07$ & $\mathrm{~A} 07$ & $65.0-69.3$ & 68.3 & 4.1 & -0.25 & 0.10 \\
\hline Ei13 & $B F L-C 06$ & $\mathrm{C} 06$ & $54.0-72.7$ & 64.9 & 3.23 & -0.29 & 0.10 \\
\hline Ei12 & $B F L-C 07$ & $\mathrm{C} 07$ & $0.0-7.0$ & 1.0 & 5.36 & -0.56 & 0.18 \\
\hline \multicolumn{8}{|c|}{ Plant height [cm] } \\
\hline Ei11 & $P H-A 06$ & A06 & $0.0-2.6$ & 1.0 & 54.0 & 10.30 & 0.79 \\
\hline Go12 & $P H-A 06$ & A06 & $1.9-5.2$ & 3.0 & 72.0 & 9.93 & 0.93 \\
\hline Ei12 & $P H-A 06$ & A06 & $1.4-5.2$ & 3.0 & 65.4 & 18.75 & 0.90 \\
\hline Go13 & $P H-A 06$ & A06 & $1.4-5.2$ & 3.0 & 87.0 & 14.90 & 0.93 \\
\hline Ei13 & $P H-A 06$ & A06 & $3.5-9.0$ & 5.0 & 48.2 & 16.66 & 0.87 \\
\hline Ei12 & $\mathrm{PH}-\mathrm{CO} 3$ & $\mathrm{C} 03$ & $41.0-62.4$ & 51.3 & 3.6 & -1.91 & 0.01 \\
\hline Ei13 & $\mathrm{PH}-\mathrm{CO} 3$ & $\mathrm{C} 03$ & $59.4-78.1$ & 71.1 & 3.0 & -2.63 & 0.02 \\
\hline Ei12 & $P H-A 03$ & A03 & $93.2-114.6$ & 102.5 & 3.4 & 1.99 & 0.01 \\
\hline \multicolumn{8}{|c|}{ Seed yield $[\mathrm{dt} / \mathrm{ha}]^{\mathrm{a}}$} \\
\hline Ei11 & Seed-A06 & A06 & $2.6-36.3$ & 20.0 & 3.4 & -0.57 & 0.09 \\
\hline Go11 & Seed-A06 & A06 & $0.0-2.1$ & 1.0 & 26.1 & -2.39 & 0.54 \\
\hline Go12 & Seed-A06 & A06 & $1.3-10.1$ & 3.0 & 19.8 & -1.20 & 0.48 \\
\hline Go13 & Seed-A06 & A06 & $1.0-12.2$ & 3.0 & 11.2 & -1.57 & 0.33 \\
\hline Ei11 & Seed-C07 & $\mathrm{C} 07$ & $40.2-51.0$ & 47.1 & 2.9 & 0.51 & 0.08 \\
\hline Go11 & Seed-C09 & C09 & $47.4-55.8$ & 48.7 & 4.2 & -0.76 & 0.05 \\
\hline \multicolumn{8}{|c|}{ Straw yield $[\mathrm{dt} / \mathrm{ha}]^{\mathrm{a}}$} \\
\hline Go11 & Straw-A06 & A06 & $0.0-2.3$ & 0.0 & 4.2 & -0.02 & 0.12 \\
\hline Go12 & Straw-A06 & A06 & $0.0-12.2$ & 0.0 & 9.4 & 1.57 & 0.26 \\
\hline Ei13 & Straw-A06 & A06 & $2.8-14.6$ & 7.0 & 18.5 & 0.51 & 0.53 \\
\hline Go13 & Straw-A06 & A06 & $0.0-2.9$ & 0.0 & 11.3 & 2.76 & 0.36 \\
\hline \multicolumn{8}{|c|}{ Harvest index $b$} \\
\hline Go12 & $H I-A 06$ & A06 & $3.0-8.1$ & 4.0 & 25.5 & -0.04 & 0.53 \\
\hline Ei13 & $H I-A 06$ & A06 & $3.0-16.0$ & 8.0 & 15.7 & -0.03 & 0.46 \\
\hline Go13 & $H I-A 06$ & A06 & $0.7-3.8$ & 2.0 & 21.4 & -0.03 & 0.52 \\
\hline Ei13 & $H I-A 07$ & $\mathrm{~A} 07$ & $46.2-56.3$ & 50.7 & 4.5 & -0.02 & 0.09 \\
\hline Go13 & $H I-A 0^{r}$ & $\mathrm{~A} 07$ & $55.7-65.3$ & 55.8 & 3.5 & -0.01 & 0.06 \\
\hline
\end{tabular}

Env environment, LG linkage group, CI LOD-1 confidence intervals in centi Morgan (cM), Pos position with highest LOD, LOD maximum LOD score, Effect effect of substituting allele of $\mathrm{P} 1$ by allel of $\mathrm{P} 2$ in the TC, $\mathbf{R}^{2}$ proportion of phenotypic variance explained by the QTL,

${ }^{a}$ five environments,

${ }^{b}$ three environments 
Two QTL were detected. The QTL PH-A06 was detected in five environments in an interval from $0.0 \mathrm{cM}$ to $9.0 \mathrm{cM}$ at the distal part of LG A06. The phenotypic variance for plant height by $\mathrm{PH}$-A06 ranged from $79 \%$ to $93 \%$. Confidence intervals overlapped among all five environments. The second QTL PH-C03 was detected in Einbeck only. Three putative QTL were discovered for seed yield on LG A06, C07 and C09. The QTL on LG A06 was detected in four environments with overlapping confidence intervals. The QTL Seed-A06 explained between $9 \%$ and $54 \%$ of phenotypic variation in seed yield. For the QTL Seed-A06 and Seed-C09 the 'Alesi-bzh' allele increased seed yield while it had a decreasing effect at Seed-C0\%.

One QTL for straw yield was detected in four individual environments. In Göttingen 2011 the 'Alesi-bzh' allele increased straw yield, while it had an decreasing effect in the other environments. Two QTL on LG A06 and A07 were identified for harvest index. At both QTL the 'Alesi-bzh' allele had an increasing effect on harvest index. The QTL $H I-A 07$ was detected only detected in the year 2013 and accounted for $6 \%$ of phenotypic variation in Einbeck 2013 and 9 \% in Göttingen 2013.

Five QTL were detected for thousand seed weight (TSW) (Tab. 4.4). The QTL on LG A01 (TSW-A01) explained between $7 \%$ and $12 \%$ of phenotypic variation in thousand seed weight. The QTL on A06 (TSW-A06) was detected in three environments and had the strongest effect on TSW. The QTL LG A07 was only detected in Einbeck 2013 and Göttingen 2013. The fifth QTL (TSW-C01) was located on LG C01 and explained $7 \%$ to $15 \%$ of variation in TSW. The QTL on LG C04b was only detected in the year 2011 (Tab. 4.4). Three QTL were detected for oil content. The allele from 'H30' at QTL Oil\%-A08 increased oil content by nearly $1 \%$. The effect of this QTL accounted for 43 $\%$ to $57 \%$ of the phenotypic variation in oil content. The QTL on LG A05 was detected in Einbeck 2012 only. The QTL on LG A06 was identified in the year 2011 only.

Most of the traits in Table 4.5 were only determined in Göttingen 2011 and 2012. Two QTL for nitrogen uptake EOF were detected on LG A06 and C06 (Tab. 4.5). Nitrogen uptake maturity was influenced by two QTL on LG C06. Both QTL were detected in Göttingen 2012 only. Three QTL were identified for the difference in nitrogen uptake between maturity and end of flowering. Two QTL were detected for nitrogen content of straw in Göttingen 2011 and Einbeck 2012. Nitrogen harvest index, nitrogen uptake efficiency EOF, Nitrogen uptake efficiency and nitrogen utilization efficiency were all influenced by a QTL on LG A06 (Tab. 4.5). Confidence intervals for nitrogen harvest index and nitrogen uptake efficiency overlapped between Göttingen 2011 and 2012. Four QTL were detected for nitrogen use efficiency (NUE). The allele from 'Alesi- $b z h$ ' increased NUE at QTL NUE-A06 and NUE-C09 while it decreased NUE at the other two QTL. 
4 QTL mapping in semi-dwarf and normal type oilseed rape hybrids

Table 4.4: Putative QTL for thousand seed weight, oil content and protein content at low nitrogen supply (six environments, 100 genotypes)

\begin{tabular}{|c|c|c|c|c|c|c|c|}
\hline Env. & QTL & LG & CI $[\mathbf{c M}]$ & Pos. $[\mathrm{cM}]$ & LOD & Effect & $\mathbf{R}^{2}$ \\
\hline \multicolumn{8}{|c|}{ Thousand seed weight $[\mathrm{g}]$} \\
\hline Ei12 & $T S W-A 01$ & A01 & $0.0-9.8$ & 0.0 & 4.0 & 0.08 & 0.12 \\
\hline Go12 & $T S W-A 01$ & A01 & $0.0-8.3$ & 0.0 & 3.7 & 0.07 & 0.09 \\
\hline Ei13 & $T S W-A 01$ & A01 & $1.1-22.9$ & 9.8 & 3.2 & 0.06 & 0.07 \\
\hline Go13 & $T S W-A 01$ & A01 & $8.3-23.0$ & 14.1 & 5.0 & 0.07 & 0.09 \\
\hline Go12 & $T S W-A 06$ & A06 & $0.0-15.2$ & 3.0 & 6.0 & 0.09 & 0.15 \\
\hline Ei13 & $T S W-A 06$ & A06 & $1.0-12.2$ & 3.0 & 11.0 & 0.11 & 0.27 \\
\hline Go13 & $T S W-A 06$ & A06 & $1.1-13.1$ & 3.0 & 16.0 & 0.14 & 0.36 \\
\hline Ei13 & $T S W-A 07$ & A07 & $58.3-69.3$ & 65.3 & 6.2 & 0.08 & 0.13 \\
\hline Go13 & $T S W-A 07$ & A07 & $58.3-69.3$ & 66.3 & 5.1 & 0.07 & 0.09 \\
\hline Go11 & $T S W-C 01$ & C01 & $40.2-60.9$ & 40.8 & 3.1 & 0.08 & 0.07 \\
\hline Ei12 & $T S W-C 01$ & C01 & $40.7-64.3$ & 48.8 & 2.8 & 0.07 & 0.09 \\
\hline Go12 & $T S W-C 01$ & C01 & $46.4-64.9$ & 50.9 & 4.3 & 0.08 & 0.11 \\
\hline Ei13 & $T S W-C 01$ & C01 & $45.4-58.9$ & 50.8 & 6.1 & 0.08 & 0.13 \\
\hline Go13 & $T S W-C 01$ & $\mathrm{C} 01$ & $47.6-57.4$ & 50.9 & 8.2 & 0.13 & 0.15 \\
\hline Ei11 & $T S W-C 04 b$ & $\mathrm{C} 04 \mathrm{~b}$ & $3.0-20.5$ & 3.6 & 2.9 & -0.09 & 0.06 \\
\hline Go11 & $T S W-C 04 b$ & $\mathrm{C} 04 \mathrm{~b}$ & $0.0-3.3$ & 2.0 & 4.3 & -0.11 & 0.10 \\
\hline \multicolumn{8}{|c|}{ Oil content $[\%]$} \\
\hline Ei12 & Oil\%-A05 & A05 & $0.0-7.0$ & 3.7 & 3.6 & 0.44 & 0.13 \\
\hline Ei11 & Oil\%-A06 & A06 & $0.0-2.5$ & 1.0 & 5.8 & 0.32 & 0.06 \\
\hline Go11 & Oil\%-A06 & A06 & $0.0-36.3$ & 3.0 & 3.5 & 0.26 & 0.05 \\
\hline Ei11 & $O i l \%-A 08$ & A08 & $0.0-4.2$ & 0.0 & 29.8 & 0.97 & 0.52 \\
\hline Go11 & Oil\%-A08 & A08 & $0.0-4.2$ & 2.0 & 20.6 & 0.74 & 0.43 \\
\hline Go12 & Oil\%-A08 & A08 & $1.8-6.6$ & 4.0 & 22.4 & 0.85 & 0.55 \\
\hline Ei13 & Oil\%-A08 & A08 & $2.9-7.8$ & 4.8 & 15.5 & 0.99 & 0.44 \\
\hline Go13 & Oil\%-A08 & $\mathrm{A} 08$ & $3.1-8.3$ & 4.8 & 26.1 & 0.96 & 0.57 \\
\hline \multicolumn{8}{|c|}{ Protein content [\%] } \\
\hline Go12 & Pro\%-A06 & $\mathrm{A} 06$ & $0.7-10.2$ & 3.0 & 11.8 & 0.28 & 0.31 \\
\hline Go13 & Pro\%-A06 & A06 & $5.6-18.0$ & 10.0 & 9.3 & 0.32 & 0.37 \\
\hline Ei11 & Pro\%-A08 & $\mathrm{A} 08$ & $0.0-17.8$ & 16.8 & 2.8 & -0.13 & 0.06 \\
\hline
\end{tabular}

Env environment, LG linkage group, CI LOD-1 confidence intervals in centi Morgan (cM), Pos position with highest LOD, LOD maximum LOD score, Effect effect of substituting allele of P1 by allel of P2 in the TC, $\mathbf{R}^{2}$ proportion of phenotypic variance explained by the QTL 
4 QTL mapping in semi-dwarf and normal type oilseed rape hybrids

Table 4.5: Putative QTL for nitrogen related traits at low nitrogen supply (four environments, 100 genotypes)

\begin{tabular}{lccccccc}
\hline Env. & QTL & LG & CI $[\mathbf{c M}]$ & Pos. $[\mathbf{c M}]$ & LOD & Effect & $\mathbf{R}^{2}$ \\
\hline Nitrogen uptake EOF $[\mathrm{kg}$ N/ha] & & & & \\
Go11 & NkgEOF-A06 & A06 & $0.0-2.6$ & 1.0 & 3.5 & 3.90 & 0.10 \\
Ei12 & NkgEOF-A06 & A06 & $0.0-22.4$ & 11.0 & 6.5 & 2.54 & 0.27 \\
Ei12 & NkgEOF-C06 & C06 & $78.8-85.4$ & 79.7 & 3.2 & 1.51 & 0.10 \\
Nitrogen uptake maturity & {$[\mathrm{kg} \mathrm{N} / \mathbf{h a}]$} \\
a & & & & \\
Go12 & NkgMat-C06 & C06 & $0.8-11.6$ & 3.0 & 7.4 & -2.07 & 0.21 \\
Go12 NkgMat-C06 & C06 & $64.5-70.2$ & 67.5 & 4.8 & 1.63 & 0.13
\end{tabular}

$\begin{array}{llllllll}\text { Go12 NkgMat-C06 } & \text { C06 } & 64.5-70.2 & 67.5 & 4.8 & 1.63 & 0.13\end{array}$

Nitrogen uptake difference maturity - EOF [kg N/ha] ${ }^{\text {a }}$

$\begin{array}{lllcccrc}\text { Go11 } & \text { Ndiff-A06 } & \text { A06 } & 0.0-2.0 & 1.0 & 14.7 & -9.30 & 0.34 \\ \text { Go12 } & \text { Ndiff-A06 } & \text { A06 } & 0.9-10.4 & 3.0 & 18.0 & -0.14 & 0.48 \\ \text { Go11 } & \text { Ndiff-C19 } & \text { C19 } & 71.0-75.4 & 73.7 & 3.3 & 3.91 & 0.06\end{array}$

Nitrogen content straw [\%] b

$\begin{array}{lllccccc}\text { Go11 } & \text { N\%straw-A06 } & \text { A06 } & 0.0-2.9 & 0.0 & 4.2 & -0.02 & 0.12 \\ \text { Ei12 } & \text { N\%straw-A09 } & \text { A09 } & 4.5-14.9 & 11.9 & 3.2 & -0.03 & 0.12\end{array}$

Nitrogen harvest index ${ }^{\text {a }}$

$\begin{array}{llllllll}\text { Go11 } & \text { NHI-A06 } & \text { A06 } & 0.0-2.1 & 0.0 & 21.2 & -0.04 & 0.46 \\ \text { Go12 } & \text { NHI-A06 } & \text { A06 } & 0.9-9.0 & 3.0 & 17.4 & -0.03 & 0.47\end{array}$

\section{Nitrogen uptake efficiency EOF}

$\begin{array}{llllllll}\text { Go11 NupEOF-A06 A06 } & 0.0-2.6 & 0.0 & 3.54 & 0.03 & 0.09\end{array}$

Nitrogen uptake efficiency ${ }^{\text {a }}$

$\begin{array}{llllllll}\text { Go11 } & \text { Nup-A06 } & \text { A06 } & 0.0-2.0 & 1.0 & 11.5 & -0.06 & 0.28 \\ \text { Go12 } & \text { Nup-A06 } & \text { A06 } & 0.8-11.8 & 3.0 & 7.5 & -0.04 & 0.22\end{array}$

Nitrogen utilization efficiency ${ }^{a}$

$\begin{array}{lllllll}\text { Go12 Nut-A06 } & \text { A06 } & 0.9-8.5 & 3.0 & 19.1 & -1.40 & 0.48\end{array}$

Nitrogen use efficiency ${ }^{a}$

\begin{tabular}{lllcccrc} 
Go11 & NUE-A06 & A06 & $0.0-2.2$ & 1.0 & 25.1 & -2.46 & 0.51 \\
Go11 & NUE-C06 & C06 & $65.9-79.3$ & 67.5 & 3.0 & 0.67 & 0.04 \\
Go12 & NUE-C08 & C08 & $13.3-22.5$ & 19.3 & 3.5 & 1.54 & 0.13 \\
Go11 & NUE-C09 & C09 & $20.3-55.7$ & 48.7 & 3.1 & -0.69 & 0.04 \\
\hline
\end{tabular}

Env environment, LG linkage group, CI LOD-1 confidence intervals in centi Morgan (cM), Pos position with highest LOD, LOD maximum LOD score, Effect effect of substituting allele of $\mathrm{P} 1$ by allel of $\mathrm{P} 2$ in the TC, $\mathbf{R}^{2}$ proportion of phenotypic variance explained by the QTL, EOF end of flowering,

${ }^{a}$ two environments,

$b$ three environments 


\section{QTL across environments with low nitrogen supply}

The analysis of QTL across environments with low nitrogen supply identified three QTL for begin of flowering on LG A01, A07 and C06 (Tab. 4.6). The 'Alesi- $b z h$ ' allele at BFL$A 07$ and BFL-C06 delayed begin of flowering. At BFL-A01 it had the opposite effect. All three QTL together explained $39 \%$ of phenotypic variance in begin of flowering. Plant height was affected by two QTL on LG A03 and A06. The QTL A06 explained the majority $(93 \%)$ of phenotypic variation in plant height.

Table 4.6: Putative QTL for agronomic traits across six environments with low nitrogen supply (100 genotypes)

\begin{tabular}{lcccccc}
\hline QTL & LG & CI [cM] & Pos.[cM] & LOD & Effect & $\mathbf{R}^{2}$ \\
\hline Begin of flowering [days] & & & & \\
BFL-A01 & A01 & $27.3-39.9$ & 31.5 & 4.7 & 0.23 & 0.16 \\
BFL-A07 & A07 & $24.3-50.1$ & 37.8 & 2.8 & -0.18 & 0.08 \\
BFL-C06 & C06 & $60.9-72.8$ & 64.9 & 4.6 & -0.23 & 0.15 \\
Plant heigth [cm] & & & & \\
PH-A03 & A03 & $93.0-113.1$ & 102.5 & 3.3 & 1.10 & 0.01 \\
PH-A06 & A06 & $1.4-5.2$ & 3.0 & 78.9 & 14.41 & 0.93 \\
Seed yield [dt/ha] a & & & & \\
Seed-A06 & A06 & $1.2-11.4$ & 5.0 & 20.1 & -1.03 & 0.45 \\
Seed-A07 & A07 & $51.4-65.3$ & 57.8 & 4.7 & -0.42 & 0.07 \\
Seed-A10 & A10 & $24.0-39.9$ & 31.5 & 4.6 & -0.40 & 0.07 \\
Seed-C06 & C06 & $54.0-74.2$ & 65.9 & 3.4 & 0.34 & 0.05 \\
Straw yield [dt/ha] a & & & & \\
Straw-A02 & A02 & $14.4-38.7$ & 25.5 & 3.2 & 0.68 & 0.04 \\
Straw-A06 & A06 & $0.0-4.0$ & 0.0 & 24.8 & 2.39 & 0.56 \\
Straw-C07 & C07 & $30.1-38.0$ & 34.5 & 3.5 & -0.70 & 0.05 \\
Harvest index b & & & & & \\
HI-A06 & A06 & $0.8-3.1$ & 2.0 & 39.7 & -0.04 & 0.74 \\
HI-A07 & A07 & $52.3-62.5$ & 55.8 & 3.9 & -0.01 & 0.03 \\
HI-A08 & A08 & $0.0-12.6$ & 4.8 & 3.5 & 0.01 & 0.03 \\
HI-C06 & C06 & $50.3-63.3$ & 55.7 & 4.9 & 0.01 & 0.04 \\
\hline
\end{tabular}

Env environment, LG linkage group, CI LOD-1 confidence intervals in centi Morgan (cM), Pos position with highest LOD, LOD maximum LOD score, Effect effect of substituting allele of P1 by allel of P2 in the TC, $\mathbf{R}^{2}$ proportion of phenotypic variance explained by the QTL,

${ }^{a}$ five environments,

${ }^{b}$ four environments 
Four QTL were detected for seed yield. The 'Alesi-bzh' allele had an increasing effect at the QTL Seed-A06, Seed-A07 and Seed-A10. The QTL Seed-A06 accounted for $45 \%$ of variance in seed yield. The other three QTL explained $19 \%$ of phenotypic variance in seed yield.

Straw yield was influenced by three QTL on LG A02, A06 and C07. The three QTL explained $65 \%$ of phenotypic variance in straw yield. The 'Alesi- $b z h$ ' allele decreased straw yield at Straw-A02 and A06 while it had an increasing effect at Straw-C0\%.

Four QTL were detected for harvest index. The QTL on LG A06 explained most (74 \%) of the phenotypic variance in harvest index. The other three QTL accounted for $10 \%$ of phenotypic variance together.

Thousand seed weight was influenced by four QTL on LG A01, A06, C01 and C02 (Tab. 4.7). These QTL explained $54 \%$ of phenotypic variance in thousand seed weight together.

Table 4.7: Putative QTL for thousand seed weight, oil yield, oil content and protein content across six environments with low nitrogen supply (100 genotypes)

\begin{tabular}{|c|c|c|c|c|c|c|}
\hline QTL & LG & CI $[\mathbf{c M}]$ & Pos. $[\mathrm{cM}]$ & LOD & Effect & $\mathbf{R}^{2}$ \\
\hline \multicolumn{7}{|c|}{ Thousand seed weight $[\mathrm{g}]$} \\
\hline$T S W-A 01$ & $\mathrm{~A} 01$ & $0.0-12.1$ & 4.0 & 4.3 & 0.06 & 0.10 \\
\hline$T S W-A 06$ & A06 & $0.9-18.2$ & 5.0 & 5.8 & 0.07 & 0.15 \\
\hline$T S W-C 01$ & $\mathrm{C} 01$ & $47.4-60.5$ & 52.9 & 7.4 & 0.08 & 0.20 \\
\hline$T S W-C 02$ & $\mathrm{C} 02$ & $0.0-6.4$ & 3.0 & 4.0 & -0.06 & 0.09 \\
\hline \multicolumn{7}{|c|}{ Oil content $[\%]$} \\
\hline$O i l \%-A 01$ & A01 & $60.5-74.0$ & 66.0 & 2.8 & -0.16 & 0.03 \\
\hline Oil\%-A06 & A06 & $0.0-2.0$ & 0.0 & 6.9 & 0.27 & 0.08 \\
\hline Oil\%-A08 & A08 & $3.0-7.1$ & 4.9 & 27.5 & 0.79 & 0.66 \\
\hline$O i l \%-C 01$ & $\mathrm{C} 01$ & $35.7-49.5$ & 41.8 & 4.0 & 0.21 & 0.04 \\
\hline \multicolumn{7}{|c|}{ Protein content [\%] } \\
\hline Pro\%-A01 & A01 & $61.0-74.0$ & 70.0 & 2.9 & 0.11 & 0.09 \\
\hline Pro\%-А0З & A03 & $121.3-133.3$ & 131.3 & 4.5 & 0.14 & 0.14 \\
\hline
\end{tabular}

Env environment, LG linkage group, CI LOD-1 confidence intervals in centi Morgan (cM), Pos position with highest LOD, LOD maximum LOD score, Effect effect of substituting allele of P1 by allel of P2 in the TC, $\mathbf{R}^{2}$ proportion of phenotypic variance explained by the QTL 
Oil content was influenced by four QTL on LG A01, A06, A08 and C01. The QTL Oil\%-A08 accounted for $66 \%$ of phenotypic variance in oil content. The allele of 'H30' increased oil content by $0.79 \%$.

Two QTL on LG A01 and A03 were detected for protein content. Both QTL accounted for $23 \%$ of phenotypic variance.

No QTL was detected for nitrogen uptake EOF (Tab. 4.8). One QTL on LG A06 was identified for nitrogen uptake at maturity. The 'Alesi- $b z h$ ' allele increased $N$ uptake maturity by about $4 \mathrm{~kg} \mathrm{~N} /$ ha. Nitrogen content of straw was influenced by a QTL on LG C01. Three QTL were detected for nitrogen harvest index. The QTL NHI-A06 accounted for $60 \%$ of variance in nitrogen harvest index with an increasing effect of the allele from 'Alesi-bzh'. One QTL on LG A05 was detected for nitrogen uptake efficiency EOF. A QTL on LG A06 explained most of the phenotypic variance in nitrogen uptake efficiency, nitrogen utilization efficiency and nitrogen use efficiency. Two other QTL with minor effects on nitrogen utilization efficiency were detected on LG C01 and C06. Nitrogen use efficiency was influenced by a second QTL on LG A07. The allele of 'Alesi-bzh' increased nitrogen use efficiency at both QTL. 
4 QTL mapping in semi-dwarf and normal type oilseed rape hybrids

Table 4.8: Putative QTL for nitrogen related traits across four environments with low nitrogen supply (100 genotypes)

\begin{tabular}{ccccccc}
\hline QTL & LG & CI $[\mathrm{cM}]$ & Pos. $[\mathrm{cM}]$ & LOD & Effect & $\mathbf{R}^{2}$ \\
\hline
\end{tabular}

Nitrogen uptake EOF $[\mathrm{kg} \mathrm{N} / \mathrm{ha}]$

no QTL

Nitrogen uptake maturity $[\mathrm{kg} \mathrm{N} / \mathrm{ha}]^{\text {a }}$

$\begin{array}{lllllll}\text { NkgMat-A06 } & \text { A06 } & 1.7-16.9 & 9.0 & 9.6 & -4.19 & 0.36\end{array}$

Nitrogen uptake difference maturity - EOF $[\mathrm{kg} \mathrm{N} / \mathrm{ha}]^{\text {a }}$

$\begin{array}{lllllll}\text { Ndiff-A06 } & \text { A06 } & 1.2-9.2 & 3.0 & 10.8 & -5.08 & 0.31\end{array}$

$\begin{array}{lllllll}\text { Ndiff-C04a } & \text { C04a } & 18.3-25.6 & 20.4 & 3.2 & 3.39 & 0.07\end{array}$

Nitrogen content straw [\%] ${ }^{b}$

$\begin{array}{lllllll}\text { N\%straw-C01 } & \mathrm{C} 01 & 15.5-30.0 & 23.6 & 5.0 & 0.02 & 0.20\end{array}$

Nitrogen harvest index ${ }^{a}$

$\begin{array}{llccccc}\text { NHI-A06 } & \text { A06 } & 1.1-10.5 & 5.0 & 25.4 & -0.03 & 0.60 \\ \text { NHI-A08 } & \text { A08 } & 0-17.0 & 4.8 & 2.5 & 0.01 & 0.03 \\ \text { NHI-C06 } & \text { C06 } & 60.7-67.7 & 63.3 & 7.4 & 0.02 & 0.11\end{array}$

Nitrogen uptake efficiency EOF

$\begin{array}{lllllll}\text { NupEOF-A05 } & \text { A05 } & 43.6-65.0 & 56.5 & 3.0 & -0.15 & 0.11\end{array}$

Nitrogen uptake efficiency ${ }^{\text {a }}$

$\begin{array}{lllllll}\text { Nup-A06 } & \text { A06 } & 1.1-13.4 & 3.0 & 10.3 & -0.05 & 0.30\end{array}$

Nitrogen utilization efficiency ${ }^{\text {a }}$

$\begin{array}{lllllll}\text { Nut-A06 } & \text { A06 } & 1.5-9.4 & 3.0 & 28.6 & -1.43 & 0.64\end{array}$

$\begin{array}{lllllll}\text { Nut-C01 } & \text { C01 } & 34.4-50.8 & 40.8 & 2.9 & -0.33 & 0.03\end{array}$

$\begin{array}{lllllll}\text { Nut-C06 } & \text { C06 } & 71.0-78.5 & 71.5 & 5.4 & 0.45 & 0.07\end{array}$

Nitrogen use efficiency ${ }^{\text {a }}$

\begin{tabular}{llccccc}
$N U E-A 06$ & $\mathrm{~A} 06$ & $0.5-14.8$ & 3.0 & 4.7 & -0.94 & 0.16 \\
$N U E-A 07$ & $\mathrm{~A} 07$ & $51.0-65.3$ & 55.8 & 2.85 & -0.76 & 0.09 \\
\hline
\end{tabular}

Env environment, LG linkage group, CI LOD-1 confidence intervals in centi

Morgan (cM), Pos position with highest LOD, LOD maximum LOD score,

Effect effect of substituting allele of P1 by allel of P2 in the TC, $\mathbf{R}^{2}$ propor-

tion of phenotypic variance explained by the QTL, EOF end of flowering,

${ }^{a}$ two environments,

${ }^{b}$ three environments 


\subsubsection{QTL at high nitrogen supply}

\section{QTL at individual environments with high nitrogen supply}

Analysis of variance for high nitrogen supply in 2011/12 and 2012/13 revealed significant variation between genotypes for all traits, except seed yield, nitrogen uptake EOF and nitrogen uptake efficiency EOF (Tab. 4.9). All traits were significantly affected by interactions of genotypes with environments. Heritabilities ranged from 0.16 (seed yield) to 0.97 (plant height). Heritabilities for traits determined only in Göttingen 2012 are probably overestimated due to one environment. Significant genotype by environment interactions were observed for all traits.

Table 4.9: Variance components and heritabilities at high nitrogen supply (four environments, 100 genotypes)

\begin{tabular}{|c|c|c|c|c|c|}
\hline Source & $\mathbf{E}$ & B & G & GE & $h^{2}$ \\
\hline Df & 3 & 4 & 99 & 297 & \\
\hline Begin of flowering (days) & $92.25 * *$ & $0.02 * *$ & $0.18 * *$ & $0.05 * *$ & 0.53 \\
\hline Plant height $(\mathrm{cm})$ & $450.42 * *$ & $0.28 *$ & $317.30 * *$ & $35.88 * *$ & 0.97 \\
\hline Seed yield (dt/ha) ${ }^{a}$ & $30.74 * *$ & $0.07 \mathrm{~ns}$ & $0.47 \mathrm{~ns}$ & $3.24 * *$ & 0.16 \\
\hline Straw yield (dt/ha) ${ }^{a}$ & $55.99 * *$ & $3.51 * *$ & $18.33^{* *}$ & $7.47 * *$ & 0.84 \\
\hline Harvest index ${ }^{a}$ & $0.45^{* *}$ & $0.03 * *$ & $0.11^{* *}$ & $0.06 * *$ & 0.81 \\
\hline Thousand seed weight (g) & $0.11^{* *}$ & $0.01 * *$ & $0.03^{* *}$ & $0.02 * *$ & 0.81 \\
\hline Oil content (\%) & $0.22 *$ & $0.07 * *$ & $0.65 * *$ & $0.24 * *$ & 0.79 \\
\hline Protein content (\%) & $0.19 * *$ & $0.02 * *$ & $0.04^{* *}$ & $0.09 * *$ & 0.37 \\
\hline Nitrogen uptake EOF (kg N/ha) b & $1113.99 *$ & $76.87 * *$ & 0 & $78.76 * *$ & - \\
\hline Nitrogen uptake maturity $(\mathrm{kg} \mathrm{N} / \mathrm{ha})^{c}$ & - & $7.55^{* *}$ & $89.16 * *$ & - & 0.72 \\
\hline Nitrogen content straw (\%) b & $3.90 * *$ & $0.04 * *$ & $0.22 * *$ & $0.22 * *$ & 0.50 \\
\hline Nitrogen harvest index ${ }^{c}$ & - & $0.03 * *$ & $0.13^{* *}$ & - & 0.78 \\
\hline Nitrogen uptake efficiency EOF b & $2.63 *$ & $0.16 * *$ & 0 & $0.16 * *$ & - \\
\hline Nitrogen uptake efficiency ${ }^{c}$ & - & $0.01 * *$ & $0.15^{* *}$ & - & 0.68 \\
\hline Nitrogen utilization efficiency ${ }^{c}$ & - & $0.27 * *$ & $1.00 * *$ & - & 0.68 \\
\hline Nitrogen use efficiency ${ }^{c}$ & - & 0 & $0.97 * *$ & - & 0.72 \\
\hline
\end{tabular}

$* *,{ }^{*},+$ Significant difference at $0.01,0.05,0.10$ probability level respectively; ns non-significant (F-test from ANOVA), negative variance components were set to zero, $\mathbf{E}$ environment, $\mathbf{B}$ block within environment, $\mathbf{G}$ genotype, $\boldsymbol{h}^{2}$ heritability, EOF end of flowering,

${ }^{a}$ three environments,

${ }^{b}$ two environments,

${ }^{c}$ Göttingen 2012 only

At high nitrogen supply seven QTL influencing begin of flowering were identified in four different environments (Tab. 4.10). Most of them explained around $10 \%$ of the phenotypic variance in begin of flowering. 
4 QTL mapping in semi-dwarf and normal type oilseed rape hybrids

Table 4.10: Putative QTL for agronomic traits at high nitrogen supply (four environments, 100 genotypes)

\begin{tabular}{|c|c|c|c|c|c|c|c|}
\hline Env. & QTL & LG & $\mathrm{CI}[\mathrm{cM}]$ & Pos. $[\mathrm{cM}]$ & LOD & Effect & $\mathbf{R}^{2}$ \\
\hline \multicolumn{8}{|c|}{ Begin of flowering [days] } \\
\hline Ei12 & $B F L-C 01$ & $\mathrm{C} 01$ & $37.2-50.8$ & 42.8 & 3.45 & 0.48 & 0.11 \\
\hline Ei12 & $B F L-C 06$ & $\mathrm{C} 06$ & $58.1-67.0$ & 61.3 & 3.9 & -0.49 & 0.12 \\
\hline Ei12 & $B F L-C 07$ & $\mathrm{C} 07$ & $0.0-11.6$ & 4.0 & 3.1 & -0.48 & 0.11 \\
\hline Go12 & $B F L-C 07$ & $\mathrm{C} 07$ & $38.3-43.7$ & 40.7 & 3.22 & -0.18 & 0.10 \\
\hline Ei13 & $B F L-A 01$ & $\mathrm{~A} 01$ & $44.8-56.0$ & 50.4 & 3.16 & 0.28 & 0.11 \\
\hline Ei13 & $B F L-A 09$ & A09 & $27.6-51.0$ & 39.0 & 2.94 & 0.29 & 0.12 \\
\hline Go13 & $B F L-A 06$ & A06 & $11.2-19.9$ & 15.0 & 39.0 & 0.51 & 0.81 \\
\hline \multicolumn{8}{|c|}{ Plant heigth $[\mathrm{cm}]$} \\
\hline Ei12 & $P H-A 06$ & A06 & $1.4-5.2$ & 3.0 & 73.6 & 25.37 & 0.94 \\
\hline Go12 & $P H-A 06$ & A06 & $1.0-5.3$ & 3.0 & 87.2 & 12.06 & 0.94 \\
\hline Ei13 & $P H-A 06$ & A06 & $1.4-5.2$ & 3.0 & 55.5 & 16.06 & 0.89 \\
\hline Go13 & $P H-A 06$ & A06 & $1.4-5.2$ & 3.0 & 102.6 & 18.39 & 0.95 \\
\hline Ei12 & $\mathrm{PH}-\mathrm{CO} 3$ & $\mathrm{C} 03$ & $52.5-78.1$ & 71.1 & 3.5 & -2.15 & 0.01 \\
\hline \multicolumn{8}{|c|}{ Seed yield $[\mathrm{dt} / \mathrm{ha}]^{\mathrm{a}}$} \\
\hline Go12 & Seed-A06 & A06 & $0.2-3.0$ & 3.0 & 15.1 & -1.82 & 0.42 \\
\hline Ei13 & Seed-A06 & A06 & $0.0-30.2$ & 12.0 & 3.0 & 0.08 & 0.14 \\
\hline \multicolumn{8}{|c|}{ Straw yield [dt/ha] } \\
\hline Ei12 & Straw-A06 & A06 & $1.3-13.3$ & 4.0 & 11.1 & 1.71 & 0.34 \\
\hline Go12 & Straw-A06 & A06 & $0.2-3.0$ & 2.0 & 17.5 & 3.91 & 0.50 \\
\hline Ei13 & Straw-A06 & A06 & $0.9-12.4$ & 6.0 & 21.0 & 0.61 & 0.65 \\
\hline Go13 & Straw-A06 & A06 & $0.0-2.5$ & 2.0 & 11.8 & 0.36 & 0.32 \\
\hline \multicolumn{8}{|c|}{ Harvest index ${ }^{a}$} \\
\hline Go12 & $H I-A 06$ & A06 & $0.8-6.0$ & 2.0 & 24.2 & -0.04 & 0.60 \\
\hline Ei13 & $H I-A 06$ & A06 & $0.0-10.2$ & 3.0 & 9.8 & -0.02 & 0.30 \\
\hline Go13 & $H I-A 06$ & A06 & $0.0-2.5$ & 2.0 & 11.6 & -0.02 & 0.33 \\
\hline
\end{tabular}

Env environment, LG linkage group, CI LOD-1 confidence intervals in centi Morgan (cM), Pos position with highest LOD, LOD maximum LOD score, Effect effect of substituting allele of $\mathrm{P} 1$ by allel of $\mathrm{P} 2$ in the TC, $\mathbf{R}^{2}$ proportion of phenotypic variance explained by the QTL,

${ }^{a}$ three environments

The QTL BFL-A06 detected in Göttingen 2013 explained $81 \%$ of the variance for begin of flowering (Tab. 4.11). Confidence intervals of QTL on same LG were not overlapping.

Plant height was significantly affected by two QTL on LG A06 and C03. The QTL PHA06 was detected in four environments in overlapping intervals between 1.0 and $5.3 \mathrm{cM}$. 
The explained phenotypic variance in plant height by this QTL ranged from $89 \%$ (Ei13) to $95 \%$ (Go13). The QTL PH-C03 was identified in Einbeck 2012 only.

One putative QTL for seed yield was identified in Göttingen 2012 and Einbeck 2013. Confidence intervals for the QTL overlapped between environments. In Göttingen 2012 the allele from 'Alesi-bzh' increased seed yield while it decreased seed yield in Einbeck 2013. A QTL on LG A06 significantly influenced straw yield at four environments (Tab. 4.10). Confidence intervals overlapped between environments ranging from $0 \mathrm{cM}$ to $13.3 \mathrm{cM}$. The explained phenotypic variance ranged from $34 \%$ (Ei12) to $65 \%$ (Go13). The 'Alesi$b z h$ ' allele reduced straw yield in all environments. One QTL on LG A06 was detected

Table 4.11: Putative QTL for thousand seed weight, oil content and protein content at high nitrogen supply (four environments, 100 genotypes)

\begin{tabular}{|c|c|c|c|c|c|c|c|}
\hline Env. & QTL & LG & $\mathrm{CI}[\mathrm{cM}]$ & Pos. $[\mathrm{cM}]$ & LOD & Effect & $\mathbf{R}^{2}$ \\
\hline \multicolumn{8}{|c|}{ Thousand seed weight [g] } \\
\hline Ei13 & $T S W-A 01$ & A01 & $2.6-23.0$ & 13.1 & 3.3 & 0.07 & 0.07 \\
\hline Ei13 & $T S W-A 06$ & A06 & $0.6-8.7$ & 3.0 & 13.6 & 0.16 & 0.36 \\
\hline Go13 & $T S W-A 06$ & $\mathrm{~A} 06$ & $0.4-19.6$ & 8.0 & 8.9 & 0.14 & 0.25 \\
\hline Ei13 & $T S W-C 01$ & $\mathrm{C} 01$ & $40.8-68.8$ & 57.9 & 3.2 & 0.07 & 0.08 \\
\hline Go13 & $T S W-C 01$ & $\mathrm{C} 01$ & $47.3-61.0$ & 53.9 & 8.2 & 0.13 & 0.22 \\
\hline \multicolumn{8}{|c|}{ Oil content $[\%]$} \\
\hline Ei12 & $O i l \%-A 06$ & A06 & $0.0-3.0$ & 2.0 & 20.0 & 0.71 & 0.37 \\
\hline Go12 & $O i l \%-A 06$ & A06 & $0.9-10.1$ & 4.0 & 16.5 & 0.70 & 0.31 \\
\hline Ei13 & $O i l \%-A 06$ & $\mathrm{~A} 06$ & $0.0-13.8$ & 1.0 & 4.4 & 0.40 & 0.16 \\
\hline Go13 & Oil\%-A06 & A06 & $0.0-14.9$ & 1.0 & 4.2 & 0.33 & 0.07 \\
\hline Ei12 & Oil\%-A08 & A08 & $1.4-17.0$ & 4.0 & 17.4 & 0.65 & 0.30 \\
\hline Go12 & Oil\%-A08 & A08 & $7.4-10.8$ & 7.8 & 21.7 & 0.82 & 0.43 \\
\hline Go13 & Oil\%-A08 & A08 & $3.0-7.2$ & 4.8 & 21.2 & 0.88 & 0.51 \\
\hline \multicolumn{8}{|c|}{ Protein content $[\%]$} \\
\hline Ei12 & Pro\%-A06 & A06 & $0.0-12.9$ & 1.0 & 14.2 & -0.36 & 0.39 \\
\hline Go12 & Pro\%-A06 & A06 & $3.4-18.9$ & 8.0 & 8.7 & -0.31 & 0.31 \\
\hline
\end{tabular}

Env environment, LG linkage group, CI LOD-1 confidence intervals in centi Morgan (cM), Pos position with highest LOD, LOD maximum LOD score, Effect effect of substituting allele of P1 by allel of P2 in the TC, $\mathbf{R}^{2}$ proportion of phenotypic variance explained by the QTL

for harvest index in three environments. In Göttingen 2012 HI-A06 accounted for $60 \%$ of phenotypic variance in harvest index. In Einbeck 2013 and Göttingen 2013 the QTL explained about one third of the variance in harvest index. The allele from 'Alesi- $b z h$ ' increased the harvest index in all three environments (Tab. 4.10). 
Five QTL in four individual environments were identified for thousand seed weight (Tab. 4.11). The allele from 'Alesi-bzh' reduced TSW at all QTL. Two QTL on LG A06 and A08 were detected for oil content. Confidence intervals for both QTL overlapped between individual environments. The QTL on A06 explained between 7\% and $37 \%$ of the phenotypic variance in oil content. The 'Alesi-bzh' allele reduced oil content at the QTL on A06 in a range from $0.33 \%$ to $0.71 \%$. The explained phenotypic variance in oil content of QTL Oil\%-A08 ranged 30\% to $51 \%$. The 'Alesi-bzh' allele reduced oil content in a range from $0.65 \%$ to $0.88 \%$.

Protein content was affected by a QTL on LG A06. The QTL accounted for $31 \%$ (Go12) or $39 \%$ (Ei12) of phenotypic variance in protein content. The 'Alesi- $b z h$ ' allele increased protein content in both environments.

Four QTL were detected for nitrogen uptake EOF (Tab. 4.12). The effect OF QTL on LG A06 had different directions in the single environments.

One QTL was detected for nitrogen uptake maturity on LG A06. It explained $23 \%$ of phenotypic variance in the trait. Two QTL were identified for the difference in nitrogen uptake between maturity and end of flowering. Together they accounted for $21 \%$ of phenotypic variance.

Nitrogen content of straw was influenced by two QTL on LG A06 and C06. Confidence intervals of both QTL overlapped between environments. The QTL on LG A06 explained about one third of the phenotypic variance in nitrogen content of straw. The QTL on C06 explained about $8 \%$. Nitrogen harvest index, nitrogen uptake efficiency EOF and nitrogen utilization efficiency were all affected by two QTL on LG A06 and LG C04b. Confidence intervals of QTL overlapped between traits and among environments.

For nitrogen uptake efficiency a single QTL was detected on LG A06 (Tab. 4.12). Three QTL on LG A03 and A06 were identified for nitrogen use efficiency. For one QTL on LG A06 the 'Alesi- $b z h$ ' allele increased nitrogen use efficiency while it had an decreasing effect at the second QTL on A06. All three QTL explained $59 \%$ of phenotypic variance in nitrogen use efficiency. 
4 QTL mapping in semi-dwarf and normal type oilseed rape hybrids

Table 4.12: Putative QTL for nitrogen related traits at high nitrogen supply (two environments, 100 genotypes)

\begin{tabular}{|c|c|c|c|c|c|c|c|}
\hline Env. & QTL & LG & $\mathrm{CI}[\mathrm{cM}]$ & Pos. $[\mathrm{cM}]$ & LOD & Effect & $\mathbf{R}^{2}$ \\
\hline \multicolumn{8}{|c|}{ Nitrogen uptake EOF [kg N/ha] } \\
\hline Ei12 & $N k g E O F-A 06$ & A06 & $3.8-14.8$ & 8.0 & 16.1 & 10.43 & 0.52 \\
\hline Go12 & $N k g E O F-A 06$ & A06 & $0.1-30.8$ & 15.0 & 3.0 & -4.02 & 0.15 \\
\hline Ei12 & $\mathrm{NkgEOF-CO4a}$ & $\mathrm{C} 04 \mathrm{a}$ & $0.0-18.1$ & 6.0 & 2.9 & 3.87 & 0.07 \\
\hline Go12 & NkgEOF-C08 & $\mathrm{C} 08$ & $10.9-28.1$ & 19.3 & 3.4 & -3.54 & 0.11 \\
\hline \multicolumn{8}{|c|}{ Nitrogen uptake maturity $[\mathrm{kg} \mathrm{N} / \mathrm{ha}]^{a}$} \\
\hline Go12 & NkgMat-A06 & A06 & $1.0-8.7$ & 3.0 & 7.45 & -5.37 & 0.23 \\
\hline \multicolumn{8}{|c|}{ Nitrogen uptake difference maturity - EOF $[\mathrm{kg} \mathrm{N} / \mathrm{ha}]^{a}$} \\
\hline Go12 & Ndiff-C06 & $\mathrm{C} 06$ & $60.4-67.5$ & 63.9 & 2.9 & 4.29 & 0.09 \\
\hline Go12 & Ndiff-C08 & $\mathrm{C} 08$ & $12.5-23.0$ & 17.1 & 3.7 & 4.93 & 0.12 \\
\hline \multicolumn{8}{|c|}{ Nitrogen content straw [\%] } \\
\hline Ei12 & N\%straw-A06 & A06 & $1.3-12.2$ & 3.0 & 11.4 & -0.03 & 0.34 \\
\hline Go12 & N\%straw-A06 & A06 & $4.1-26.2$ & 17.0 & 7.0 & -0.06 & 0.31 \\
\hline Ei12 & N\%straw-C06 & $\mathrm{C} 06$ & $32.8-47.3$ & 42.4 & 3.3 & 0.02 & 0.08 \\
\hline Go12 & N\%straw-C06 & $\mathrm{C} 06$ & $48.5-69.3$ & 60.3 & 2.7 & 0.03 & 0.07 \\
\hline \multicolumn{8}{|c|}{ Nitrogen harvest index ${ }^{a}$} \\
\hline Go12 & NHI-A06 & A06 & $0.0-2.0$ & 0.0 & 11.7 & -0.02 & 0.34 \\
\hline Go12 & $\mathrm{NHI}-\mathrm{CO} 4 \mathrm{~b}$ & $\mathrm{C} 04 \mathrm{~b}$ & $15.5-39.5$ & 23.3 & 3.5 & -0.01 & 0.08 \\
\hline \multicolumn{8}{|c|}{ Nitrogen uptake efficiency EOF } \\
\hline Ei12 & NupEOF-A06 & A06 & $3.9-14.4$ & 8.0 & 16.3 & 0.05 & 0.51 \\
\hline $\operatorname{Ei} 12$ & NupEOF-CO4a & $\mathrm{C} 04 \mathrm{a}$ & $0.0-18.0$ & 6.0 & 3.5 & 0.02 & 0.09 \\
\hline \multicolumn{8}{|c|}{ Nitrogen uptake efficiency ${ }^{a}$} \\
\hline Go12 & Nup-A06 & A06 & $0.8-8.3$ & 3.0 & 7.8 & -0.02 & 0.23 \\
\hline \multicolumn{8}{|c|}{ Nitrogen utilization efficiency ${ }^{a}$} \\
\hline Go12 & Nut-A06 & A06 & $0.0-20.9$ & 3.0 & 7.8 & -0.02 & 0.23 \\
\hline Go12 & $\mathrm{Nut}-\mathrm{CO} 4 \mathrm{~b}$ & $\mathrm{C} 04 \mathrm{~b}$ & $10.5-21.2$ & 14.5 & 2.7 & 0.01 & 0.07 \\
\hline \multicolumn{8}{|c|}{ Nitrogen use efficiency ${ }^{a}$} \\
\hline Go12 & NUE-A03 & A03 & $66.8-87.1$ & 71.8 & 3.72 & -0.34 & 0.08 \\
\hline Go12 & $N U E-A 06$ & A06 & $0.7-10.6$ & 3.0 & 7.77 & -0.77 & 0.42 \\
\hline Go12 & $N U E-A 06$ & A06 & $42.7-57.6$ & 49.9 & 4.07 & 0.35 & 0.09 \\
\hline
\end{tabular}

Env environment, LG linkage group, CI LOD-1 confidence intervals in centi Morgan (cM), Pos position with highest LOD, LOD maximum LOD score, Effect effect of substituting allele of $\mathrm{P} 1$ by allel of $\mathrm{P} 2$ in the TC, $\mathbf{R}^{2}$ proportion of phenotypic variance explained by the QTL, EOF end of flowering,

${ }^{a}$ Göttingen 2012 only 


\section{QTL across environments with high nitrogen supply}

Begin of flowering at high nitrogen supply was affected by four QTL on LG A02, A05, A06 and C07 (Tab. 4.13). Together they explained $42 \%$ of phenotypic variance.

Two QTL on LG A06 and A07 were detected for plant height. The QTL PH-A06 explained $92 \%$ of phenotypic variance in plant height. The allele from 'Alesi- $b z h$ ' reduced plant height by about $18 \mathrm{~cm}$.

Seed yield was affected by two QTL on LG A06 and C02. The 'Alesi-bzh' allele had an increasing effect on seed yield at both QTL. Straw yield was affected by one QTL on LG A06 with an explained phenotypic variance of $74 \%$.

Two QTL on LG A06 and A07 were detected for harvest index. Together they accounted for $73 \%$ of phenotpypic variation in harvest index.

Table 4.13: Putative QTL for begin of flowering, plant height, seed yield, straw yield and harvest index across four environments with high nitrogen supply (100 genotypes)

\begin{tabular}{|c|c|c|c|c|c|c|}
\hline QTL & LG & $\mathrm{CI}[\mathrm{cM}]$ & Pos. $[\mathrm{cM}]$ & LOD & Effect & $\mathbf{R}^{2}$ \\
\hline \multicolumn{7}{|c|}{ Begin of flowering [days] } \\
\hline$B F L-A 02$ & $\mathrm{~A} 02$ & $13.2-35.7$ & 23.5 & 2.82 & 0.16 & 0.08 \\
\hline$B F L-A 05$ & $\mathrm{~A} 05$ & $82.0-95.8$ & 91.9 & 2.88 & 0.17 & 0.09 \\
\hline$B F L-A 06$ & A01 & $40.3-49.7$ & 47.4 & 5.51 & 0.24 & 0.16 \\
\hline$B F L-C 07$ & $\mathrm{C} 07$ & $0-11.3$ & 4.0 & 2.92 & -0.18 & 0.09 \\
\hline \multicolumn{7}{|c|}{ Plant heigth [cm] } \\
\hline$P H-A 06$ & A06 & $1.4-5.2$ & 3.0 & 88.1 & 17.90 & 0.92 \\
\hline $\mathrm{PH}-\mathrm{CO} 7$ & $\mathrm{C} 07$ & $22.1-30.1$ & 22.5 & 2.7 & -0.85 & 0.002 \\
\hline \multicolumn{7}{|c|}{ Seed yield $[\mathrm{dt} / \mathrm{ha}]^{a}$} \\
\hline Seed-A06 & A06 & $0.7-8.6$ & 3.0 & 13.3 & -1.21 & 0.39 \\
\hline Seed-C02 & $\mathrm{C} 02$ & $75.5-54.5$ & 50.7 & 5.1 & -0.65 & 0.11 \\
\hline \multicolumn{7}{|c|}{ Straw yield [dt/ha] } \\
\hline Straw-A06 & A06 & $4.3-12.3$ & 7.0 & 23.7 & 4.00 & 0.74 \\
\hline \multicolumn{7}{|c|}{ Harvest index a } \\
\hline$H I-A 06$ & A06 & $0.8-4.0$ & 2.0 & 28.7 & -0.04 & 0.67 \\
\hline$H I-A 0^{r}$ & $\mathrm{~A} 07$ & $50.6-61.1$ & 55.7 & 4.3 & -0.01 & 0.06 \\
\hline
\end{tabular}

Env environment, LG linkage group, CI LOD-1 confidence intervals in centi Morgan (cM), Pos position with highest LOD, LOD maximum LOD score, Effect effect of substituting allele of P1 by allel of P2 in the TC, $\mathbf{R}^{2}$ proportion of phenotypic variance explained by the QTL,

${ }^{a}$ three environments 
Three QTL were detected for thousand seed weight (Tab. 4.14). The allele of 'Alesi- $b z h$ ' reduced seed yield at all three QTL. Oil content was influenced by four QTL on different linkage groups. The QTL Oil\%-A08 accounted for $42 \%$ of variation in oil content with an increasing effect of $0.59 \%$ by the allele of 'H30'. The QTL on LG A06 explained another $34 \%$ of phenotypic variation in oil content. Two QTL for protein content with opposite effects were detected on LG A03 and A06.

Nitrogen uptake EOF and nitrogen uptake maturity were both affected by a QTL on LG A06 (Tab. 4.15). The allele of 'Alesi- $b z h$ ' decreased nitrogen uptake EOF and increased nitrogen uptake maturity. Two QTL on LG C06 and C08 were detected for the difference in nitrogen uptake. The nitrogen content of straw was affected by three QTL on LG A06, C04b and C06. Together they accounted for $59 \%$ of phenotypic variance. Two QTL on LG A06 and C04b were identified for nitrogen harvest index.

Nitrogen uptake efficiency at EOF was influenced by two QTL on LG A06 and C08.

Nitrogen uptake efficiency was affected by two QTL on LG A06 and C04b with opposite effects. Two QTL were detected for nitrogen utilization efficiency. The allele of 'Alesi$b z h$ ' increased nitrogen utilization efficiency at both QTL. Three QTL on two LG were identified for nitrogen use efficiency. The two QTL on LG A06 had opposite effects.

Table 4.14: Putative QTL for thousand seed weight, oil yield, oil content and protein content across four environments with high nitrogen supply (100 genotypes)

\begin{tabular}{|c|c|c|c|c|c|c|}
\hline QTL & LG & $\mathrm{CI}[\mathrm{cM}]$ & Pos. $[\mathrm{cM}]$ & LOD & Effect & $\mathbf{R}^{2}$ \\
\hline \multicolumn{7}{|c|}{ Thousand seed weight $[\mathrm{g}]$} \\
\hline$T S W-A 06$ & A06 & $0-13.0$ & 1.0 & 8.0 & 0.08 & 0.21 \\
\hline$T W S-A 0^{r}$ & A07 & $54.0-69.3$ & 60.8 & 4.6 & 0.06 & 0.12 \\
\hline$T S W-C 01$ & $\mathrm{C} 01$ & $42.7-64.6$ & 54.9 & 4.6 & 0.06 & 0.13 \\
\hline \multicolumn{7}{|c|}{ Oil content $[\%]$} \\
\hline Oil\%-A06 & A06 & $0.7-2.9$ & 2.0 & 20.1 & 0.55 & 0.34 \\
\hline Oil\%-A08 & A08 & $1.7-4.8$ & 4.0 & 22.5 & 0.59 & 0.42 \\
\hline Oil\%-A09 & A09 & $6.9-20.9$ & 15.2 & 2.7 & -0.16 & 0.03 \\
\hline$O i l \%-C 01$ & $\mathrm{C} 01$ & $42.9-60.4$ & 48.8 & 3.7 & 0.21 & 0.05 \\
\hline \multicolumn{7}{|c|}{ Protein content [\%] } \\
\hline Pro\%-A03 & A03 & $125.2-133.3$ & 132.3 & 4.6 & 0.13 & 0.14 \\
\hline Pro\%-A06 & A06 & $0-3.0$ & 2.0 & 8.5 & -0.17 & 0.25 \\
\hline
\end{tabular}

Env environment, LG linkage group, CI LOD-1 confidence intervals in centi Morgan (cM), Pos position with highest LOD, LOD maximum LOD score, Effect effect of substituting allele of P1 by allel of P2 in the TC, $\mathbf{R}^{2}$ proportion of phenotypic variance explained by the QTL 
4 QTL mapping in semi-dwarf and normal type oilseed rape hybrids

Table 4.15: Putative QTL for nitrogen affected traits across two environments with high nitrogen supply (100 genotypes)

\begin{tabular}{|c|c|c|c|c|c|c|}
\hline QTL & LG & CI $[\mathrm{cM}]$ & Pos. $[\mathrm{cM}]$ & LOD & Effect & $\mathbf{R}^{2}$ \\
\hline \multicolumn{7}{|c|}{ Nitrogen uptake EOF [kg N/ha] } \\
\hline$N k g E O F-A 06$ & A06 & $0.5-23.1$ & 12.0 & 4.7 & 3.87 & 0.21 \\
\hline \multicolumn{7}{|c|}{ Nitrogen uptake maturity $[\mathrm{kg} \mathrm{N} / \mathrm{ha}]^{\text {a }}$} \\
\hline NkgMat-A06 & A06 & $1.0-8.7$ & 3.0 & 7.45 & -5.37 & 0.23 \\
\hline
\end{tabular}

Nitrogen uptake difference maturity - EOF $[\mathrm{kg} \mathrm{N} / \mathrm{ha}]^{\text {a }}$

$\begin{array}{lllllll}\text { Ndiff-C06 } & \text { C06 } & 60.4-67.5 & 63.9 & 2.9 & 4.29 & 0.09 \\ \text { Ndiff-C08 } & \text { C08 } & 12.5-23.0 & 17.1 & 3.7 & 4.93 & 0.12\end{array}$

Nitrogen content straw [\%]

$\begin{array}{lllccrc}\text { N\%straw-A06 } & \text { A06 } & 3.6-19.0 & 10 & 11.1 & -0.04 & 0.38 \\ \text { N\%straw-C04b } & \text { C04b } & 13.6-18.9 & 14.5 & 5.2 & 0.04 & 0.13 \\ \text { N\%straw-C06 } & \text { C06 } & 34.1-54.6 & 45.4 & 3.1 & 0.02 & 0.08\end{array}$

Nitrogen harvest index ${ }^{a}$

$\begin{array}{lllllll}\text { NHI-A06 } & \text { A06 } & 0-9.2 & 0.0 & 11.7 & -0.02 & 0.34\end{array}$

$\begin{array}{lllllll}N H I-C 04 b & \text { C04b } & 15.5-39.5 & 23.3 & 3.5 & -0.01 & 0.08\end{array}$

Nitrogen uptake efficiency EOF

$\begin{array}{llccrrr}\text { NupEOF-A06 } & \text { A06 } & 0-24.5 & 13.0 & 4.0 & 0.02 & 0.19 \\ \text { NupEOF-C08 } & \text { C08 } & 9.2-28.6 & 19.3 & 2.6 & -0.01 & 0.08\end{array}$

Nitrogen uptake efficiency ${ }^{\text {a }}$

$\begin{array}{lllcrrr}\text { Nup-A06 } & \text { A06 } & 0.8-8.3 & 3.0 & 7.8 & -0.02 & 0.23 \\ \text { Nup-C04a } & \text { C04a } & 9.5-21.4 & 14.5 & 2.7 & 0.01 & 0.07\end{array}$

Nitrogen utilization efficiency ${ }^{\text {a }}$

$\begin{array}{llccccc}\text { Nut }- \text { A06 } & \text { A06 } & 0-20.9 & 0.0 & 4.2 & -0.47 & 0.14 \\ \text { Nut }-C 04 b & \text { C04b } & 10.5-21.1 & 14.5 & 2.7 & -0.41 & 0.08\end{array}$

Nitrogen use efficiency ${ }^{a}$

\begin{tabular}{llcccrc}
$N U E-A 03$ & A03 & $66.8-87.1$ & 71.8 & 3.7 & -0.34 & 0.08 \\
$N U E-A 06$ & A06 & $0.9-10.2$ & 3.1 & 13.6 & -0.78 & 0.40 \\
$N U E-A 06$ & A06 & $42.2-57.0$ & 50.0 & 4.00 & 0.38 & 0.06 \\
\hline
\end{tabular}

Env environment, LG linkage group, CI LOD-1 confidence intervals in centi Morgan (cM), Pos position with highest LOD, LOD maximum LOD score, Effect effect of substituting allele of $\mathrm{P} 1$ by allel of $\mathrm{P} 2$ in the TC, $\mathbf{R}^{2}$ proportion of phenotypic variance explained by the QTL, EOF end of flowering,

a Göttingen 2012 only 
4 QTL mapping in semi-dwarf and normal type oilseed rape hybrids

\subsubsection{Discussion}

Linkage map

For the construction of the linkage map 139 DH-lines were genotyped with 541 polymorphic SSR and SNP markers. Fifty-five marker loci differed significantly from the expected segregation ratio. The occurrence of marker loci with disturbed segregation is common in microspore-derived DH populations of Brassica napus and other plant species (Foisset and Delourme, 1996). A total of 437 markers were assembled to 22 linkage groups. Based on alignment with other linkage maps for Brassica napus and informations about the physical position of SNP markers, 21 LG could be assigned to the 19 chromosomes of Brassica napus. Linkage group C04 and C05 were split into two parts and LG 22 could not be assigned to any chromosome. The reduction of the LOD threshold to 2.5 and an increase of the maximum distance between markers to $40 \mathrm{cM}$ did not lead to better results. Some LGs contain relatively large gaps between markers. For example on LG A06 the markers linked to the dwarf gene (SNP-bzh and SNP-bzhrga1) on the distal part of LG A06 are about $33 \mathrm{cM}$ away from the next linked marker. This incomplete markercoverage may be caused by differences in recombination frequencies in different parts of the genome. Using more marker for genotyping of DH lines might 'fill' these gaps with additional marker.

The use of more DH-lines would reduce the number of co-segregating markers. The total map length of $1301 \mathrm{cM}$ (Kosambi) is relatively short, compared to other Brassica napus maps. Delourme et al. (2013) generated an integrated Brassica napus linkage map based on four populations. The integrated map comprises 7367 marker loci and covers a total genetic length of $2250 \mathrm{cM}$. In comparison to those maps the map in the present experiment covers about $58 \%$ of the Brassica napus genome.

\section{QTL mapping}

The phenotypic data in the present study were obtained from testcross hybrids (TC). The testcrosses carry only one allele from the DH lines in combination with another, unknown allele from the tester. Therefore, genetic effects of QTL detected in testcrosses are always confounded by interactions with tester alleles (Schön et al., 1994). If a tester allele is completely dominant over the alleles carried by the DH lines, no QTL will be detected. The chances of detecting a QTL are a function of the genetic variance generated by the cross itself and the interaction with the tester alleles (Schön et al., 1994). Furthermore the detection of QTL is influenced by the size of the mapping population, heritability of a trait, number of loci affecting the trait, genome size and marker density. The estimation of the QTL effect on the variation in a trait is biased by low heritabilities and small population sizes (Beavis, 1998). With decreasing population size the overestimation of 
QTL effects increases. The detected QTL for each trait represent the minimal number of genes determining the trait. A QTL is detected as significant if the LOD score exceeds a significance threshold. The threshold represent a $5 \%$ probability of detecting a false positive QTL (type I error) (Rifkin, 2012). Thus, more QTL can be detected by reducing the threshold but this would also increase the type I error rate. The number of undetected QTL influences the proportion of phenotypic variance explained $\left(\mathrm{R}^{2}\right)$ by all QTL for an individual trait. The higher the proportion of detected QTL influencing a trait, the higher the explained phenotypic variance for the trait. In the present study values of $\mathrm{R}^{2}$ across environments ranged from $11 \%$ for nitrogen uptake efficiency EOF at low nitrogen supply (Tab. 4.8) to $93 \%$ for plant hight at low nitrogen supply (Tab. 4.6). Most of the QTL explained only small proportion of the phenotypic variance. Only the QTL at the distal part of LG A06 contributed more than $20 \%$ to the phenotypic variance of some traits.

In individual environments with low nitrogen supply 34 QTL were detected for 17 traits (Tab. 4.3-4.5). At high nitrogen supply 36 QTL were identified for 17 traits (Tab. 4.10Tab. 4.12). Some of these QTL were detected in one or two environments only. A few QTL were expressed in all environments. Differences in the expression of QTL among environments is common and can be explained by QTL by environment interactions. Shi et al. (2009) identified 401 consensus QTL for nine traits in two populations tested at ten environments. Nearly $80 \%$ of the 401 consensus QTL were identified in one or two environments, and no consensus QTL, except one for flowering time appeared in all environments. The presence of significant genotype by environment interactions for all traits at low and high nitrogen supply (Tab. 4.2, Tab. 4.9) indicates the presence of QTL x environment interaction as well. Interactions between QTL and environment can be tested using a two-factorial ANOVA model with marker genotype (closest marker to the QTL) and environment as factors. Other reasons for environmental differences in the expression of QTL may be a high residual error, reducing the heritability of a trait. The size of the mapping population can also influence the power of detecting a QTL.

The most important characteristic of testcross hybrids in this study is the segregation into semi-dwarf and normal growth types. The segregation is caused by a single dwarf gene $B z h$ with two alleles ( $b z h$ or $B z h$ ) with an additive effect (Foisset et al., 1995). Semidwarf hybrids have the allelic composition $b z h / B z h$ and normal type hybrids $B z h / B z h$. The SNP marker (bzhrga1) inside the dwarf gene $B z h$ was mapped to a position on the distal part (3 cM) of LG A06 (Appendix A).

\section{QTL for agronomic traits}

Seed yield is the most important trait in oilseed rape breeding. Seed yield is a com- 
plex trait and reflects the interaction of the environment with growth and development processes throughout the life cycle of a plant (Shi et al., 2009). Several QTL studies in different crops suggest that QTL affecting crop yield are involved in diverse pathways, such as flowering time, plant height, seed number, seed weight and straw yield. Shi et al. (2009) identified 55 QTL for seed yield in oilseed rape and 47 of the 55 QTL co-localized with other yield associated traits.

In the present study seven QTL affecting seed yield at low and/or high N supply were identified (Tab. 4.6, Tab. 4.13). Two QTL on LG A06 and A07 controlled seed yield as well as other yield related traits.

The QTL at the distal part of LG A06 explained $45 \%$ of the phenotypic variation in seed yield at low nitrogen supply (Tab. 4.6) and $46 \%$ of phenotypic variance in seed yield at high N supply (Tab. 4.13). A substitution of the 'Alesi- $b z h$ ' allele would reduce seed yield by $1.0 \mathrm{dt} / \mathrm{ha}$ at low nitrogen and by $1.3 \mathrm{dt} /$ ha at high nitrogen supply. Nevertheless, seed yield of semi-dwarf hybrids at high nitrogen supply was not significantly higher compared to normal types (see chapter 2). This might be caused by negative effects of other, undetected QTL for seed yield at high nitrogen supply.

In addition to seed yield a QTL on LG A06 affected plant height, straw yield, harvest index and thousand seed weight at both nitrogen levels. A QTL at the distal part of LG A06 was also identified for begin of flowering at low nitrogen supply. Based on the position of the QTL on LG A06 and the co-localization of the dwarf locus in the same genomic region, it is most likely that all traits were affected by the dwarf gene $B z h$ itself. The pleiotropic effect of the $B z h$ gene seems to be reasonable because the mutated dwarf allele bzh manipulates the signaling pathway of gibberellic acid in plants (Li et al., 2011). Gibberellic acid is a growth hormone in plants and influences many traits such as stem and root extension, leaf expansion, seed germination and floral induction (Sun and Gubler, 2004).

The 'Alesi- $b z h$ ' allele had an opposite effect at the QTL on LG A06 detected at high nitrogen supply in Einbeck 2013 (Tab. 4.10). The confidence interval for Seed-A06 was much larger compared to other environments. It might be that this QTL represent a second genomic region on LG A06 influencing seed yield. Ding et al. (2012) conducted a QTL study for seed yield at low and normal phosphorus levels. At low phosphorus level the authors identified a QTL for seed yield on LG A06 in an interval of 30 to $38 \mathrm{cM}$. This QTL accounted for $11 \%$ to $13 \%$ of the variation in seed yield. The same QTL influenced pod number and branch number at low phosphorus supply.

A second genomic region with effects on seed yield and several other traits was identified on LG A07 at low nitrogen supply. The QTL explained $7 \%$ of the phenotypic variance (0.42 dt/ha) in seed yield across all environments with low nitrogen supply (Tab. 4.6). 
The QTL on LG A07 was also identified for harvest index and nitrogen use efficiency (Tab. 4.6, Tab. 4.8). The same QTL (overlapping confidence intervals) was identified for thousand seed weight in Einbeck and Göttingen 2013 (Tab. 4.4). QTL for seed yield and thousand seed weight on A07 were identified by Quijada et al. (2006) as well. Additional QTL for seed yield were detected on LG A10 and C06 at low nitrogen supply (Tab. 4.6).

Three QTL explained $71 \%$ of phenotypic variation in straw yield at low nitrogen supply (Tab. 4.6. The allele of parent 1 ('Alesi-bzh') reduced straw yield at the QTL Straw-A02 and Straw-A06 by 0.7 or $2.4 \mathrm{dt} / \mathrm{ha}$, respectively. For QTL Straw-C07 the allele from parent 1 increased straw yield by $0.7 \mathrm{dt} / \mathrm{ha}$. At high nitrogen supply only the QTL Straw-A06 was detected (Tab. 4.13). The higher number of QTL detected for straw yield at low nitrogen compared to high nitrogen supply might be caused by a better differentiation among genotypes at nitrogen deficient conditions (higher stress level). The QTL for straw yield detected by Miro (2010) were not identified in this experiment.

Harvest index at low and high nitrogen supply was significantly influenced by QTL on LG A06 and A07 (Tab.4.6, Tab. 4.13). Miro (2010) identified two QTL for harvest index on Chromosome A07. One QTL was detected at low and high nitrogen supply levels, the other only at high nitrogen supply. In the present experiment two additional QTL for harvest index were identified at low nitrogen supply on LG A08 and C06 (Tab. 4.6). Together they accounted for $7 \%$ of phenotypic variation in harvest index at low nitrogen supply. A study by Radoev et al. (2008) identified QTL for harvest index on LGs 5, 6, 10, 12, 13, 17 and 19 .

Five genomic regions influenced thousand seed weight at low and high nitrogen supply (Tab. 4.7, Tab. 4.14). The QTL on LG A06 and LG C01 were identified at both nitrogen levels. The 'Alesi-bzh' allele at QTL TSW-A06 caused a reduction in thousand seed weight and explained $15 \%$ (low nitrogen) or $21 \%$ (high nitrogen) of the trait variance. The QTL TSW-C01 accounted for $20 \%$ (low nitrogen) or $13 \%$ (high nitrogen) of variance in thousand seed weight with an decreasing effect of the 'Alesi- $b z h$ ' allele. Fan et al. (2010) identified three QTL for thousand seed weight on LG A01 and A07. The QTL on LG A01 explained $9 \%$ of the variance in thousand seed weight. One QTL on LG A07 explained between 13 and $18 \%$ of phenotypic variance and the other other QTL between 5 and $21 \%$. In the present experiment a QTL for thousand seed weight on LG A01 $\left(\mathrm{R}^{2}=10\right.$ $\%$ ) was detected at low nitrogen supply (Tab. 4.6). At high nitrogen supply a QTL for thousand seed weight $\left(\mathrm{R}^{2}=12 \%\right)$ was identified on A07 (Tab. 4.14).

The DH lines used for TC production segregated for erucic acid content due to the use of the parental line 'H30' (high erucic acid content). Marker assisted selection for low erucic content was only successful for one of the two loci influencing erucic acid content (Breuer personal communication). Therefore the QTL for oil content on LG A08 (Tab. 4.7, Tab. 
4.14) most likely corresponds to the erucic acid gene on A08 described by Jourdren et al. (1996). A QTL for oil content at low and high nitrogen supply was also identified on LG A06 in vicinity to the dwarf locus. The 'Alesi-bzh' allele reduced oil content at the QTL Oil\%-A06 at both nitrogen levels with a stronger effect at high nitrogen supply. This is in accordance with results in chapter 3 . The reason for a reduction of oil content by the 'Alesi- $b z h$ ' allele is not clear. Oil content and protein content are negatively correlated. Therefore the QTL on LG A01 (low nitrogen supply) and LG A06 (high nitrogen supply) affecting oil content had a opposite effect on protein content (Tab. 4.7, Tab. 4.14).

QTL for nitrogen related traits

Nitrogen uptake efficiency at maturity was affected by a QTL on LG A06. At low nitrogen supply this QTL accounted for $30 \%$ of variance (Tab. 4.8). At high nitrogen supply the QTL explained $23 \%$ of phenotypic variance in nitrogen uptake efficiency (Tab. 4.15). In the present study none of the QTL for nitrogen uptake efficiency reported by Miro (2010) (chromosomes A01, A04, A07, C05, C06 and C07) was detected. The fact that maximal $30 \%$ of variance for nitrogen uptake efficiency was explained indicates that several other QTL are not detected.

Nitrogen utilization efficiency at low nitrogen supply (mean across two environments) was affected by three QTL on LG A06, C01 and C06 (Tab. 4.8). All three QTL explained $74 \%$ of the phenotypic variance for nitrogen utilization at low nitrogen supply. The 'Alesi-bzh' allele increased nitrogen utilization efficiency at QTL Nut-A06 and NutC01 while it had a decreasing effect on Nut-C06. The higher number of QTL detected across environments compared to individual environments can be explained by a higher heritability across several environments instead of only one. At high nitrogen supply two QTL were identified on LG A06 and C04b (Tab. 4.15). At both QTL the 'Alesi- bzh' allele improved nitrogen utilization efficiency. Together these QTL explained $30 \%$ of phenotypic variance in nitrogen utilization efficiency at high nitrogen supply. QTL for nitrogen utilization efficiency at low nitrogen (LG A07 and A09) and high nitrogen supply (LG A03, A09 and C07) identified by Miro (2010) were not detected.

Two QTL on LG A06 and A07 were identified for nitrogen use efficiency across low nitrogen environments (Tab. 4.8). The QTL NUE-A07 explained $9 \%$ of phenotypic variation in nitrogen use efficiency. Miro (2010) identified a QTL for nitrogen use efficiency on LG A07 at low and high nitrogen supply. The explained phenotypic variance for nitrogen use efficiency ranged from $6 \%$ (low nitrogen) to $18 \%$ at high nitrogen supply. In the same study the author reported another QTL for nitrogen use efficiency on chromosome C09 which explained $9 \%$ of variance at low nitrogen supply and $7 \%$ at high nitrogen supply. In the present experiment a QTL for nitrogen use efficiency on LG C09 was detected at low nitrogen supply in Göttingen 2011 only (Tab. 4.5). Other QTL reported 
by Miro (2010) on chromosomes A09, A07, C04 and C07 could not be detected. The QTL for nitrogen use efficiency on A06 was mapped to the position of the dwarf gene and was detected at low and high nitrogen supply. At both nitrogen supply levels the dwarf allele from 'Alesi-bzh' improved nitrogen use efficiency. At low nitrogen supply the QTL explained $16 \%$ and $42 \%$ of the phenotypic variance in nitrogen use efficiency at high nitrogen supply (Tab. 4.8, Tab. 4.15). Two additional QTL on A03 and A06 were detected at high nitrogen supply accounting for $8 \%$ or $9 \%$ of variance in nitrogen use efficiency, respectively (Tab. 4.15).

In the present experiment different QTL were detected for seed yield and yield related traits (straw yield and harvest index) as well as nitrogen related traits (nitrogen uptake efficiency, nitrogen utilization efficiency and nitrogen use efficiency) among the two nitrogen supply levels. This indicates that different genetic mechanisms (genes or regulatory regions) are involved in the expression of a trait at different nitrogen levels. 


\section{References}

Beavis, W. D. (1998). Molecular Dissection of Complex Traits. CRC Press LLC.

Choi, S. R., Teakle, G. R., Plaha, P., Kim, J. H., Allender, C. J., Beynon, E., Piao, Z. Y., Soengas, P., Han, T. H., King, G. J., et al. (2007). The reference genetic linkage map for the multinational Brassica rapa genome sequencing project. Theoretical and Applied Genetics, 115(6):777-792.

Cowen, N. (1988). The use of replicated progenies in marker-based mapping of QTL's. Theoretical and Applied Genetics, 75(6):857-862.

Delourme, R., Falentin, C., Fomeju, B. F., Boillot, M., Lassalle, G., André, I., Duarte, J., Gauthier, V., Lucante, N., Marty, A., et al. (2013). High-density SNP-based genetic map development and linkage disequilibrium assessment in Brassica napus L. BMC Genomics, 14(1):120.

Ding, G., Zhao, Z., Liao, Y., Hu, Y., Shi, L., Long, Y., and Xu, F. (2012). Quantitative trait loci for seed yield and yield-related traits, and their responses to reduced phosphorus supply in Brassica napus. Annals of Botany, 109(4):747-759.

Fan, C., Cai, G., Qin, J., Li, Q., Yang, M., Wu, J., Fu, T., Liu, K., and Zhou, Y. (2010). Mapping of quantitative trait loci and development of allele-specific markers for seed weight in Brassica napus. Theoretical and Applied Genetics, 121(7):1289-1301.

Foisset, N. and Delourme, R. (1996). Segregation distortion in androgenic plants. In In vitro haploid production in higher plants, pages 189-201. Springer.

Foisset, N., Delourme, R., Barret, P., and Renard, M. (1995). Molecular tagging of the dwarf BREIZH (Bzh) gene in Brassica napus. Theoretical and Applied Genetics, 91(5):756-761.

Girke, A. (2002). Neue Genpools aus resynthetisiertem Raps (Brassica napus L.) für die Hybridzüchtung. URL der Dissertation: http://webdoc. sub. gwdg. de/diss/2002/girke/girke. pdf. 


\section{REFERENCES}

Gül, M. K. (2003). QTL Mapping and Analysis of QTL x Nitrogen Interactions for Some Yield Components in Brassica napus L. Turkish Journal of Agriculture and Forestry, 27(2):71-76.

Jourdren, C., Barret, P., Horvais, R., Foisset, N., Delourme, R., and Renard, M. (1996). Identification of RAPD markers linked to the loci controlling erucic acid level in rapeseed. Molecular Breeding, 2(1):61-71.

Kosambi, D. (1943). The estimation of map distances from recombination values. Annals of Eugenics, 12(1):172-175.

Lancashire, P. D., Bleiholder, H., Boom, T., Langelüddeke, P., Stauss, R., Weber, E., and Witzenberger, A. (1991). A uniform decimal code for growth stages of crops and weeds. Annals of Applied Biology, 119(3):561-601.

Lander, E. S., Green, P., Abrahamson, J., Barlow, A., Daly, M. J., Lincoln, S. E., and Newburg, L. (1987). MAPMAKER: an interactive computer package for constructing primary genetic linkage maps of experimental and natural populations. Genomics, $1(2): 174-181$.

Li, H., Wang, Y., Li, X., Gao, Y., Wang, Z., Zhao, Y., and Wang, M. (2011). A GAinsensitive dwarf mutant of Brassica napus L. correlated with mutation in pyrimidine box in the promoter of GID1. Molecular Biology Reports, 38(1):191-197.

Miro, B. (2010). Identification of traits for Nitrogen Use Efficiency in oilseed rape (Brassica napus L.). http://hdl.handle.net/10443/1067, Newcastle University.

Paran, I. and Zamir, D. (2003). Quantitative traits in plants: beyond the QTL. Trends in Genetics, 19(6):303-306.

Paulmann, W. and Frauen, M. (1998). Erfahrungsbericht zur Entwicklung und Saatguterzeugung von restaurierten Winterraps-Hybridsorten. Bericht über die 48 . Tagung der Arbeitsgemeinschaft der Saatzuchtleiter, BAL Gumpenstein, 48:25-27.

Piquemal, J., Cinquin, E., Couton, F., Rondeau, C., Seignoret, E., Perret, D., Villeger, M.-J., Vincourt, P., Blanchard, P., et al. (2005). Construction of an oilseed rape (Brassica napus L.) genetic map with SSR markers. Theoretical and Applied Genetics, 111(8):1514-1523.

Quijada, P. A., Udall, J. A., Lambert, B., and Osborn, T. C. (2006). Quantitative trait analysis of seed yield and other complex traits in hybrid spring rapeseed (Brassica napus L.): 1. Identification of genomic regions from winter germplasm. Theoretical and Applied Genetics, 113(3):549-561. 


\section{REFERENCES}

Radoev, M., Becker, H. C., and Ecke, W. (2008). Genetic analysis of heterosis for yield and yield components in rapeseed (Brassica napus L.) by quantitative trait locus mapping. Genetics, 179(3):1547-1558.

Rifkin, S. A. (2012). Quantitative Trait Loci (QTL) Methods and Protocols. Springer.

Schön, C. C., Melchinger, A. E., Boppenmaier, J., Brunklaus-Jung, E., Herrmann, R. G., and Seitzer, J. F. (1994). RFLP mapping in maize: quantitative trait loci affecting testcross performance of elite European flint lines. Crop Science, 34(2):378-389.

Schranz, M. E., Lysak, M. A., and Mitchell-Olds, T. (2006). The ABC's of comparative genomics in the Brassicaceae: building blocks of crucifer genomes. Trends in Plant Science, 11(11):535-542.

Shi, J., Li, R., Qiu, D., Jiang, C., Long, Y., Morgan, C., Bancroft, I., Zhao, J., and Meng, J. (2009). Unraveling the complex trait of crop yield with quantitative trait loci mapping in Brassica napus. Genetics, 182(3):851-861.

Sun, T.-P. and Gubler, F. (2004). Molecular mechanism of gibberellin signaling in plants. Annual Review in Plant Biology, 55:197-223.

Utz, H. (2001). Plabstat - ein Computerprogramm zur statistischen Analyse von pflanzenzüchterischen Experimenten. Institut für Pflanzenzüchtung, Saatgutforschung und Populationsgenetik der Universität Hohenheim.

Uzunova, M. and Ecke, W. (1999). Abundance, polymorphism and genetic mapping of microsatellites in oilseed rape (Brassica napus L.). Plant Breeding, 118(4):323-326.

Voorrips, R. (2002). MapChart: software for the graphical presentation of linkage maps and QTLs. Journal of Heredity, 93(1):77-78.

Wang, S., Basten, C., Gaffney, P., and Zeng, Z. (2006). Windows QTL Cartographer 2.5 user manual. North Carolina State University, Bioinformatics Research Center, Raleigh.

Zeng, Z.-B. (1994). Precision mapping of quantitative trait loci. Genetics, 136(4):14571468. 


\section{Summary}

The cultivation of winter oilseed rape is characterised by high rates of nitrogen fertilisation. This can cause large nitrogen surpluses after seed harvest of oilseed rape. Most of the rapeseed oil is used for the production of biofuels. New regulatory standards in the European Union demand a reduction in greenhouse gas (GHG) emissions from biofuels of $60 \%$ (by 2018) compared to fossil fuels. Energy input to produce mineral nitrogen fertiliser is responsible for a high proportion of GHG emissions in the production chain of rapeseed oil.

The environmental aspects and new legislative regulations illustrate the future challenge of maintaining current seed yields while using less nitrogen fertiliser than today. The development of oilseed rape cultivars with improved nitrogen use efficiency is one contribution to cope with this challenge. The use of semi-dwarf oilseed rape types might be a step towards this direction.

The aim of this study was to analyse the agronomic performance of semi-dwarf and normal oilseed rape hybrids at low and high nitrogen supply. Several nitrogen related traits were analysed with regard to nitrogen use efficiency. The genetic mechanisms controlling these agronomic and nitrogen related traits were analysed by QTL mapping.

A population of 150 oilseed rape hybrids, segregating in 75 semi-dwarf and 75 normal hybrids was developed from a DH population. DH lines were generated from the cross 'Alesi-bzh' x 'H30'. 'Alesi-bzh' is a dwarf line carrying the bzh dwarf allel. The DH population is segregating into dwarf and normal type lines. The hybrids were tested in field experiments in Einbeck and Göttingen at low nitrogen supply (without nitrogen fertilization) in 2010/2011. In 2011/2012 and 2012/2013 108 hybrids were tested at the same locations at low and high nitrogen supply.

On average, semi-dwarf hybrids produced a significantly higher seed yield (2.4 dt/ha) at low nitrogen supply compared to normal hybrids. At high nitrogen supply both growth types produced similar seed yields with a non-significant difference of $0.2 \mathrm{dt} / \mathrm{ha}$. In general semi-dwarf hybrids formed significantly less straw in all environments than normal hybrids. The combinations of higher or similar seed yields and less straw yield resulted in a higher harvest index of semi-dwarf hybrids at both nitrogen supply levels. Semi-dwarfs had a significantly higher nitrogen utilization efficiency compared to normal hybrids at 
low and high nitrogen supply. That means they produced more $\mathrm{kg}$ seed per $\mathrm{kg}$ nitrogen taken up. The difference between the growth types was 2.7 and $1.1 \mathrm{~kg}$ seeds per $\mathrm{kg}$ nitrogen taken up at low and high nitrogen supply, respectively. Therefore, semi-dwarf hybrids revealed a higher nitrogen use efficiency at both nitrogen levels. The variation in nitrogen uptake efficiency contributed more to genetic variation in nitrogen use efficiency than variation in nitrogen utilization efficiency.

QTL mapping identified a QTL on linkage group (LG) A06 with pleiotropic effects on seed yield, straw yield, harvest index and nitrogen use efficiency at low and high nitrogen supply. Due to the position of the QTL it is most likely the effect of the dwarf gene $B z h$ itself. Another QTL with pleiotropic effects on seed yield, harvest index and nitrogen use efficiency was identified on LG A07 at low nitrogen supply.

Based on the results of the present study semi-dwarf hybrids produce higher seed yields and show a higher nitrogen use efficiency than normal type hybrids, especially at nitrogen deficient conditions. 


\section{Appendix A}

A01

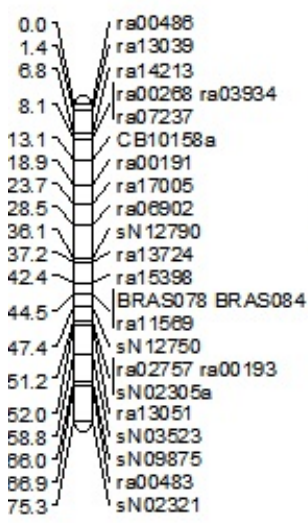

A05

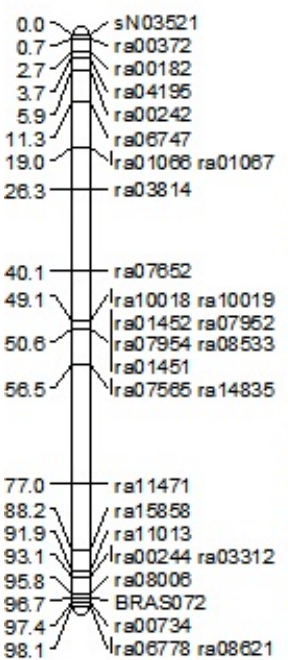

A02

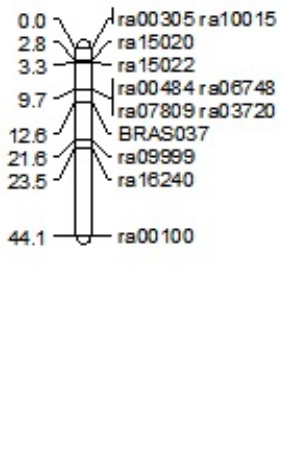

A06

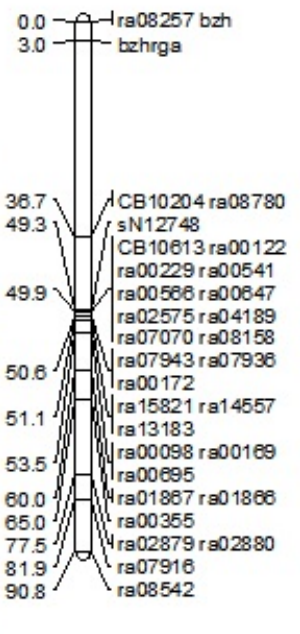

A03

A04

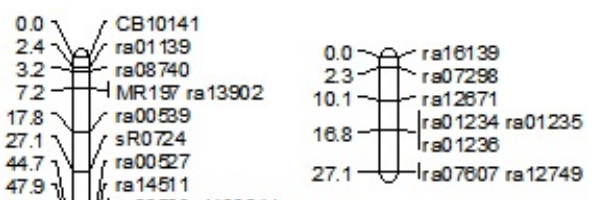

A07

A08

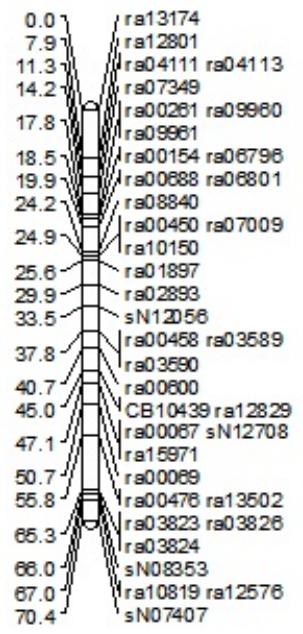




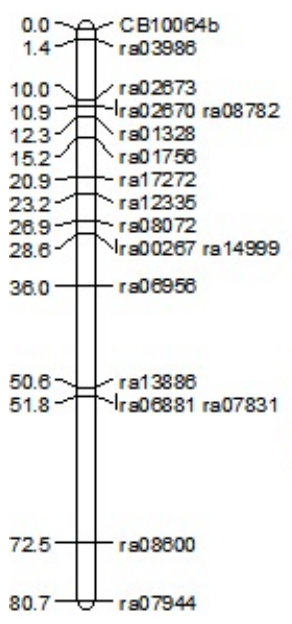

C03

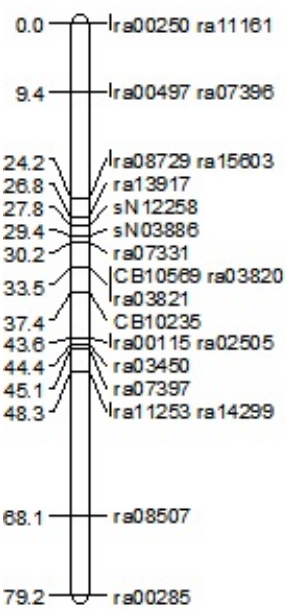

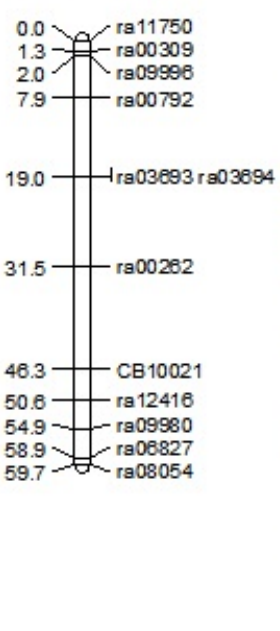

9.5 1 r 800238 ra00568

$\left.\begin{array}{ll}9.5 \\ 11.7\end{array}\right)\left(\begin{array}{ll}\text { CB10687 ra14808 } & 0.0 \\ \text { ra13151 } & 4.4 \\ \text { r800084 } & \text { ra00418 }\end{array}\right.$

18.9. ICB10158b ra00586 8.0 rra08792 sN1 1840

18.9 -

20.6 - $\mathrm{ra1} 2596$

$27.6 \mathrm{~W}=/ \mathrm{r} 800057$

$29.7-U_{\mathrm{ra} 10934}^{\mathrm{r} 200171}$

30.4 r $r 03116$

$34.2-\mathrm{r}=14574$

$40.8-A r=2341$ ra03985

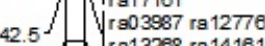

$50.9^{4}$ Ys NO0983 sN03523

$71.9-\mathcal{L}_{\text {r803282 }}$ c04a

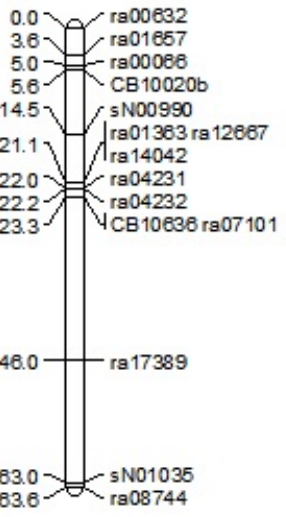

c04b

C05a 

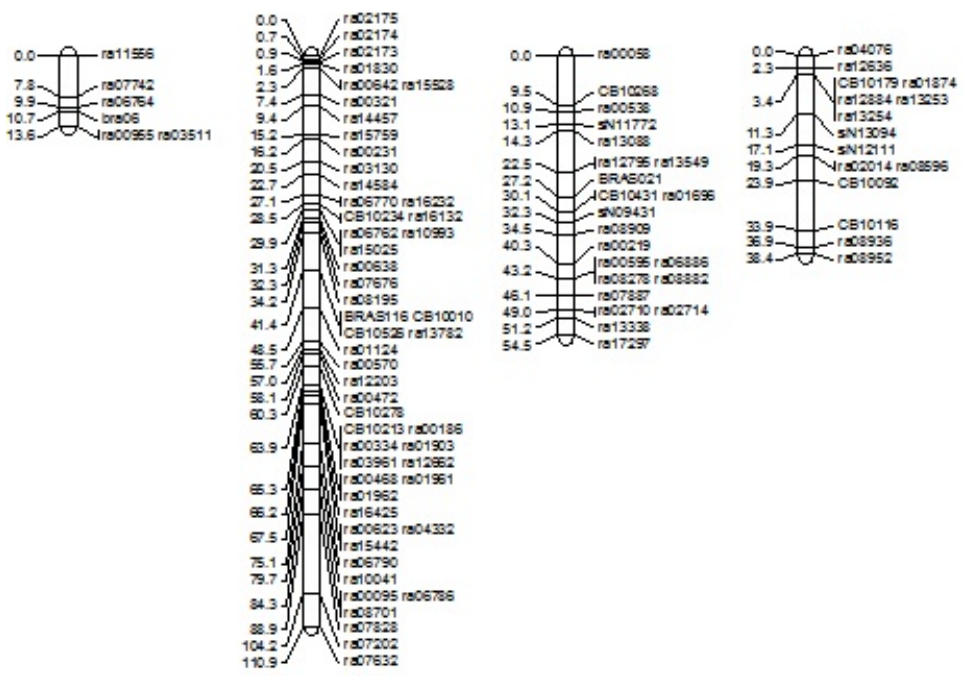

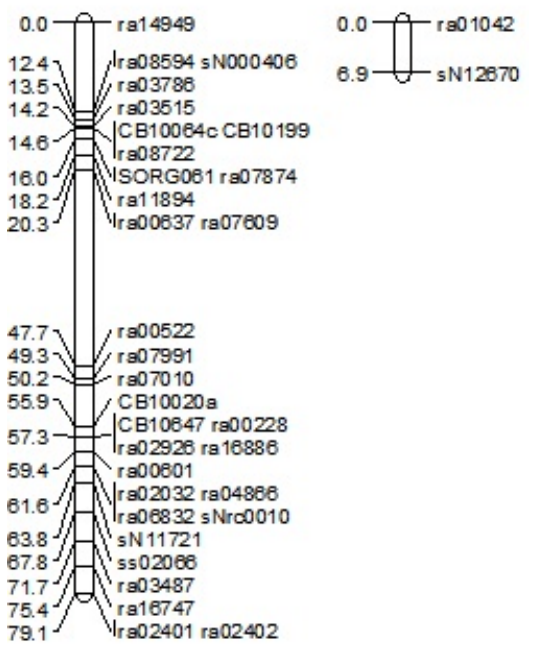


Table 4.16: Linkage map of 'Alesi-bzh' x 'H30' population

\begin{tabular}{|c|c|c|}
\hline No. of marker & Marker name & Position (cM) \\
\hline \multicolumn{3}{|l|}{ LG A01 } \\
\hline 1 & ra00486 & 0.0 \\
\hline 2 & ra13039 & 1.4 \\
\hline 3 & ra14213 & 6.8 \\
\hline 4 & ra00268 & 8.1 \\
\hline 5 & ra03934 & 8.1 \\
\hline 6 & ra07237 & 8.1 \\
\hline 7 & CB10158b & 13.1 \\
\hline 8 & ra00191 & 18.9 \\
\hline 9 & ra17005 & 23.7 \\
\hline 10 & ra06902 & 28.5 \\
\hline 11 & sN12790 & 36.1 \\
\hline 12 & ra13724 & 37.2 \\
\hline 13 & ra15398 & 42.4 \\
\hline 14 & BRAS078 & 44.5 \\
\hline 15 & BRAS084 & 44.5 \\
\hline 16 & ra11569 & 44.5 \\
\hline 17 & sN12750 & 47.4 \\
\hline 18 & $\mathrm{ra0} 2757$ & 51.2 \\
\hline 19 & ra00193 & 51.2 \\
\hline 20 & sN02305a & 51.2 \\
\hline 21 & ra13051 & 52.0 \\
\hline 22 & sN03523rb & 58.8 \\
\hline 23 & sN09875 & 66.0 \\
\hline 24 & ra00483 & 66.9 \\
\hline 25 & sN02321 & 75.3 \\
\hline \multicolumn{3}{|l|}{ LG A02 } \\
\hline 26 & ra00305 & 0.0 \\
\hline 27 & ra10015 & 0.0 \\
\hline 28 & ra15020 & 2.8 \\
\hline 29 & ra15022 & 3.3 \\
\hline 30 & $\mathrm{ra00484}$ & 9.7 \\
\hline 31 & $\mathrm{ra06748}$ & 9.7 \\
\hline
\end{tabular}


Table 4.16 - continued from previous page

\begin{tabular}{|c|c|c|}
\hline No. of marker & Marker name & Position (cM) \\
\hline 32 & ra07809 & 9.7 \\
\hline 33 & ra03720 & 9.7 \\
\hline 34 & BRAS037 & 12.6 \\
\hline 35 & ra09999 & 21.6 \\
\hline 36 & ra16240 & 23.5 \\
\hline 37 & ra00100 & 44.1 \\
\hline \multicolumn{3}{|l|}{ LG A03 } \\
\hline 38 & CB10141 & 0.0 \\
\hline 39 & ra01139 & 2.3 \\
\hline 40 & $\mathrm{ra08740}$ & 3.2 \\
\hline 41 & MR197 & 7.2 \\
\hline 42 & ra13902 & 7.2 \\
\hline 43 & $\mathrm{ra00539}$ & 17.8 \\
\hline 44 & sr000724 & 27.1 \\
\hline 45 & $\mathrm{ra00527}$ & 44.7 \\
\hline 46 & ra14511 & 47.9 \\
\hline 47 & $\mathrm{ra0} 03268$ & 49.9 \\
\hline 48 & sN08841 & 49.9 \\
\hline 49 & CB10427 & 50.3 \\
\hline 50 & CB10136 & 52.1 \\
\hline 51 & ra01939 & 52.1 \\
\hline 52 & ra07763 & 52.8 \\
\hline 53 & $\mathrm{ra08553}$ & 52.8 \\
\hline 54 & $\mathrm{ra06297}$ & 53.5 \\
\hline 55 & ra08208 & 56.6 \\
\hline 56 & ra16303 & 56.6 \\
\hline 57 & ra11738 & 61.4 \\
\hline 58 & ra14665 & 64.6 \\
\hline 59 & $\mathrm{ra0} 0358$ & 65.2 \\
\hline 60 & ra11597 & 65.9 \\
\hline 61 & ra02122 & 66.6 \\
\hline 62 & sN12947 & 68.8 \\
\hline 63 & ra11930 & 68.8 \\
\hline 64 & ra00277 & 75.3 \\
\hline
\end{tabular}


Table 4.16 - continued from previous page

\begin{tabular}{|c|c|c|}
\hline No. of marker & Marker name & Position (cM) \\
\hline 65 & $\mathrm{ra07363}$ & 75.3 \\
\hline 66 & $\mathrm{ra} 08485$ & 75.3 \\
\hline 67 & ra01018 & 76.4 \\
\hline 68 & $\mathrm{ra08285}$ & 91.7 \\
\hline 69 & ra13260 & 96.5 \\
\hline 70 & sore0001 & 115.5 \\
\hline 71 & $\mathrm{ra00335}$ & 118.0 \\
\hline 72 & $\mathrm{ra0} 7756$ & 121.3 \\
\hline 73 & CB10413 & 135.3 \\
\hline \multicolumn{3}{|l|}{ LG A04 } \\
\hline 74 & ra16139 & 0.0 \\
\hline 75 & ra07298 & 2.3 \\
\hline 76 & ra12671 & 10.1 \\
\hline 77 & $\mathrm{ra01234}$ & 16.8 \\
\hline 78 & $\mathrm{ra0} 1235$ & 16.8 \\
\hline 79 & ra01236 & 16.8 \\
\hline 80 & $\mathrm{ra07607}$ & 27.1 \\
\hline 81 & ra12749 & 27.1 \\
\hline \multicolumn{3}{|l|}{ LG A05 } \\
\hline 82 & sN03521f & 0.0 \\
\hline 83 & ra00372 & 0.7 \\
\hline 84 & $\mathrm{ra00182}$ & 2.7 \\
\hline 85 & $\mathrm{ra0} 4195$ & 3.7 \\
\hline 86 & $\mathrm{ra00242}$ & 5.9 \\
\hline 87 & ra06747 & 11.3 \\
\hline 88 & ra01066 & 19.0 \\
\hline 89 & ra01067 & 19.0 \\
\hline 90 & ra03814 & 26.3 \\
\hline 91 & $\mathrm{ra0} 0652$ & 40.1 \\
\hline 92 & $\operatorname{ra10018}$ & 49.1 \\
\hline 93 & ra10019 & 49.1 \\
\hline 94 & $\mathrm{ra0} 01452$ & 50.6 \\
\hline 95 & ra07952 & 50.6 \\
\hline 96 & ra07954 & 50.6 \\
\hline
\end{tabular}


Table 4.16 - continued from previous page

\begin{tabular}{|c|c|c|}
\hline No. of marker & Marker name & Position (cM) \\
\hline 97 & $\mathrm{ra08533}$ & 50.6 \\
\hline 98 & ra01451 & 50.6 \\
\hline 99 & ra07565 & 56.5 \\
\hline 100 & ra14835 & 56.5 \\
\hline 101 & ra11471 & 77.0 \\
\hline 102 & ra15858 & 88.2 \\
\hline 103 & ra11013 & 91.9 \\
\hline 104 & $\mathrm{ra00244}$ & 93.1 \\
\hline 105 & ra03312 & 93.1 \\
\hline 106 & $\mathrm{ra08006}$ & 95.8 \\
\hline 107 & BRAS72 & 96.7 \\
\hline 108 & $\mathrm{ra00734}$ & 97.4 \\
\hline 109 & $\operatorname{ra06778}$ & 98.1 \\
\hline 110 & $\mathrm{ra08621}$ & 98.1 \\
\hline LG A06 & & \\
\hline 111 & bzh & 0.0 \\
\hline 112 & bzhrga & 3.0 \\
\hline 113 & CB10204 & 36.7 \\
\hline 114 & $\mathrm{ra08780}$ & 36.7 \\
\hline 115 & sN12748 & 49.3 \\
\hline 116 & CB10613 & 49.9 \\
\hline 117 & ra00122 & 49.9 \\
\hline 118 & ra00229 & 49.9 \\
\hline 119 & ra00541 & 49.9 \\
\hline 120 & $\mathrm{ra} 00566$ & 49.9 \\
\hline 121 & $\mathrm{ra00647}$ & 49.9 \\
\hline 122 & $\mathrm{ra0} 2575$ & 49.9 \\
\hline 123 & ra04189 & 49.9 \\
\hline 124 & ra07070 & 49.9 \\
\hline 125 & ra08158 & 49.9 \\
\hline 126 & ra07943 & 50.6 \\
\hline 127 & ra07936 & 50.6 \\
\hline 128 & $\mathrm{ra} 00172$ & 50.6 \\
\hline 129 & ra15821 & 51.1 \\
\hline
\end{tabular}


Table 4.16 - continued from previous page

\begin{tabular}{|c|c|c|}
\hline No. of marker & Marker name & Position (cM) \\
\hline 130 & ra14557 & 51.1 \\
\hline 131 & ra13183 & 51.1 \\
\hline 132 & ra00098 & 53.5 \\
\hline 133 & ra00169 & 53.5 \\
\hline 134 & ra00695 & 53.5 \\
\hline 135 & ra01867 & 60.0 \\
\hline 136 & ra01866 & 60.0 \\
\hline 137 & $\mathrm{ra00355}$ & 65.0 \\
\hline 138 & ra02879 & 77.5 \\
\hline 139 & ra02880 & 77.5 \\
\hline 140 & ra07916 & 81.9 \\
\hline 141 & $\mathrm{ra0} 0542$ & 90.8 \\
\hline \multicolumn{3}{|l|}{ LG A07 } \\
\hline 142 & ra13174 & 0.0 \\
\hline 143 & ra12801 & 7.9 \\
\hline 144 & ra04111 & 11.3 \\
\hline 145 & ra04113 & 11.3 \\
\hline 146 & ra07349 & 14.2 \\
\hline 147 & ra00261 & 17.8 \\
\hline 148 & ra09960 & 17.8 \\
\hline 149 & ra09961 & 17.8 \\
\hline 150 & ra00154 & 18.5 \\
\hline 151 & ra06796 & 18.5 \\
\hline 152 & ra00688 & 19.9 \\
\hline 153 & ra06801 & 19.9 \\
\hline 154 & ra08840 & 24.2 \\
\hline 155 & ra00450 & 24.9 \\
\hline 156 & ra07009 & 24.9 \\
\hline 157 & ra10150 & 24.9 \\
\hline 158 & ra01897 & 25.6 \\
\hline 159 & ra02893 & 29.9 \\
\hline 160 & sN12056 & 33.5 \\
\hline 161 & $\mathrm{ra00458}$ & 37.8 \\
\hline 162 & ra03589 & 37.8 \\
\hline
\end{tabular}


Table 4.16 - continued from previous page

\begin{tabular}{|c|c|c|}
\hline No. of marker & Marker name & Position (cM) \\
\hline 163 & ra03590 & 37.8 \\
\hline 164 & ra00600 & 40.7 \\
\hline 165 & CB10439 & 45.0 \\
\hline 166 & ra12829 & 45.0 \\
\hline 167 & $\mathrm{ra00067}$ & 47.1 \\
\hline 168 & sN12708 & 47.1 \\
\hline 169 & ra15971 & 47.1 \\
\hline 170 & ra00069 & 50.7 \\
\hline 171 & $\mathrm{ra00476}$ & 55.8 \\
\hline 172 & ra13502 & 55.8 \\
\hline 173 & ra03823 & 65.3 \\
\hline 174 & ra03826 & 65.3 \\
\hline 175 & $\mathrm{ra03824}$ & 65.3 \\
\hline 176 & sN8353 & 66.0 \\
\hline 177 & ra10819 & 67.0 \\
\hline 178 & ra12576 & 67.0 \\
\hline 179 & sN7407 & 70.4 \\
\hline \multicolumn{3}{|l|}{ LG A08 } \\
\hline 180 & $\mathrm{ra0} 4387$ & 0.0 \\
\hline 181 & ra04388 & 0.0 \\
\hline 182 & BRAS039b & 4.8 \\
\hline 183 & ra08917 & 8.3 \\
\hline 184 & ra13648 & 8.3 \\
\hline 185 & ra07020 & 9.1 \\
\hline 186 & ra07232 & 10.3 \\
\hline 187 & ra01958 & 12.5 \\
\hline 188 & ra01956 & 12.5 \\
\hline 189 & $\mathrm{ra00574}$ & 13.8 \\
\hline 190 & ra14354 & 19.7 \\
\hline \multicolumn{3}{|l|}{ LG A09 } \\
\hline 191 & CB10064b & 0.0 \\
\hline 192 & ra03986 & 1.4 \\
\hline 193 & ra02673 & 10.0 \\
\hline 194 & ra02670 & 10.9 \\
\hline
\end{tabular}


Table 4.16 - continued from previous page

\begin{tabular}{|c|c|c|}
\hline No. of marker & Marker name & Position (cM) \\
\hline 195 & $\mathrm{ra0} 08782$ & 10.9 \\
\hline 196 & ra01328 & 12.3 \\
\hline 197 & ra01756 & 15.2 \\
\hline 198 & ra17272 & 20.9 \\
\hline 199 & ra12335 & 23.2 \\
\hline 200 & ra08072 & 26.9 \\
\hline 201 & ra00267 & 28.6 \\
\hline 202 & ra14999 & 28.6 \\
\hline 203 & ra06956 & 36.0 \\
\hline 204 & ra13886 & 50.6 \\
\hline 205 & ra06881 & 51.8 \\
\hline 206 & ra07831 & 51.8 \\
\hline 207 & $\mathrm{ra0} 8600$ & 72.5 \\
\hline 208 & ra07944 & 80.7 \\
\hline LG A10 & & \\
\hline 209 & ra11750 & 0.0 \\
\hline 210 & ra00309 & 1.3 \\
\hline 211 & ra09996 & 2.0 \\
\hline 212 & ra00792 & 7.9 \\
\hline 213 & ra03693 & 19.0 \\
\hline 214 & ra03694 & 19.0 \\
\hline 215 & $\mathrm{ra00262}$ & 31.5 \\
\hline 216 & CB10021 & 46.3 \\
\hline 217 & ra12416 & 50.6 \\
\hline 218 & ra09980 & 54.9 \\
\hline 219 & ra06827 & 58.9 \\
\hline 220 & $\mathrm{ra0} 0054$ & 59.7 \\
\hline LG C01 & & \\
\hline 221 & $\mathrm{ra00238}$ & 0.0 \\
\hline 222 & $\mathrm{ra00568}$ & 0.0 \\
\hline 223 & CB10587 & 9.5 \\
\hline 224 & ra14808 & 9.5 \\
\hline 225 & ra13151 & 11.7 \\
\hline 226 & $\mathrm{ra00084}$ & 16.0 \\
\hline \multicolumn{3}{|c|}{ Continued on next page } \\
\hline
\end{tabular}


Table 4.16 - continued from previous page

\begin{tabular}{|c|c|c|}
\hline No. of marker & Marker name & Position (cM) \\
\hline 227 & CB10158c & 18.9 \\
\hline 228 & $\mathrm{ra00586}$ & 18.9 \\
\hline 229 & ra13931 & 18.9 \\
\hline 230 & ra12596 & 20.6 \\
\hline 231 & ra11653 & 25.9 \\
\hline 232 & $\mathrm{ra00057}$ & 27.6 \\
\hline 233 & $\mathrm{ra00171}$ & 29.0 \\
\hline 234 & ra10934 & 29.7 \\
\hline 235 & ra03116 & 30.4 \\
\hline 236 & ra14574 & 34.2 \\
\hline 237 & ra04908 & 40.8 \\
\hline 238 & ra08390 & 40.8 \\
\hline 239 & ra02341 & 40.8 \\
\hline 240 & ra03935 & 40.8 \\
\hline 241 & ra17161 & 40.8 \\
\hline 242 & ra03987 & 42.5 \\
\hline 243 & ra12776 & 42.5 \\
\hline 244 & ra13268 & 42.5 \\
\hline 245 & ra14161 & 42.5 \\
\hline 246 & sN00983f & 50.9 \\
\hline 247 & sN03523ra & 50.9 \\
\hline 248 & ra03282 & 71.9 \\
\hline LG C02 & & \\
\hline 249 & ra00418 & 0.0 \\
\hline 250 & $\mathrm{ra0} 0564$ & 4.4 \\
\hline 251 & $\mathrm{ra08792}$ & 8.0 \\
\hline 252 & sN11840 & 8.0 \\
\hline LG C03 & & \\
\hline 253 & $\mathrm{ra00250}$ & 0.0 \\
\hline 254 & ra11161 & 0.0 \\
\hline 255 & ra00497 & 9.4 \\
\hline 256 & ra07396 & 9.4 \\
\hline 257 & ra08729 & 24.2 \\
\hline 258 & ra15603 & 24.2 \\
\hline \multicolumn{3}{|c|}{ Continued on next page } \\
\hline
\end{tabular}


Table 4.16 - continued from previous page

\begin{tabular}{|c|c|c|}
\hline No. of marker & Marker name & Position (cM) \\
\hline 259 & ra13917 & 26.8 \\
\hline 260 & sN12258 & 27.8 \\
\hline 261 & sN03886i & 29.4 \\
\hline 262 & ra07331 & 30.2 \\
\hline 263 & CB10569a & 33.5 \\
\hline 264 & ra03820 & 33.5 \\
\hline 265 & ra03821 & 33.5 \\
\hline 266 & CB10235 & 37.4 \\
\hline 267 & $\mathrm{ra00115}$ & 43.6 \\
\hline 268 & ra02505 & 43.6 \\
\hline 269 & ra03450 & 44.4 \\
\hline 270 & ra07397 & 45.1 \\
\hline 271 & ra11253 & 48.3 \\
\hline 272 & ra14299 & 48.3 \\
\hline 273 & $\mathrm{ra08507}$ & 68.1 \\
\hline 274 & $\mathrm{ra00285}$ & 79.2 \\
\hline \multicolumn{3}{|l|}{ LG C04a } \\
\hline 275 & MR155 & 0.0 \\
\hline 276 & CB10335 & 18.4 \\
\hline 277 & ra08343 & 26.4 \\
\hline 278 & ra14555 & 29.8 \\
\hline \multicolumn{3}{|l|}{ LG C04b } \\
\hline 279 & $\mathrm{ra00632 \textrm {s } 0 2}$ & 0.0 \\
\hline 280 & $\mathrm{ra} 01657$ & 3.6 \\
\hline 281 & ra00066 & 5.0 \\
\hline 282 & $\mathrm{CB} 10020 \mathrm{c}$ & 5.6 \\
\hline 283 & sN00990a & 14.5 \\
\hline 284 & ra01363 & 21.1 \\
\hline 285 & ra12667 & 21.1 \\
\hline 286 & ra14042 & 21.1 \\
\hline 287 & ra04231 & 22.0 \\
\hline 288 & $\mathrm{ra} 04232$ & 22.2 \\
\hline 289 & CB10636 & 23.3 \\
\hline 290 & ra07101 & 23.3 \\
\hline
\end{tabular}


Table 4.16 - continued from previous page

\begin{tabular}{lll}
\hline No. of marker & Marker name & Position $(\mathbf{c M})$ \\
\hline 291 & ra17389 & 46.0 \\
292 & sN01035r & 63.0 \\
293 & ra08744 & 63.6
\end{tabular}

\section{LG C05a}

294

295

296

297

298

299

300

301

302

303

304

305

306

307

308

LG C05b

309

310

311

312

313

314

LG C06

315

316

317

318

319

320

321

$\begin{array}{ll}\text { ra14135 } & 0.0 \\ \text { ra07718 } & 0.8 \\ \text { ra17279 } & 7.2 \\ \text { ra00234 } & 32.0 \\ \text { ra17237 } & 32.0 \\ \text { ra01586 } & 35.4 \\ \text { sN11578 } & 35.6 \\ \text { ra00237 } & 36.3 \\ \text { ra04210 } & 36.3 \\ \text { ra14670 } & 39.9 \\ \text { sN00103 } & 39.9 \\ \text { sN01088a } & 39.9 \\ \text { snrc0018 } & 40.4 \\ \mathrm{CB} 10027 & 40.5 \\ \text { ra12304 } & 44.4\end{array}$

0.0

7.2

32.0

32.0

35.4

35.6

36.3

3.3

39.9

40.4

40.5

44.4

$\begin{array}{lll}309 & \text { ra11556 } & 0.0 \\ 10 & \text { ra07742 } & 7.8 \\ 11 & \text { ra06764 } & 9.9 \\ 12 & \text { BRAS106 } & 10.7 \\ 13 & \text { ra00955 } & 13.6 \\ 14 & \text { ra03511 } & 13.6\end{array}$

$\begin{array}{lll}15 & \mathrm{ra} 02175 & 0.0 \\ 16 & \mathrm{ra} 02174 & 0.7 \\ 17 & \mathrm{ra} 02173 & 0.9 \\ 18 & \mathrm{ra} 01830 & 1.6 \\ 19 & \mathrm{ra} 00642 & 2.3 \\ 20 & \mathrm{ra} 15528 & 2.3 \\ 21 & \mathrm{ra} 00321 & 7.4\end{array}$

Continued on next page 
Table 4.16 - continued from previous page

\begin{tabular}{|c|c|c|}
\hline No. of marker & Marker name & Position (cM) \\
\hline 322 & ra14457 & 9.4 \\
\hline 323 & ra15759 & 15.2 \\
\hline 324 & ra00231 & 16.2 \\
\hline 325 & ra03130 & 20.5 \\
\hline 326 & ra14584 & 22.7 \\
\hline 327 & $\mathrm{ra06770}$ & 27.1 \\
\hline 328 & ra16232 & 27.1 \\
\hline 329 & CB10234 & 28.5 \\
\hline 330 & $\operatorname{ra16132}$ & 28.5 \\
\hline 331 & $\mathrm{ra06762}$ & 29.9 \\
\hline 332 & ra10993 & 29.9 \\
\hline 333 & $\operatorname{ra} 15025$ & 29.9 \\
\hline 334 & $\mathrm{ra00638}$ & 31.3 \\
\hline 335 & $\mathrm{ra07676}$ & 32.3 \\
\hline 336 & ra08195 & 34.2 \\
\hline 337 & BRAS116 & 41.4 \\
\hline 338 & CB10010 & 41.4 \\
\hline 339 & CB10526 & 41.4 \\
\hline 340 & ra13782 & 41.4 \\
\hline 341 & $\mathrm{ra01124}$ & 48.5 \\
\hline 342 & $\mathrm{ra} 00570$ & 55.7 \\
\hline 343 & ra12203 & 57.0 \\
\hline 344 & $\mathrm{ra00472}$ & 58.1 \\
\hline 345 & CB10278 & 60.3 \\
\hline 346 & CB10213 & 63.9 \\
\hline 347 & $\mathrm{ra00186}$ & 63.9 \\
\hline 348 & ra00334 & 63.9 \\
\hline 349 & ra01903 & 63.9 \\
\hline 350 & ra03961 & 63.9 \\
\hline 351 & ra12662 & 63.9 \\
\hline 352 & $\mathrm{ra00468}$ & 65.3 \\
\hline 353 & ra01961 & 65.3 \\
\hline 354 & $\mathrm{ra01962}$ & 65.3 \\
\hline 355 & $\operatorname{ra} 16425$ & 66.2 \\
\hline
\end{tabular}


Table 4.16 - continued from previous page

\begin{tabular}{|c|c|c|}
\hline No. of marker & Marker name & Position (cM) \\
\hline 356 & ra00623 & 67.5 \\
\hline 357 & $\mathrm{ra} 04332$ & 67.5 \\
\hline 358 & ra15442 & 67.5 \\
\hline 359 & ra06790 & 75.1 \\
\hline 360 & ra10041 & 79.7 \\
\hline 361 & $\mathrm{ra00095}$ & 84.3 \\
\hline 362 & ra06786 & 84.3 \\
\hline 363 & ra08701 & 84.3 \\
\hline 364 & ra07828 & 88.9 \\
\hline 365 & ra07202 & 104.2 \\
\hline 366 & ra07632 & 110.9 \\
\hline LG C07 & & \\
\hline 367 & ra00058 & 0.0 \\
\hline 368 & CB10268 & 9.5 \\
\hline 369 & $\mathrm{ra00538}$ & 10.9 \\
\hline 370 & sN11772 & 13.1 \\
\hline 371 & ra13088 & 14.3 \\
\hline 372 & ra12795 & 22.5 \\
\hline 373 & ra13549 & 22.5 \\
\hline 374 & BRAS121 & 27.2 \\
\hline 375 & CB10431 & 30.1 \\
\hline 376 & ra01696 & 30.1 \\
\hline 377 & sN09431 & 32.3 \\
\hline 378 & ra08909 & 34.5 \\
\hline 379 & ra00219 & 40.3 \\
\hline 380 & $\mathrm{ra} 00595$ & 43.2 \\
\hline 381 & $\mathrm{ra} 06886$ & 43.2 \\
\hline 382 & ra08278 & 43.2 \\
\hline 383 & $\mathrm{ra08882}$ & 43.2 \\
\hline 384 & $\mathrm{ra} 07887$ & 46.1 \\
\hline 385 & ra02710 & 49.0 \\
\hline 386 & ra02714 & 49.0 \\
\hline 387 & ra13338 & 51.2 \\
\hline 388 & ra17297 & 54.5 \\
\hline
\end{tabular}


Table 4.16 - continued from previous page

\begin{tabular}{|c|c|c|}
\hline No. of marker & Marker name & Position (cM) \\
\hline \multicolumn{3}{|l|}{ LG C08 } \\
\hline 389 & ra04076 & 0.0 \\
\hline 390 & ra12636 & 2.3 \\
\hline 391 & CB10179 & 3.4 \\
\hline 392 & $\mathrm{ra01874}$ & 3.4 \\
\hline 393 & ra12884 & 3.4 \\
\hline 394 & ra13253 & 3.4 \\
\hline 395 & ra13254 & 3.4 \\
\hline 396 & sN13094 & 11.3 \\
\hline 397 & sN12111 & 17.1 \\
\hline 398 & ra02014 & 19.3 \\
\hline 399 & $\mathrm{ra08596}$ & 19.3 \\
\hline 400 & CB10092 & 23.9 \\
\hline 401 & CB10116 & 33.9 \\
\hline 402 & ra08936 & 36.9 \\
\hline 403 & ra08952 & 38.4 \\
\hline \multicolumn{3}{|l|}{ LG C09 } \\
\hline 404 & ra14949 & 0.0 \\
\hline 405 & $\mathrm{ra08594}$ & 12.4 \\
\hline 406 & sN0406 & 12.4 \\
\hline 407 & ra03786 & 13.5 \\
\hline 408 & $\mathrm{ra0} 03515$ & 14.2 \\
\hline 409 & CB10064c & 14.6 \\
\hline 410 & CB10199a & 14.6 \\
\hline 411 & ra08722 & 14.6 \\
\hline 412 & sorg061 & 16.0 \\
\hline 413 & ra07874 & 16.0 \\
\hline 414 & ra11894 & 18.2 \\
\hline 415 & ra00637 & 20.3 \\
\hline 416 & ra07609 & 20.3 \\
\hline 417 & $\mathrm{ra} 00522$ & 47.7 \\
\hline 418 & ra07991 & 49.3 \\
\hline 419 & ra07010 & 50.2 \\
\hline 420 & CB10020b & 55.9 \\
\hline
\end{tabular}


Table 4.16 - continued from previous page

\begin{tabular}{lll}
\hline No. of marker & Marker name & Position (cM) \\
\hline 421 & CB10647 & 57.3 \\
422 & ra00228 & 57.3 \\
423 & ra02926 & 57.3 \\
424 & ra16886 & 57.3 \\
425 & ra00601 & 59.4 \\
426 & ra02032 & 61.6 \\
427 & ra04866s02 & 61.6 \\
428 & ra06832 & 61.6 \\
429 & snrc0010 & 61.6 \\
430 & sN11721r & 63.8 \\
431 & ss002066 & 67.8 \\
432 & ra03487 & 71.7 \\
433 & ra16747 & 75.4 \\
434 & ra02401 & 79.1 \\
435 & ra02402 & 79.1 \\
LG 22 & & \\
436 & ra01042 & 0.0 \\
437 & sN12670 & 6.9 \\
\hline \hline
\end{tabular}




\title{
Curriculum vitae
}

\section{PERSONAL DETAILS}

\section{Sebastian Miersch}

Born: May 26, 1983 - Hoyerswerda, Germany

Nationality: German

Email: sebastian.miersch@gmx.net

\section{EDUCATIONAL BACKGROUND}

May 2010 - May 2014 PhD Program for Agricultural Sciences

Faculty of Agricultural Sciences

Georg-August-Universität Göttingen

\section{Oct.2003 - Nov. 2009 Diploma in Agricultural Sciences}

Institute for Agricultural and Nutritional Sciences

Martin-Luther Universität Halle-Wittenberg

$1999-2002$

\author{
High School Diploma \\ Minor in Economics \\ Vocational Grammar School Döbeln
}

